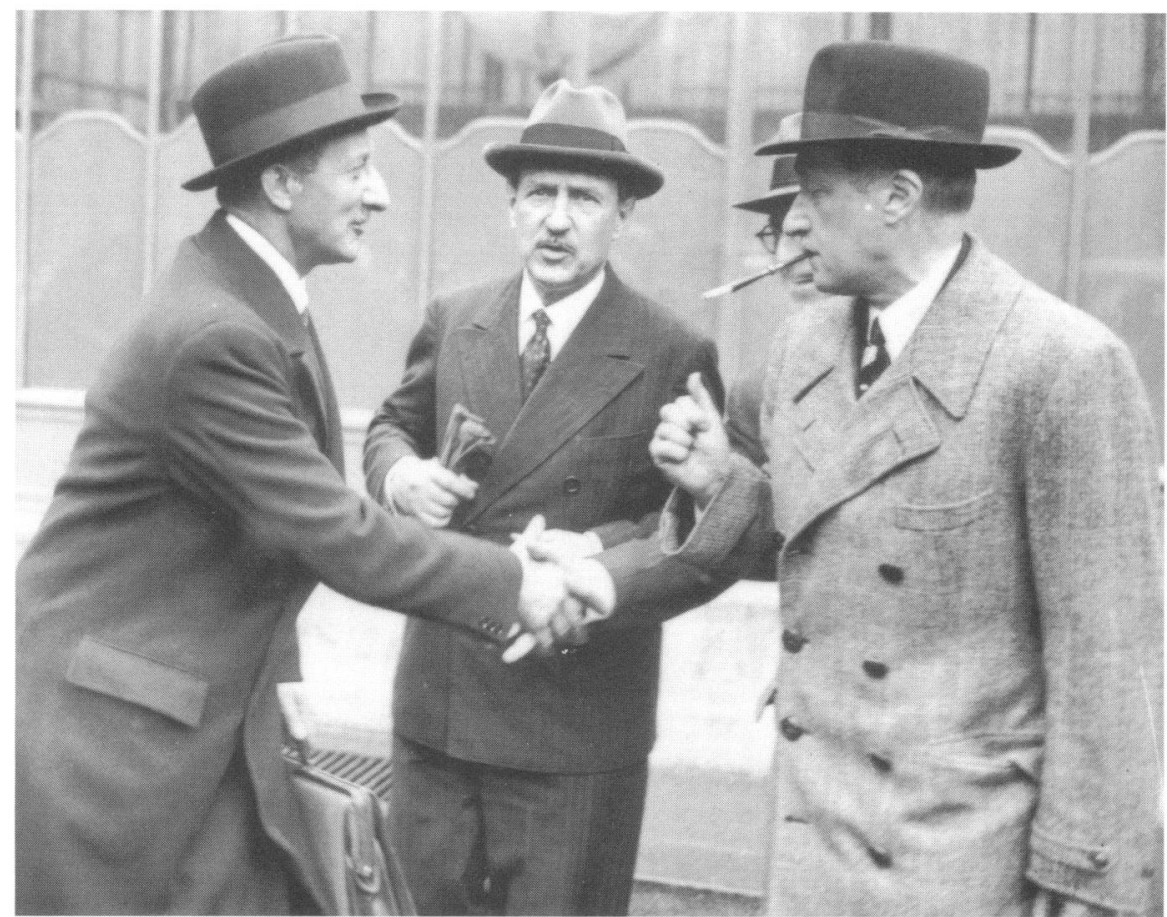

$\triangle$

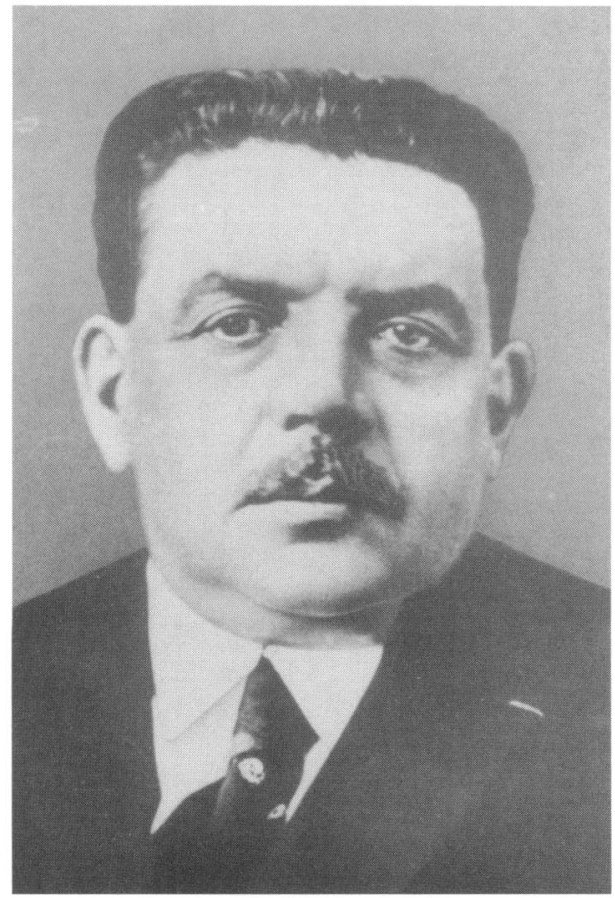

Nach einer Ministerratssitzung im Elysée Palast am 27. September 1938: von links nach rechts: Außenminister Georges Bonnet, Camille Chautemps (stellvertr. Ministerpräsident), César Campinchi (Marineminister) und Paul Marchandeau (Finanzminister). (Bibliothèque Nationale, Abteilung: Drucke und Photographien, Paris)

$\triangleleft$

Portrait von Edouard Herriot um 1939. (Bayerische Staatsbibliothek, Abteilung: Karten und Bilder, München) 


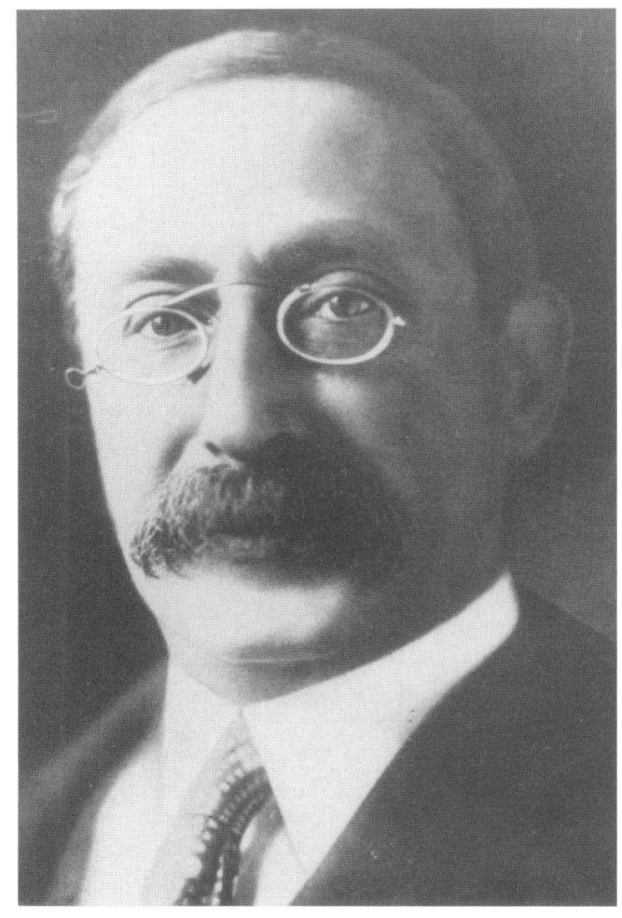

$<$

Portrait von Léon Blum un 1939. Bayerische Stantsbibliothek, Abteilang: Karten und Bilder, Hindon

Parteitas der SFIO ron 1925: Léon Blum (Mitte), links won Blum Pierre Renaudel und reches von Blum Vincent Auriol Bibliotheque Nationale, Abteilung: Drucke und Pbotographich, Parts

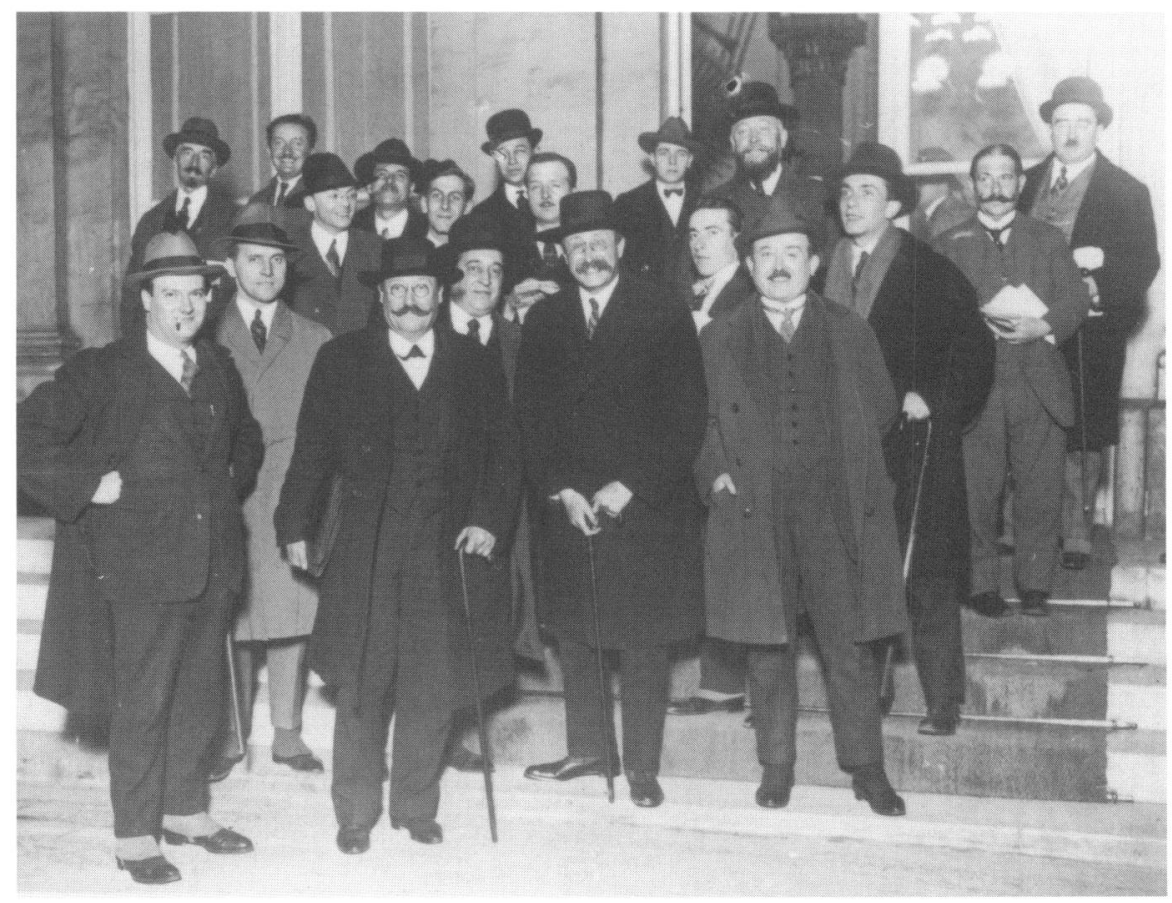




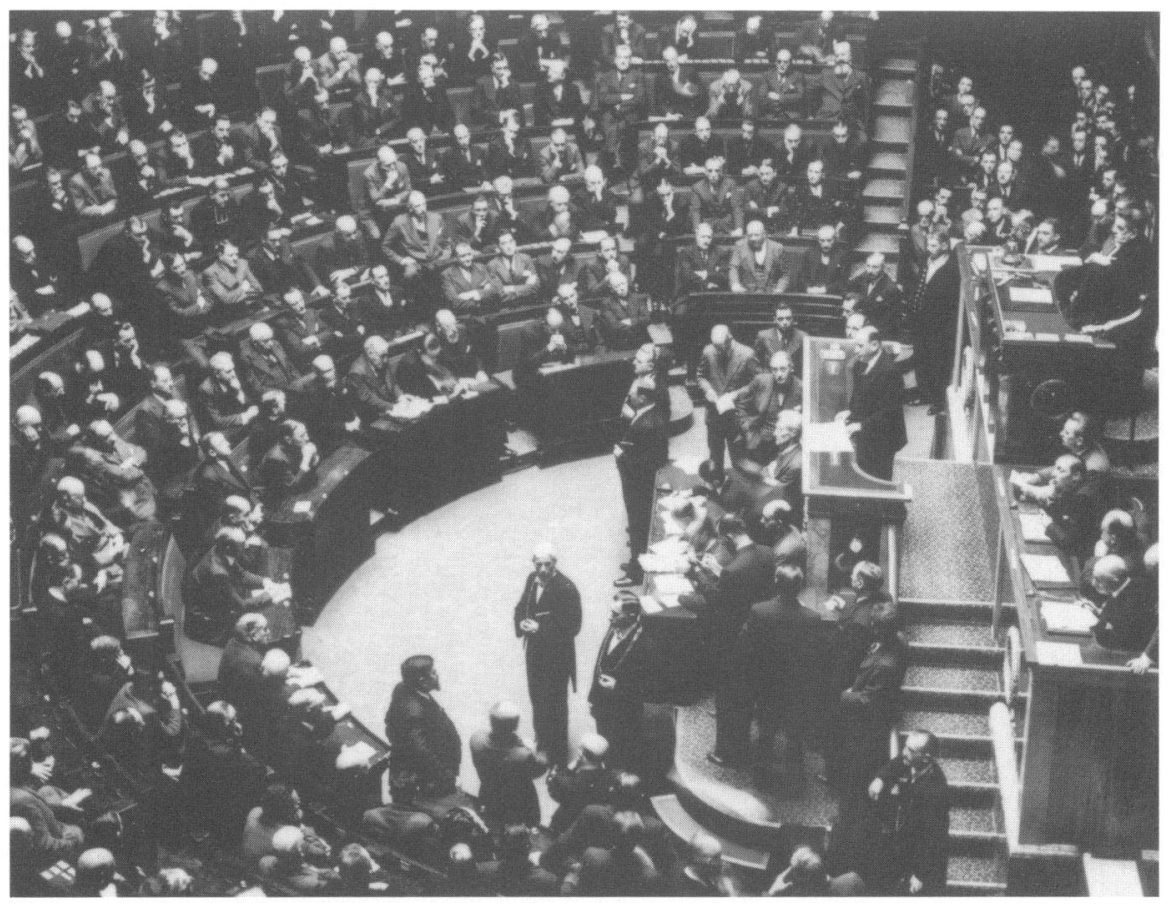

Parlamentsdebatte 1926: Parlanentsprisident oben: Edouard I lerriot (Biblotbeque Natio nale, Abtulung: Drake and Photographicin, Paris

Stantsakt 192t: Üherführung won Jean faurés in das Panthem: lidouard Herriot und Léon Blum (Biblotbeqte Vationale, Abteilung: Dracke und Pbotographion, Paris)

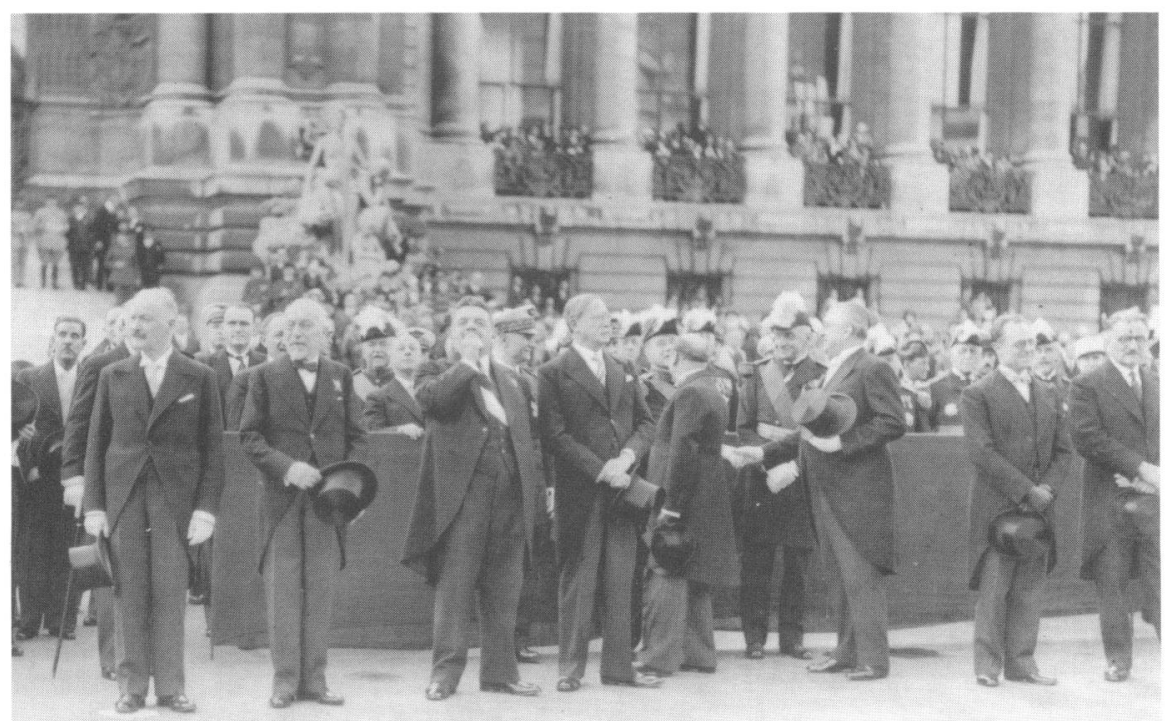




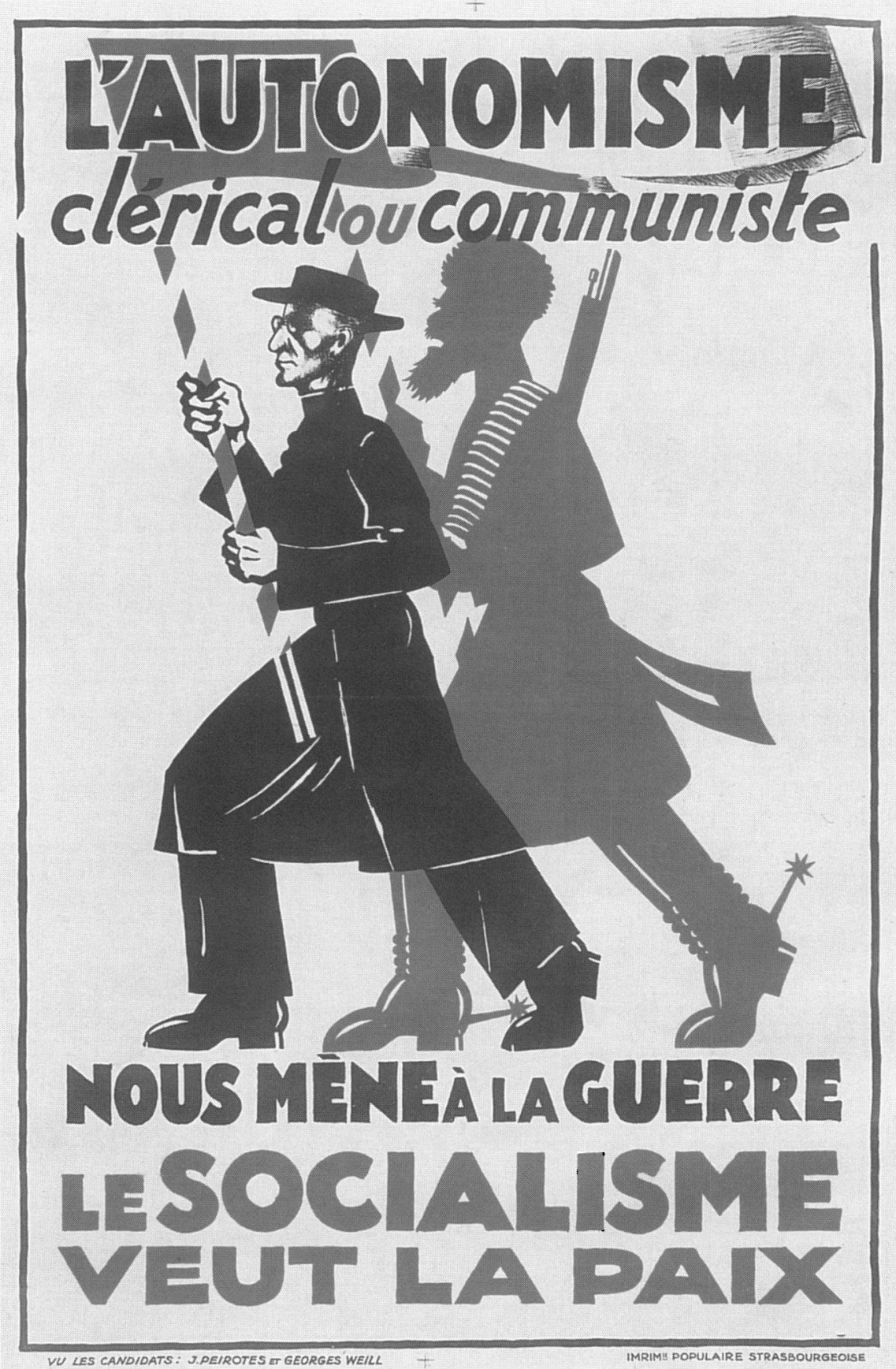

Wahlplakat der SFIO von 1928 (Bibliothèque Nationale, Abteilung: Drucke und Photographien, Paris) 


\section{Teil A: \\ Faktoren der Bündnispolitik}




\section{Parteien und Parteiensystem in der Dritten Republik}

Im Mittelpunkt dieses ersten Abschnittes steht die Frage nach der Entstehung und Entwicklung der Parteien in Frankreich. Geschichte und Tradition der französischen Parteien sollen vergegenwärtigt werden, um die Ausgangsposition und die weitere Entwicklung in der Zwischenkriegszeit erklären und verstehen zu können. Bevor die Funktionsweise der ausgewählten Parteien in der parlamentarischen Demokratie der Dritten Republik untersucht werden kann, ist es sinnvoll, auf deren historische Entwicklung und politische Tradition einzugehen.

\section{Zur Entwicklung der Parteien}

Die Französische Revolution gilt als die Geburtsstunde des modernen Frankreich. In diese Zeit fällt auch die Entstehung des Parteibegriffes, der negativ konnotiert worden ist, weil man die Parteien für eine Gefährdung des als Einheit postulierten Gemeinwillens hielt. In der „Partei“ wurde eine organisierte Vertretung von partikularen Interessen gesehen, die in Konkurrenz zu einer auf das Gemeinwohl ausgerichteten Willensbildung und -entscheidung stand. Verständlich wird diese negative Beurteilung der Parteien, wenn man die Definition der Nation in den Blick nimmt, die ebenfalls in der Französischen Revolution ihre entscheidende Prägung erhielt. Dem Begriff der Nation ist im Sinne Rousseaus die Prämisse Primat der volonté générale vor der volonté particulière 1 - zugrunde gelegt worden. Ihr zufolge soll jeder Franzose als Glied der französischen Nation den Primat der volonté generale vor der volonté particulière anstreben ${ }^{2}$. Aus der Definition der Nation leitete sich auch das Selbstverständnis des Abgeordneten ${ }^{3}$ ab, der sich als Repräsentant der Nation sah und eine enge Parteiorganisation ablehnte, denn in ihr erblickte er eine Einengung seiner parlamentarischen Freiheit.

Gleichwohl gab es parallel hierzu seit 1815 auch eine andere Betrachtungsweise, die die politische Partei nicht mehr nur als Gefährdung des einheitlich verstandenen Nationalwillens und als Vertreterin von Einzel- oder Sonderinteressen betrachtete, sondern als konstitutives Element des parlamentarischen Systems er-

1 J.-J. Rousseau, Du contrat social, Oxford 1972, S. 115, 198. Rousseau betont den Primat der volonté générale vor der volonté particulière im Buch I, Kapitel VI: „Chacun de nous met en commun sa personne et toute sa puissance sous la suprême direction de la volonté générale, et nous recevons en corps chaque membre comme partie indivisible du tout.“; S. 115 und auch Buch IV, Kapitel 1.

2 R. von Albertini, Parteiorganisation und -begriff in Frankreich 1789-1940, in: HZ 193 (1961), S. 529-600, hier S. 530.

3 Vgl. R. von Albertini, Parteiorganisation und -begriff, S. 577-582; P. R. Rohden, Demokratie und Partei in Frankreich, in: Derselbe (Hg.), Demokratie und Partei, Wien 1932, S. 137-140. 
kannte und als notwendiges und nützliches Instrument für die Meinungsbildung innerhalb des Verfassungsrahmens sah4.

Mit der schrittweisen Zunahme der Organisation der Parteien ging auch eine veränderte Bewertung der Parteien im politischen System einher. Die Keimzelle der ersten Organisation ${ }^{5}$ bildeten sogenannte Wahlkomitees vor Ort, die sich um die Wahlpropaganda und die Kandidatenaufstellung kümmerten. Hinzu kam die Presse, die zunehmend eine wichtige Rolle bei der Organisation des Wahlkampfes vor Ort spielte, da sie sowohl über die Kandidatenaufstellung informierte als auch die Programme der einzelnen Kandidaten verbreitete. Obwohl man sich gegen zentralistische Bestimmungen und Beeinflussungen zu wehren versuchte, kam es zu Versuchen, die Kandidatenaufstellung und die Propaganda zentral zu koordinieren und zu steuern. Aus diesen Überlegungen resultierte die Idee, an die Spitze dieser Wahlkomitees auf lokaler Ebene ein Zentralkomitee zu setzen. Aber im wesentlichen blieb die organisatorische Grundform unangetastet, denn die Lokalkomitees standen weiterhin untereinander nur in sehr losem Kontakt und traten vor allem nur zu Wahlzeiten aktiv in Erscheinung. Die Verbindung nach Paris kam allein durch den Abgeordneten zustande, der innerhalb des Parlaments frei entscheiden konnte. Ein weiteres Charakteristikum des französischen Parlamentarismus, das vor allem bei den politischen Kräften der Mitte bzw. der rechten Mitte verbreitet war, stellte die Zugehörigkeit innerhalb des Parlaments zu Gruppen dar, die mit den Parteien außerhalb des Parlaments nicht identisch waren ${ }^{6}$. Diese Entwicklung setzte sich bis in die Dritte Republik fort und überdauerte diese sogar.

Die Entwicklung der Parteien verlief in der Dritten Republik in drei Phasen. Als erste Phase kann die Zeit vom Beginn der Dritten Republik ${ }^{7}$ bis zum Ende des 19. Jahrhunderts bezeichnet werden. In diesem Zeitraum hatten sich trotz des neuen politischen Systems mit allgemeinem Wahlrecht weder zentrale Organisationen herausgebildet, noch war ein breiter Demokratisierungsprozeß der Gesellschaft, der die Entwicklung organisierter Massenparteien gefördert wie auch erforderlich gemacht hätte, in Gang gekommen. Vielmehr blieb es beim bisher entwickelten Komiteesystem, das zu Wahlzeiten aktiv wurde. Das neue parlamentarische System legte diesen eklatanten Mangel an gutorganisierten Parteien

4 Ebenda.

5 Die ersten Organisationsformen von Parteien, die jedoch noch reine Wahlorganisationen waren, sind zwischen 1819 und 1848 festzustellen; vgl. R. von Albertini, Parteiorganisation und -begriff, S. 554-558.

6 Z.B. teilte sich die Alliance républicaine et démocratique, eine politische Kraft der rechten Mitte, in der Deputiertenkammer auf vier parlamentarische Gruppen auf. So schrieben sich Abgeordnete der Alliance républicaine et démocratique in folgende Gruppen ein: Gauche républicaine et démocratique, L'Action républicaine et sociale, Républicains de gauche und vereinzelt in die Gruppe der $R a-$ dical et radical-socialiste; vgl. G. Bourgin/J. Carrère (Hg.), Manuel des partis politiques en France, Paris 1924, S. 69/70.

7 Als eigentlicher Beginn der Dritten Republik gilt nach rein formalen Kriterien das Jahr 1870 mit der Ausrufung der Republik. Aber erst ab 1875 wurde mit der Verabschiedung der drei grundlegenden Verfassungsartikel der Dritten Republik ein erster Schritt in Richtung Republik getan. Aber der Kampf um die parlamentarische Regierungsform war noch nicht endgültig gewonnen. Vgl. dazu auch R. Hudemann, Fraktionsbildung im französischen Parlament. Zur Entwicklung des Parteiensystems in der frühen Dritten Republik (1871-1875), München 1979; D. Mollenhauer, Auf der Suche nach der „wahren Republik“. 
schon sehr bald offen, denn es wurde von der Instabilität der Regierungen dominiert ${ }^{8}$. Um dem jungen parlamentarischen Regierungssystem nachhaltig zu Stabilität zu verhelfen, setzte sich Gambetta, der als der „große Vorkämpfer des republikanisch-demokratischen Gedankens" 9 bezeichnet werden kann, für festorganisierte Parteien ein, die die Regierung stützen sollten ${ }^{10}$. Gambetta konnte sich mit seiner Auffassung nicht durchsetzen. Im gegnerischen Lager hielten sich besonders zwei Grundpositionen hartnäckig in der Diskussion, die hier anhand von zwei bekannten Staatsrechtlern exemplarisch dargestellt werden sollen.

Emile Faguet ${ }^{11}$, Vertreter des republikanischen Liberalismus, sah in der Trennung zwischen einer Majoritäts- und einer Minderheitspartei die Spaltung der Nation in zwei Teile. Aus seiner Sicht war der Parteigeist nur als ein Mangel an Patriotismus zu verstehen und nicht vereinbar mit der Idee der Freiheit, die sich an einem Staatsbegriff orientierte, der eine Trennung zwischen Staatsgewalt und Gesellschaft vornimmt und den Parteien nur den Platz von „corps intermédiares“ zwischen Staat und Individuum zuwies.

Victor Micelli ${ }^{12}$ hingegen unterschied einen Parlamentarismus mit organisierten und mit losen Parteien, erkannte aber in beiden Fällen einen Verlust an staatlicher Autorität und eigenständiger Regierungsgewalt. Er begründete dies damit, daß bei organisierten Parteien zwar eine gewisse Stabilität gesichert sei, die politische Entscheidung aber aus dem Parlament in unkontrollierte Gremien verlagert werde. Diese wiederum würden von partikularen Interessen geleitet und der Exekutive diese Partikularinteressen aufdrängen. Gäbe es keine Mehrheitspartei, müsse man auf Parteikoalitionen zurückgreifen, die Desintegration, zweifelhafte Kompromisse oder gar Blockierung der Regierungs- und Staatsgewalt zur Folge haben könnten. Die lose Partei- und Fraktionsstruktur hingegen lasse dem Parlament zwar die politische Entscheidung, aber die Instabilität der Kabinette sei damit kaum zu vermeiden.

8 Bereits die Jahre von 1875 bis zum Ende des 19. Jahrhunderts waren geprägt von häufigen Regierungswechseln, womit ein charakteristisches Merkmal der frühen Dritten Republik die Instabilität der Regierungen wurde; vgl. A. Soulier, L'instabilité ministerielle sous la Troisième République 1871-1938; R. Hudemann, Fraktionsbildung, S. 149-258; J.-M. Mayeur, La vie politique sous la Troisième République, S. 71-137.

9 R. von Albertini, Parteiorganisation und -begriff, S. 561. Zum Beitrag Gambettas für das republikanisch-demokratische System allgemein siehe H. Stannard, Gambetta and the foundation of the Third Republic, London 1921; D. Amson, Gambetta ou le rêve brisé, Paris 1994; J. P. T. Bury, Gambetta's Final Years. „The Era of Difficulties“ 1877-1882, London 1982; Derselbe, Gambetta and the Making of the Third Republic, London 1973; zuletzt P. Antonmattei, Léon Gambetta, héraut de la République, Paris 1999.

10 Gambetta war der Úberzeugung, daß eine republikanische Partei vonnöten sei, die mit großer Mehrheit im Parlament eine Regierung bilden bzw. unterstützen könnte. Dieses Ziel glaubte er am besten mittels eines geänderten Wahlrechtes zu erreichen. Anstelle des 1875 eingeführten Einmannwahlkreises mit zwei Wahldurchgängen setzte er sich wieder für die Listenwahl ein, um damit auch den Druck vom Wahlkandidaten zu nehmen, weil dieser dann nicht mehr an die engen Interessen seiner Wähler gebunden war, sondern sich auch den großen nationalen Fragen zuwenden konnte; vgl. R. von Albertini, Parteiorganisation und -begriff, S. 563.

1 E. Faguet, Le Libéralisme, Paris 1902; vgl. auch R. von Albertini, Parteiorganisation und -begriff, S. 567.

$12 \mathrm{~V}$. Micelli, Les partis politiques dans leurs rapports avec le gouvernement de cabinet, in: Revue du Droit public et de la Science politique, Bd. 4 (1895), S. 154-176; vgl. auch R. von Albertini, Parteiorganisation und -begriff, S. 567. 
In einer zweiten Phase der Dritten Republik, die etwa den Zeitraum von 1900 bis zum Ersten Weltkrieg umfaßt, wurde eine generelle Tendenz zur Organisation sichtbar, die mit der zunehmenden Organisierung des gesellschaftlichen Bereiches einherging und in der Gründung von Wirtschaftsverbänden, Gewerkschaften ${ }^{13}$ und politischen Vereinigungen ${ }^{14}$ ihren Ausdruck fand. Dieser erneute Anlauf zu strafferen Organisationsformen wird in Relation mit dem allgemeinen Trend zur „Fundamentaldemokratisierung" (Karl Mannheim) ${ }^{15}$ gesetzt und als politische Bewusstseinsbildung bisher unorganisierter Massen verstanden. Ein verändertes Verhältnis zum Parteiwesen setzte definitiv ein, als sich in Frankreich nationale Parteien herausbildeten. Vor allem mit der Gründung der SFIO ${ }^{16}$ fand eine einschneidende Veränderung statt. Unterstützt wurde dieser Meinungswechsel durch die Arbeit Ostrogorskis ${ }^{17}$ und dem oben erwähnten allgemeinen Trend zur Organisierung. Ein weiterer Punkt, der zur Verdichtung der Organisation der Parteien in Frankreich führte, war die Diskussion um das Proporzsystem bei Wahlen ${ }^{18}$, denn die Listenwahl mit proportionaler Vertretung verlangte geradezu nach Organisation. An der Diskussion um das Wahlrecht, genauer gesagt am Proporzsystem, entzündete sich in Frankreich die Diskussion um die Macht und den Einfluß der Parteien im Parlament. Als bedeutendste Vertreter des Proporzsystems galten Jean Jaurès und Georges Lachapelle. Sie waren der Meinung, daß ein parlamentarisches System nur mit stark organisierten Parteien funktionsfähig sei. Außerdem hielten sie an der Überzeugung fest, daß ein Deputierter, unterstützt

13 Zur Gründung der Gewerkschaften in Frankreich: S. Jauch/R. Morell/U. Schickler, Gewerkschaftsbewegung in Frankreich und Deutschland. Ein kontrastiver Vergleich ihrer zentralen Merkmale bis zum Ersten Weltkrieg, Frankfurt a. Main 1984; G. Lefranc, Le mouvement syndical sous la Troisième République, Paris 1967; Derselbe, Le Syndicalisme en France, Paris 1971; R. Mouriaux, La CGT, Paris 1982. Zu den christlich orientierten Gewerkschaften siehe M. Launay, Le Syndicalisme chrétien en France de 1885 à nos jours, Paris 1984.

14 Im Zuge der Dreyfus-Affäre wurde von Intellektuellen 1898 die Ligue des droits de l'bomme et du citoyen gegründet. Von politischen Kräften außerhalb des Parlaments wurden Ligen gegründet, die sowohl auf der politischen Linken wie auf der Rechten anzusiedeln waren. Zum Phänomen der Ligen: L.-E. Jacques, Les partis politiques sous la IIIe République, Paris 1913, S. 409-419; S. Berstein, La Ligue, in: J.-F. Sirinelli (Hg.), Histoire des droites en France, Bd. 2, Paris 1992, S. 61-111.

15 Vgl. R. von Albertini, Parteiorganisation und -begriff, S. 565; K. Mannheim, Mensch und Gesellschaft im Zeitalter des Umbaus, Darmstadt 1958, S. 51: „Warum diese Disproportionalitäten auf die Dauer für unsere Gesellschaft untragbar sind, wird an zwei Wesenszügen der modernen Gesellschaft deutlich. Einerseits aktiviert die industrielle Gesellschaft immer mehr auch diejenigen Schichten und Gruppen, die früher am politischen Leben nur passiv teilnahmen. Ich möchte diese neue weitgehende Aktivierung der Massen die „Fundamentaldemokratisierung der Gesellschaft" nennen." Zu den Soziologen der Zwischenkriegszeit allgemein: R. Blombert, Intellektuelle im Aufbruch. Karl Mannheim, Alfred Weber, Norbert Elias und die Heidelberger Sozialwissenschaften der Zwischenkriegszeit, München/Wien 1999.

$16 \mathrm{Zu}$ den Gründungsparteitagen der SFIO vom 23. 4.-25. 4. 1905 und vom 29. 10.-1. 11. 1905 siehe L'Humanité vom 24. 4.-26. 4. 1905, jeweils S. 1, sowie L'Humanité vom 29. 10.-2. 11. 1905, jeweils S. 1.

17 M. Ostrogorski, La démocratie et les partis politiques, Paris 1912. Ostrogorski beschäftigte sich in diesem Werk vor allem mit den politischen Kräften in Großbritannien und den Vereinigten Staaten. Literatur zu den Erkenntnissen Ostrogorskis hinsichtlich des französischen Systems: G. Quagliariello, La politica senza partiti. Ostrogorski e l'organizzazione della politica tra ' 800 e ' 900 , Roma/Bari 1993; S. Berstein, „Antipartitismo“ alla francese, in: G. Orsina (Hg.), Contro i partiti. Saggi sul pensiero di Moisei Ostrogorski, Roma/Bari 1993, S. 93-107.

18 Zum Wahlsystem in Frankreich bieten einen guten Überblick: R. Huard, Le suffrage universel en France (1848-1946), Paris 1991; M. Prélot/J. Borlouis, Institutions politiques et Droit constitutionnel, Paris ${ }^{11} 1992$; P. Rosanvallon, Le sacre du citoyen. Histoire du suffrage universel en France, Paris 1992; M. Duverger, L'influence des systèmes électoraux sur la vie politique, Paris 1950. 
von seiner Partei und gewählt aufgrund von deren Programm, sich einer Fraktionsdisziplin unterordnen werde. Die Ausgangsposition für diese Überlegungen war, daß entweder eine Mehrheitspartei geschlossen hinter der Regierung stehe, oder daß durch organisierte Parteien stabile Koalitionen zustande kommen könnten. Die Gegner des Proporzsystems plädierten für das repräsentative Element der parlamentarischen Demokratie. Darunter verstanden sie einen unabhängigen Abgeordneten, der nur der Nation als Ganzer verantwortlich war. Sie kritisierten, daß mit dem Proporzsystem die Parteigremien gestärkt und sich zwischen den Abgeordneten und den Wähler stellen würden. Außerdem hätte durch die Listenwahl der Wähler keine freie Wahl mehr und könnte auch keinen direkten Kontakt mehr zum Abgeordneten erlangen. Das Mißtrauen gegen organisierte Parteien und ihre Bedeutung blieb in Frankreich trotz verschiedener Anläufe zu straff organisierten Parteien ${ }^{19}$ groß. Diese Abneigung war besonders stark im Parti radical et radical-socialiste vertreten, der sich als Erbe der Französischen Revolution und als Verfechter des Republikanismus verstand und zugleich die wichtigste Partei im Parteiensystem der Dritten Republik darstellte. Die republikanischen Politiker der Dritten Republik und allen voran die Radikalsozialisten bevorzugten die Demokratie mit direkter Repräsentation gemäß Léon-Ernest Jacques "gouvernement de la nation par la nation elle-même (... “ 20 .

Der Beginn der dritten Phase der Entwicklung der Parteien wurde im Jahr 1910 eingeleitet. Die „Groupes“ im Parlament wurden als Parteigremien anerkannt und erhielten damit eine Aufwertung, da ihnen ein Anrecht auf proportionale Vertretung in den großen parlamentarischen Kommissionen zugestanden wurde. Außerdem konnten sie ihre Ausschussmitglieder selbst bestimmen; bis zu diesem Zeitpunkt waren sie noch per Los ernannt worden. Mit dieser Neuregelung hielt die Organisation weiteren Einzug in das politische System Frankreichs. Darüber hinaus wollte man den Minderheiten Rechnung tragen und die Gesetzesvorbereitung rationalisieren. Die Bedeutung der Kommissionen nahm damit einerseits zu. Die Debatten verlagerten sich vom Plenum in die Ausschüsse. Es wurde wiederum sichtbar, wie wichtig organisierte Parteien waren und wie sehr sie in Frankreich fehlten ${ }^{21}$. Gleichzeitig jedoch wurden Stimmen laut, die mit diesem Verfahren die Unabhängigkeit des Abgeordneten gefährdet sahen.

19 So hatte Daladier als Vorsitzender des Parti radical in den Jahren 1927 bis 1929 mehrere Versuche unternommen, seine Partei sowie die Fraktion zu disziplinieren. Jedoch blieben diese Versuche langfristig gesehen vergeblich. Vgl. dazu das Prozeßbeispiel II, Kapitel 1. Ähnlich schickte sich auch Pierre-Etienne Flandin an, die Alliance Démocratique zu mehr Disziplin zu bewegen. Aber auch seine Disziplinierungsversuche führten nicht zum gewünschten Erfolg; vgl. den Nachlaß Flandin in der BN, DON 31357 sowie das Teilarchiv der Alliance Démocratique DON 37260. Für die konservative Fédération républicaine siehe: $\mathrm{H}$. Weinreis, Liberale und autoritäre Republik. $\mathrm{Re}-$ gimekritik und Regimekonsens der französischen Rechten zur Zeit des nationalsozialistischen Aufstiegs in Deutschland (1928-1934), hier vor allem S. 22-33; G. Le Béguec, Le parti, in: J.-F. Sirinelli (Hg.), Histoire des Droites en France, Bd. 2: Cultures, Paris 1992, S. 13-59.

20 L.-E. Jacques, Les partis politiques sous la Troisième République, S. 442.

21 Während der großen Kammerdebatte am 1.7.1910 über den neuen Stellenwert der "groupe“ verweist Abel Ferry interessanterweise auf das Reglement im Deutschen Reichstag : „(...) où les partis sont fortement constitués - c'est peut-être une leçon pour tous les partis - ils ont introduit dans leur règlement la représentation comprise dans un état moderne."; J.O., Chambre des Députés vom 1.7.1910, S. 759. 
Die Aufwertung der „Groupes“ war vorerst nur als Hilfe für die Bestellung der Kommissionen gedacht und machte aus den Fraktionen noch keine dauerhaften Zentren der politischen Willensbildung. Erst am Ende der dritten Entwicklungsphase der Parteien der Dritten Republik erfolgte die volle Anerkennung der "Groupes“ durch eine Neuregelung im Jahr 193222, durch die festgelegt wurde, daß die "Groupes" beim Generalsekretär der Kammer eine "déclaration politique" abgeben mußten. Die Parlamentarier, die unabhängig bleiben wollten, waren verpflichtet, dies anzuzeigen. Auch die Bureaux der "Groupes" wurden mit gewissen Kompetenzen ausgestattet. Von diesem Moment an bestimmten die Fraktionspräsidenten zusammen mit den Kommissionsvorsitzenden die Tagesordnung des Parlaments. Diese Zusammenarbeit gewann immer mehr Bedeutung und somit entwickelten sich die "Groupes“ zu wirklichen offiziellen Organen der legislativen Autorität ${ }^{23}$.

\section{Parteiensystem}

Für die Herausbildung und Prägung des französischen Parteiensystems können zwei wesentliche Bedingungsfaktoren genannt werden: die institutionellen und die politisch-kulturellen Faktoren. Zur Kategorie der institutionellen Faktoren gehören z. B. das oben schon kurz angesprochene Wahlsystem und der Wahlmodus $^{24}$, die sicherlich ihren Beitrag zur charakteristischen Ausformung des Parteiensystems der Dritten Republik in Frankreich geleistet haben. In dem folgenden Abschnitt sollen aber die politisch-kulturellen Faktoren erörtert werden, da sie für die leitende Fragestellung dieser Untersuchung grundlegend sind.

Im Parteiensystem bildeten sich bis zum Ende des 19. Jahrhunderts drei Tendenzen heraus: die Rechte ${ }^{25}$, das „Centre ${ }^{\text {“26 }}$ und die Linke ${ }^{27}$. Während die Rechte,

22 Bereits in der Festlegung vom 1.7. 1910 erkannte die Deputiertenkammer die parlamentarischen Gruppen als offizielle Organe der Assemblée nationale an. Am 10.6. 1932 wurde dieser Status mit einem juristischen Statut untermauert; vgl. dazu J.O., Chambre des Députés vom 11.6. 1932, S. 2290. Allgemein zur Funktion und dem Status der parlamentarischen Gruppen: P. Arrighi, Le statut des partis politiques, Paris 1948, S. 14; A. Soulier, L'instabilité ministerielle, S. 195.

23 Vgl. hierzu auch P. Arrighi, Le statut des partis politiques, S. 14.

${ }^{24}$ Literatur zum Wahlsystem und zum Wahlmodus im Frankreich der Zwischenkriegszeit: P. Pombeni, Introduzione alla storia dei partiti politici, Bologna 21990 , S. 291ff; Ph. M. Williams, Politics in post-war France. Parties and the Constitution in the Fourth Republic, London 21958, S. 309 ff.; F. Goguel, L'influence des systèmes électoraux sur la vie politique d'après l'expérience française, in: M. Duverger, L'influence des systèmes électoraux sur la vie politique, Paris 1950, S. 69-83; M. Duverger, Institutions politiques et Droit Constitutionnel, Bd. 2, Paris 1973, S. 129-149; R. Huard, Le suffrage universel en France; M. Prélot/J. Borlouis, Institutions Politiques et Droit Constitutionnel, Paris ${ }^{11} 1990$, S. 507-510.

251903 rekrutierte sich die gemäßigte Rechte in der Fédération républicaine aus den verschiedenen Strömungen der politischen Rechten wie Républicains modérés, Progressistes bzw. Droite républicaine. Ein weiterer Flügel, der sich im Laufe der zwanziger Jahre in der Fédération républicaine entwickelte, kam aus den katholischen politischen Kreisen wie der Action libérale populaire, der Droite catholique traditionnelle und der Fédération nationale catbolique. 1924 gründete eine katholische Bewegung mit sozialem Schwerpunkt den Parti démocrate populaire. Zur Entwicklung der rechten politischen Strömungen in der Dritten Republik Frankreichs siehe R. Rémond, Les Droites en France, Paris 1993 (Neuauflage von 1982); J.-M. Mayeur, La vie politique sous la Troisième République, S. 137-174 und S. 296-305; F. Martin Jr., The Creation of the Action Liberrale Populaire. An Example of Party Formation in Third Republic France, in: French Historical Stu- 
die „Conservateurs" sich für eine autoritäre monarchisch-klerikale Staatsform aussprachen, bekannnte sich die Linke zur Republik und ihren Traditionen. Der Parti radical et radical-socialiste, der im ausgehenden 19. Jahrhundert die Republik prägte, reklamierte für sich, der Repräsentant der republikanischen Tradition zu sein. Auf diese Weise wurde er, wie der französische Historiker Maurice Sorre ihn einmal bezeichnet hatte, „zum wichtigsten Regulator des politischen Lebens der Dritten Republik"28. Denn er konnte sowohl Koalitionen zur linken mit den Sozialisten wie zur rechten mit den Liberalen eingehen.

Vor dem Ersten Weltkrieg dominierte der „Bloc des gauches“ das politische System Frankreichs, der sich nach der Bedrohung der Republik während der Dreyfus-Affäre ${ }^{29}$ zwischen Republikanern und den Linkskräften entwickelt hatte. Um den nationalistischen, den klerikalen und den konservativen Kräften, die in dieser Affäre eine entscheidende Rolle gespielt hatten, ein Gegengewicht zu setzen, formierte sich der sogenannte Linksblock, der die Devise „défense républicaine“ und "Pas d'ennemis à gauche“ ausgab. Dieser Linksblock konnte unter WaldeckRousseau und seinem Nachfolger Combes eine Politik der weiteren Festigung der Republik erfolgreich gestalten. Ab 1906 jedoch setzte eine gewisse Lockerung, wenn nicht sogar eine allmähliche Auflösung dieses Linksblockes ein. Diese Entwicklung wurde durch drei Faktoren ausgelöst: 1) Dadurch, daß der Parti radical nun eine Regierungspartei geworden war, verlor er seine Intransigenz. Einige Radikalsozialisten näherten sich konservativen Positionen an, andere richteten ihren Blick auf die extremen Sozialisten. So kam es zu Teilabspaltungen bzw. es entstanden verschiedene Flügel im Parti radical, die eine größere Heterogenität entstehen ließen. Dadurch wurde vor allem die Entscheidungskraft des Parti radical geschmälert. 2) Von seiten der Sozialisten wurde die Gangart härter. Mit der Formierung der sozialistischen Partei gewannen die Vertreter des Klassenkampfdogmas an Gewicht, und die Sozialisten beurteilten Koalitionen mit bürgerlichen Parteien sehr skeptisch bzw. lehnten diese ab. Die SFIO wurde zunehmend mit anarchistischen Strömungen und revolutionären syndikalistischen Bewegungen konfrontiert. Um den Rückhalt in der Arbeiterschaft nicht zu verlieren, entfernte sie sich nach und nach von den Radikalsozialisten. 3) Ein weiterer neuer Aspekt, der seine Wirkung zeigte und die bisherigen Allianzen aufweichte, war die Frage nach der

dies 11 (1976), S. 670 ff.; J.-C. Delbreil, Le parti démocrate populaire. Des origines au MRP, 19191944, Paris 1990; Le Béguec, Le Parti, in: J.-F. Sirinelli (Hg.), Histoire des Droites en France, Bd. 2, S. 13-60.

26 Das „Centre“ bildete vor allem die Alliance Démocratique, deren Abgeordnete sich im Parlament auf bis zu vier verschiedene parlamentarische Gruppen verteilten. Zur Alliance Démocratique siehe R. Sanson, Centre et Gauche (1901-1914): L'Alliance Républicaine Démocratique et le Parti radical-socialiste, in: Revue d'Histoire Moderne et Contemporaine 39 (1992), S. 493-512. Zur Alliance Démocratique in der Zwischenkriegszeit siehe dieselbe, La relation entre Alliance démocratique et Parti radical, in: H. Möller/M. Kittel (Hg.), Demokratie in Deutschland und Frankreich 1918-1933/40, S. 203-218. Zur Problematik des "Centre“ vgl. M. Duverger, L'Eternel Marais. Essai sur le centrisme français, in: Revue française de Science Politique 14 (1964), S. 33-49; A. Siegfried, Tableau des partis politiques en France, S. $172 \mathrm{f}$.

27 Die Linke wurde vor allem durch die parlamentarischen Gruppen der SFIO und des Parti radical bis hin zur linken Mitte, bestehend aus den parlamentarischen Gruppen der Républicains-socialistes, zeitweise einschließlich der Gauche radicale, repräsentiert.

28 M. Sorre, Der französische Radikalismus zwischen den beiden Kriegen, in: O. Hauser (Hg.), Parteien, S. 105.

29 P. Birnbaum (Hg.), La France de l'Affaire Dreyfus, Paris 1994. 
Wahlrechtsreform. Die Konservativen und die extreme Linke befürworteten eine Änderung des Wahlrechts und sprachen sich für das Verhältniswahlrecht mit Listenwahl aus. Sie gerieten dadurch in Gegensatz zu den Radikalsozialisten, die weiterhin am „scrutin uninominal par arrondissement“ festhalten wollten ${ }^{30}$. Schließlich kam es bei den Wahlen von 1914 wieder zu einer Neuauflage des Bloc des gauches, da sich der progressive Teil der Radikalsozialisten und Sozialisten über die Fragen der Militärdienstzeit und der Steuerreform verständigen konnte.

In der Zwischenkriegszeit erweiterte sich das Parteiensystem insofern, als nunmehr vier Hauptströmungen das Geschehen bestimmten: die politische Rechte, die bürgerliche Mitte, die Radikalsozialisten und die Sozialisten: Fédération républicaine ${ }^{31}$, Le Parti républicain-socialiste, Alliance Démocratique, Parti radical et radical-socialiste und SFIO. Nach der Spaltung der SFIO 1920 entstand mit der Kommunistischen Partei eine linksextremistische Gruppierung. Die 1924 gegründete Partei Parti démocrate populaire ${ }^{32}$ vertrat vor allem den französischen Katholizismus.

Angesichts der Instabilität der Koalitionsbildungen stieß das Parteiensystem jedoch schon im Lauf der zwanziger Jahre auf wachsende Kritik, die in den dreiBiger Jahren in ein allgemeines Krisenbewußtsein mündete ${ }^{33}$. Es wurde moniert, daß das parlamentarische System der Dritten Republik mit dem Trend zur Massendemokratie und der gesellschaftlichen Entwicklung nicht mehr vereinbar sei. Denn das Parlament sei, so der Vorwurf, zu unbeweglich für die moderne Massengesellschaft geworden, was vor allem auch mit dem veralteten Parteienverständnis in Frankreich zusammenhänge.

Den Parteien wurde einerseits ins Stammbuch geschrieben, an alten Parteiprogrammen festzuhalten, damit erstarrt und unbeweglich geworden und nicht mehr in der Lage zu sein, Lösungsvorschläge für die aktuellen Finanz- und Wirtschaftsprobleme anbieten zu können. Andererseits wurde ihnen vorgehalten, keine Programme mehr zu vertreten und sich nur noch an wirtschaftlichen Interessen auszurichten. Beide Kritikpunkte trafen paradoxerweise zu, denn die alten Parteitraditionen bzw. - ideologien hatten weiterhin für Wahlkoalitionen und die parlamentarische Taktik ihre Bedeutung, genügten aber nicht mehr für die Lösung anstehender epochenspezifischer Probleme. Ein typisches Beispiel für dieses Di-

3o So kam es bei den Wahlen von 1910 z.B. zu Allianzen zwischen konservativen und sozialistischen Kräften, die dazu führten, daß einige sozialistische Kandidaten mit Hilfe der Konservativen ein Mandat erringen konnten. Vgl. dazu J. Carrère/G. Bourgin, Manuel des partis politiques en France, S. 14.

31 Sie legte sich 1924 einen neuen Namen zu und benannte sich von Fédération républicaine in Union républicaine démocratique um. Die Fédération républicaine wurde 1903 von Eugène Motte gegründet und umfaßte auch die Anhänger von de Méline und de Ribot. Sie repräsentierte damals eine neue rechte politische Kraft, da sie sich überzeugt zur parlamentarischen Republik bekannte. Ausführlich zur Fédération républicaine: W. D. Irvine, French Conservatism in Crisis: The Republican Federation of France in the 1930s, Louisiana University Press 1979.

32 Zum Parti démocrate populaire, der 1919 gegründet worden ist, siehe J.-C. Delbreil, Centrisme et démocratie-chrétienne en France; J.-M. Mayeur, Des partis catholiques à la démocratie chrétienne, XIXe-XXe siècles, Paris 1980.

33 Zur ausführlichen Diskussion der Erneuerung des parlamentarischen Systems in Frankreich in den 1930er Jahren: C. Wurm, Westminster als Modell. Parlament, Parteien und "Staatsreform" im Frankreich der Dritten und Vierten Republik, in: J. Kocka/H.-J. Puhle/K. Tenfelde (Hg.), Von der Arbeiterbewegung zum modernen Sozialstaat. Festschrift für Gerhard A. Ritter zum 65. Geburtstag, München 1994, S. 409-428. 
lemma stellt der Parti radical dar, der 1924 wie auch 1932 einerseits wieder an das alte Bündnis mit der SFIO vor dem Ersten Weltkrieg anknüpfen wollte, sich aber andererseits in Wirtschafts- und Finanzfragen nicht auf die Politik der SFIO einließ. Für die Zeit des Wahlkampfes und der ersten politischen Aktionen schien eine gewisse Übereinstimmung zwischen den alten Weggefährten SFIO und Parti radical zu bestehen, wie sich z.B. in den Themen Laizismus, Einheitsschule, Lösung der Reparationsfragen und Stärkung des Völkerbundes widerspiegelte. Auf der parlamentarischen Ebene hingegen zerbrach das Cartel des gauches von 192434 letztlich daran, daß der Parti radical nicht bereit war, den sozialistischen Finanzund Wirtschaftsprojekten zur Lösung der Inflation und der Währungsschwäche des Franc zu folgen.

Im Zentrum der Kritik am parlamentarischen System standen aber nicht nur die Parteien, sondern auch die traditionellen republikanischen Institutionen, wie z.B. die Einrichtung der Komitees, die in den Departements eine Abhängigkeit des Abgeordneten verursachten, denn dieser mußte sich für die Sonderinteressen der einzelnen Departements einsetzen und verlor dabei den Blick für die nationalen Probleme, die einer Lösung harrten. Parteigegner kritisierten außerdem, daß Beschlüsse einzelner Parteigremien zu sehr den parlamentarischen Entscheidungsprozeß beeinflussen würden, wie das z.B. 1928 durch den Parteitag des Parti radical in Angers passiert war. Die Radikalsozialisten hatten auf ihrem Parteitag beschlossen, ihre Minister aus der Regierung Poincaré zurückzuziehen. Gleichzeitig wurde auch der Vorwurf erhoben, daß vereinzelte Parteigremien übermäßigen Einfluß hätten, weil keine Parteidisziplin und keine Fraktionsdisziplin herrsche.

Trotz der frühen Parlamentarisierung in Frankreich blieb die Entwicklung der Parteien in der Dritten Republik in einem gewissen Stadium stecken, da das Festhalten an der alten politischen Tradition einer innovativen Lösung der neuen wirtschaftlichen und finanzpolitischen Probleme, die Frankreich in der Nachkriegszeit ereilten, im Wege stand.

${ }^{3+}$ Jedoch war dies nur eine Seite der Medaille. Der wesentliche Faktor für den Sturz der Regierung Herriot lag nicht auf parlamentarischer Ebene, sondern kam von außerhalb des Parlaments und ging vor allenı von der Bank von Frankreich aus. Vgl. dazu ausführlich Prozeßbeispiel I, Kapitel 6. 


\section{Parteipolitik im Rahmen der "republikanischen Synthese“,}

\section{Zur republikanischen politischen Kultur Frankreichs}

Vergegenwärtigen wir uns noch einmal kurz die verschiedenen Prägungslinien, die durch die politische Geschichte Frankreichs seit der Französischen Revolution gelaufen sind. Dabei ist zum einen an den Dualismus, der die politischen Systeme Frankreichs seit der Französischen Revolution dominiert und geprägt hat, zu erinnern. Auf der einen Ebene spielte im politischen Leben Frankreichs seit der Französischen Revolution der stete Konflikt zwischen Monarchisten und Republikanern eine bedeutende Rolle, während im Ringen um das jeweilige politische System das Alternieren von zwei anderen Regierungstypen, nämlich der repräsentativen Tradition und der plebiszitären in Frankreich bestimmend war. Noch zu Beginn der Französischen Revolution galt der Glaube an das repräsentative Modell der Demokratie. Die Abgeordneten der Nationalversammlung waren der Meinung, daß die Intentionen des Volkes am besten durch gewählte Vertreter umgesetzt werden können². Jedoch bereits in der Verfassung von $1793^{3}$ wurde dieses repräsentative System eingeschränkt und durch plebiszitäre Elemente ergänzt, die dem allgemeinen Willen durch jährliche Wahlen und durch Volksabstimmungen nachzukommen suchten. Repräsentative und plebiszitäre Systeme wechselten sich im 19. Jahrhundert in Frankreich ${ }^{4}$ ab; sie prägten das politische Leben und fanden ihren Niederschlag in den verschiedenen Verfassungen Frankreichs, die jeweils stärker durch das repräsentative oder durch das plebiszitäre Element charakterisiert waren.

1 S. Hoffmann, Paradoxes of the French Political Community, in: Derselbe, In Search of France, New York 21965 , S. 1-117.

2 Vgl. dazu die Verfassung von 1791: L. Duguit/H. Monnier/R. Bonnard, Les Constitutions et les principales lois politiques de la France depuis 1789. Précédés de notices historiques, Paris ${ }^{7} 1952$, S. 197-229; O. Duhamel, L'Histoire constitutionnelle de la France, Paris 1995, S. 16-21; Y. Guchet, Histoire constitutionnelle (1789-1958), Paris 21990, S. 57-84; J. Godechot, Les constitutions de la France depuis 1789, Paris 1970; Ch. Debbasch/J.-M. Pontier, Les constitutions de la France, Paris 1983, S. 5-39; M. Duverger, Constitutions et documents politiques, Paris 121989, S. $18-42$.

3 Zur Verfassung von 1793 siehe O. Duhamel, L'Histoire constitutionnelle, S. 23-28; Y. Guchet, Histoire constitutionnelle, S. 85-106; M. Duverger, Constitutions et documents politiques, S. 78-87; Ch. Debbasch/J.-M. Pontier, Les constitutions de la France, S. 47-55.

$4 \mathrm{Zu}$ den verschiedenen Verfassungen, die sich in Frankreich bis zur Verfassung der Dritten Republik von 1875 abwechselten, siehe L. Duguit/H. Monnier/R. Bonnard, Les Constitutions et les principales lois politiques de la France depuis 1789; D.W.S. Lidderdale, Le Parlement Français, Paris 1954, S. 36-38; O. Duhamel, L'Histoire constitutionnelle de la France; Y. Guchet, Histoire constitutionnelle; M. Duverger, Constitutions et documents politiques; Ch. Debbasch/J.-M. Pontier, Les constitutions de la France. 
Einen weiteren Prägungsstrang der politischen Kultur Frankreichs, der ebenfalls in der Französischen Revolution seinen Ausgangspunkt nahm, stellt der Gegensatz Katholizismus - Laizismus dar. Lange Zeit schien dieser Gegensatz so fundamental zu sein, daß man auch von den „Deux Frances“5 sprach.

Alle diese Stränge spielten auch eine wichtige Rolle in der Zeit zwischen 1871 und 1879, als es darum ging, die Republik in Frankreich und damit die repräsentative Demokratie definitiv zu etablieren. Auch in der Anfangsphase der Dritten Republik rangen die Anhänger der beiden Prinzipien miteinander, da die verschiedenen Verfassungsartikel der Dritten Republik beide Elemente berücksichtigten und zuließen ${ }^{6}$. Es standen sich zu Beginn der Dritten Republik die sich seit der Französischen Revolution herauskristallisierenden beiden Blöcke - Republik und laizistische Gesellschaft auf der einen und Monarchie und katholische Gesellschaft auf der anderen Seite - gegenüber. Letztlich gelang es dem republikanischen Lager ${ }^{7}$ und hier allen voran den Radikalsozialisten, sich im Kampf gegen die Konservativen durchzusetzen. In den verschiedenen Auseinandersetzungen mit den Konservativen, wie z.B. in der MacMahon-Krise ${ }^{8}$ entschied sich das Kräfteverhältnis endgültig zugunsten der Republik. Ab 1880 nahm der Ausbau und die Etablierung der Republik auch symbolische Formen an; diese wurden sichtbar in der Verlegung des Parlaments von Versailles nach Paris, mit der Deklaration des 14. Juli zum Nationalfeiertag und der Erklärung der Marseillaise zur Nationalhymne 9 . Einen ganz wesentlichen Schritt für die weitere Zementierung der Republik stellte die Verabschiedung der Schulgesetze Jules Ferrys ${ }^{10}$ dar.

5 Unter „Deux Frances“ versteht man einmal das Frankreich der Revolution, das demokratisch und laizistisch war und zum anderen das Frankreich der Konterrevolution, das monarchistisch und katholisch geprägt war. Vgl. zu den „Deux Frances“ P. Nora (Hg.), Les lieux de mémoire, 3 Bde, Bd. 1: Conflits et Partages, Paris ${ }^{3}$ 1997, hier besonders S. 106-139.

6 Zum Text der Verfassungsgesetze der Dritten Republik Frankreichs von 1875, der jedoch 1879, 1904 und 1926 partielle Veränderungen erhielt, siehe E. Walder, Von der Dritten zur Vierten Republik, Bern 1950, S. 9-16; zu den genannten Veränderungen siehe ebenda, S. 17-19.

7 Wie heterogen sich auch das republikanische Lager gestaltete, zeigte sich in der Aufteilung der Républicains auf die verschiedenen Gruppen im Parlament. Vgl. dazu R. Hudemann, Fraktionsbildung im französischen Parlament, S. 36-55; J.-M. Mayeur/M. Reberioux, The Third Republic from its Origins to the Great War, 1871-1914, Cambridge 1984, S. 37 ff.; J.-M. Mayeur, Les débuts de la Troisième République 1871-1898, Paris 1973; G. Dupeux, La IIle République, 1871-1914, in: G. Duby (Hg.), Histoire de la France, les temps nouveaux de 1852 à nos jours, Paris 1991, S. 143178; J.-P. Azéma/M. Winock, La IIIe République (1870-1940), Paris 1976, besonders S. 13-123.

$8 \mathrm{Zu}$ den Ereignissen um den 16. 5. 1877 siehe F. Caron, Frankreich im Zeitalter des Imperialismus 1851-1918. Geschichte Frankreichs Bd. 5, hrsg. von J. Favier, Stuttgart 1991, S. 276-286; P. Jeambrun, Jules Grévy ou la République debout, o.O. 1991; J.-M. Mayeur, Les débuts de la Troisième République 1871-1898, S. 26-54; O. Rudelle, La République absolue 1870-1889, Limoges 1982; S. 51-64; P. du Vachat, 1877. La crise du seize mai ou l'étrange République, Paris 1981; zuletzt F. Broche, La IIIe République, de Thiers à Casimir-Perier 1870-1895, Paris 2001.

9 Im Zuge der Republikanisierung Frankreichs wurden noch weitere Maßnahmen durchgeführt, wie z.B. die Amnestie der Beteiligten des Kommune-Aufstandes 1880. 1881 erfolgte die Verabschiedung eines liberalen Pressegesetzes, 1883 eine Justizreform. Ausführlich dazu J. P. T. Bury, Gambetta's Final Years. „The Era of Difficulties“ 1877-1882, London/New York 1982, S. 140168.

10 Die Schulgesetze Jules Ferrys von 1882-1886 führten letztlich zur Durchsetzung des Laizismus in Frankreich; vgl. C. Auspitz, The radical bourgeoisie. The Ligue de l'enseignement and the origins of the Third Republic 1866-1885, Cambridge 1982; P. Barral, Jules Ferry. Une volonté pour la République, Nancy 1985; M. Ozouf, L'École de la France. Essai sur la Révolution, l'utopie et l'enseignement, Paris 1984; F. Ponteil, Histoire de l'enseignement en France. Les grandes étapes 17891964, Paris 1966; J.-M. Gaillard, Jules Ferry, Paris 1989; O. Rudelle, De Jules Ferry à Raymond 


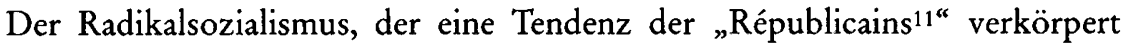
hatte, prägte nach dieser Entscheidung nachhaltig die politische Kultur der Dritten Republik und lieferte gleichzeitig das Fundament für die republikanische Synthese, die parteiübergreifend das nationale Dach des politischen Systems der Dritten Republik bildete.

In dem Maße, in dem sich nach 1875 trotz verschiedener Krisen in Frankreich der republikanisch-laizistische Konsens etablierte, entfiel auch die Tendenz zur Ausgliederung und die separat-parteiliche Organisation weltanschaulich-konfessioneller Bereiche. Systemoppositionelle Kräfte wie Boulangismus ${ }^{12}$, revolutionärer Syndikalismus ${ }^{13}$ und Royalismus ${ }^{14}$ formierten sich vielmehr als primär außerparlamentarische Bewegungen, die Parteien meist explizit ablehnten ${ }^{15}$.

Poincaré, ou l'échec du constitutionnalisme républicain, in: S. Berstein/O. Rudelle (Hg.), Le modèle républicain, Paris 1992, S. 91-116.

11 Die Républicains setzten sich aus verschiedenen Gruppen zusammen. Zu ihnen gehörten die gemäßigten und die radikalen Republikaner, die die linken Republikaner repräsentierten. Die Radicaux wiederum durchliefen von 1868/1869, als sich zum ersten Mal eine Gruppe als „radical“ bezeichnete, bis zur Gründung des Parti républicain radical et radical-socialiste 1901 eine sehr wechselvolle Zeit, auch wenn es programmatische und personelle Kontinuitäten gab, wie z.B. in der Person Camille Pelletans. Dennoch spaltete sich in den Jahren 1876 bis 1881 nochmals dieses radikale Milieu in "Opportunistes" und „Intransigeants“, wobei mit „Opportunistes“ die Gruppe der "Républicains de gouvernement" um Gambetta und Ferry bezeichnet worden war und die „Intransigeants“ ihrem Ideal einer "République démocratique et sociale“ anhingen. In den neunziger Jahren des 19. Jahrhunderts näherten sich diese beiden Tendenzen wieder an und gingen $1910 \mathrm{im}$ Parti républicain et radical-socialiste auf; vgl. D. Mollenhauer, Auf der Suche nach der "wahren“ Republik, besonders S. 1-32; P. Barral, Les Fondateurs de la troisième République, Paris 1968; C. Nicolet, L'idée républicaine en France. Essai d'histoire critique, Paris 1982; C. Auspitz, The radical bourgeoisie.

12 Zur Boulangerkrise 1888 siehe A. Dansette, Le Boulangisme, Paris 1946; J. Garrigues, Le Général Boulanger, Paris 1991; derselbe, Le Boulangisme, Paris 1992; W. D. Irvine, The Boulanger Affair reconsidered. Royalism, Boulangisme and the Origins of the Radical Right in France, Oxford/ New York 1989; Ph. Levillain, Boulanger, fossoyeur de la monarchie, Paris 1982; L.B. Fulton, The Boulanger Affair revisited: the preservation of the Third Republic, In: French Historical Studies 17 (1991), S. 310-329; O. Rudelle, La République absolue 1870-1889, S. 105-174; M. Burns, Rural society and French politics. Boulangism and the Dreyfus Affair 1886-1900, Princeton 1984; F. H. Seager, The Boulanger affair: political crossroad of France, 1886-1889, New York 1969; U. Stark, Die nationalrevolutionäre Herausforderung der Dritten Republik 1880-1900. Auflösung und Erneuerung des Rechts-Links-Schemas in Frankreich, Berlin 1991. Zur Krise der Republik durch den Boulangismus und deren Überwindung siehe E. Bendikat, Wahlkämpfe in Europa 1884 bis 1889 , Wiesbaden 1989, S. 355-398.

13 Zum revolutionären Syndikalismus vgl. H. Dubief, Le syndicalisme révolutionnaire, Paris 1969; J. Julliard, Pelloutier et les Origines du syndicalisme d'action directe, Paris 1971; G. Lefranc, Le mouvement syndical sous la IIIe République, Paris 1967; Derselbe, Le Syndicalisme en France, Paris 1971; Derselbe, Le Mouvement socialiste sous la troisième République. Bd 1: De 1875-1919, Neuauflage Paris 1977.

14 Wie z. B. die Action française; vgl. A. Chebel d'Apollonia, L'extrême-droite en France. De Maurras à le Pen, Brüssel 1988; Ch. T. Muret, French Royalist Doctrines since the Revolution, New York 1933; Z. Sternhell, La droite révolutionnaire 1885-1914. Les origines françaises du fascisme, Paris 21984; E. Weber, L'Action française, Paris 1985; V. Nguyen, Aux origines de l'Action Française. Intelligence et politique à l'aubre du XXe siècle, Paris 1991; M. Winock/J.-P. Azéma, L'Action Française, in: Derselbe, Histoire de l'extrême-droite en France, Paris 1993, S. 44-67.

15 Gemeint sind hier vor allem die zur extremen Rechten nationalistischer, militant-katholischer, militärischer Ausrichtung gehörenden Bewegungen, die sich in Ligen organisierten. Die ersten Ligen mit dieser Ausrichtung entstanden 1886 in Folge des Boulangismus und 1898 im Gefolge der Dreyfus-Affäre. Zu nennen sind hier z. B. die Ligue antisémite und die Ligue de la Patrie française, die sich wie die Action française während der Dreyfus-Affäre formierten; vgl. J. Goguel, La politique des partis sous la IIIle République, Bd. I, S. 128ff; L.-E. Jacques, Les partis politiques sous la Troisième République, besonders S. 344-350. Zu den Ligen in der Dritten Republik siehe v.a. S. 
Nach der Krise des 16. Mai 1877, in der die restaurativen Kräfte nochmals die große Hoffnung geschöpft hatten, den Kampf um die Staatsform für sich entscheiden zu können, entschied die Dreyfus-Affäre' ${ }^{16}$, die sich von 1894 bis 1906 hinzog, die Auseinandersetzung endgültig zugunsten der republikanischen Kräfte. Die Trennung von Kirche und Staat, die Combes mit sozialistischer Unterstützung $1905^{17}$ vollzog, stärkte ebenfalls die Republik.

Der Radikalsozialismus, der sich aus einem Zweig der Républicains entwickelt hatte, war durch den nach der Amnestie der Kommunarden 1880 wieder an Einfluß gewinnenden Sozialismus etwas mehr nach rechts, in die linke Mitte des Parteienspektrums des damaligen Frankreich, gedrängt worden. Der radikalsozialistischen Bewegung gelang es, mit ihrer Doktrin einen Großteil der französischen Gesellschaft anzusprechen. Sie wurde dadurch immer mehr zu deren politischem Sprachrohr. Die Radikalsozialisten sahen sich darüber hinaus als Vertreter des „Dritten Standes“, der sich für Individualismus, Egalitarismus und für Fortschritt und gegen die Bevormundung durch die Reaktion einsetzte. Weiter lebte in ihm die Ablehnung des Zentralismus und der Vorrang des Individuums vor dem Staat fort. Er repräsentierte vor allem das mittlere und kleinere Bürgertum ${ }^{18}$, konnte aber auch Teile des agrarischen Frankreich und der Intellektuellen an sich binden. Zum Sozialismus zog er klare Grenzen, indem er trotz einer kritischen Haltung gegenüber Großbürgertum und Großfinanz den Klassenkampf strikt ablehnte. Das Ziel war nicht die Befreiung des Proletariats, sondern die gleichberechtigte Teilhabe des Bürgers, des Volkes („le peuple“) an der Macht zu sichern. Ein weiterer Unterschied des Radikalsozialismus zum Sozialismus bestand im Primat der Politik und der politischen Reformen. Eine gerechtere Ordnung sollte nicht, wie bei den Sozialisten, durch die Vergesellschaftung der Produktionsmittel erreicht werden, sondern durch eine demokratische Willensbildung, durch ein gleichberechtigtes Erziehungs- und Bildungsprogramm und eine Angleichung der Einkommen.

Wie diese kurze Skizze zeigt, konnte es partiell zu Überschneidungen zwischen radikalsozialistischer und sozialistischer Programmatik und den jeweiligen Interessen kommen, und damit war auch eine Rivalität im Kampf um die Wählergunst verbunden. Obwohl es zwischen Radikalsozialisten und Sozialisten auch Phasen

Berstein, La Ligue, in: J.-F. Sirinelli (Hg.), L'Histoire des Droites en France. Bd. 2: Cultures, Paris 1992, S. 61-111; J.-P. Rioux, Nationalisme et conservatisme. La Ligue de la patrie française 18991904, Paris 1977.

16 Zur Dreyfus-Affäre siehe P. Birnbaum, L’Affaire Dreyfus. La République en péril, Paris 1994; Derselbe (Hg.), La France de l'affaire Dreyfus, Paris 1994; S. Thalheimer (Hg.), Die Affäre Dreyfus, München 21986; N. L Kleeblatt (Hg.), The Dreyfus Affair. Art, Truth and Justice, Berkeley 1987; M. Winock, Le mythe fondateur. L'affaire Dreyfus, in: S. Berstein/O. Rudelle (Hg.), Le modèle républicain, $S$. $131-146$.

$17 \mathrm{Zu}$ den Trennungsgesetzen siehe M. Larkin, Church and state after the Dreyfus Affair. The separation issue in France, London 1974; J.-M. Mayeur (Hg.), La séparation de l'Eglise et de l'Etar, Paris 1966; M. Ozouf, L'Ecole, L'Église et la République 1871-1914, Paris 1963; P. Chevallier, La séparation de l'église et de l'école; R. Rémond, L'anticléricalisme en France de 1815 à nos jours, Paris/Bruxelles 1987; J. Mac Manners, Church and State in France 1870-1914, London 1972.

18 Erinnert sei an die "nouvelles couches“, die Gambetta in den Kampf um die Mobilisierung für die Republik einbezogen wissen wollte; vgl. J. Gouault, Comment la France est devenue républicaine. Les élections générales et partielles à l'Assemblée nationale 1870-1875, Paris 1954; J.-M. Mayeur, Les débuts de la Troisième République 1871-1898, S. 26-94. 
erfolgreicher Kooperation ${ }^{19}$ gab, geriet die Zusammenarbeit häufig in eine Krise, da der Radikalsozialismus zwar politisch und ideologisch links stand, jedoch sozial eher rechts orientiert war und eine bürgerliche Wirtschaftspolitik verfocht. André Siegfried definiert den Radikalsozialisten in seinem Buch „Tableau des partis en France“ folgendermaßen: „(...) politiquement son coeur est à gauche, mais sa poche est à droite (...) et en pratique chaque Français a une poche ${ }^{20 "}$, und bezüglich der bürgerlichen Wirtschaftspolitik galt für den Radikalsozialisten: „Les réformes, il est bon d'en parler, il est imprudent de les faire. "21

Seit den Jahren 1877/79 entstand eine republikanische politische Kultur, die auf einem breiten Konsens in der französischen Gesellschaft ruhte und die das politische System der Dritten Republik Frankreichs entscheidend geformt hat. Stanley Hoffmann entwickelte aus dieser auf einem breiten Konsens basierenden republikanischen Kultur ${ }^{22}$ das Modell der republikanischen Synthese ${ }^{23}$, die bis in die dreiBiger Jahre des 20. Jahrhunderts das Fundament des politischen Systems Frankreichs bildete und stützte, jedoch allmählich schrittweise erschüttert wurde ${ }^{24}$. Das Modell dient im folgenden als Passepartout für die Verhältnisse des politischen Systems im Frankreich der Zwischenkriegszeit und soll anhand der Wahlkämpfe zwischen den beiden Weltkriegen verifiziert werden. Von besonderem Interesse ist hierbei unter Berücksichtigung der Leitfrage dieser Arbeit die politische Kultur anhand des Wahlkampfverhaltens der Radikalsozialisten und Sozialisten. Der Gegenblock - das rechte Wahlbündnis - wird daher nur kursorisch berücksichtigt werden.

19 Eine sehr erfolgreiche Phase der politischen Zusammenarbeit erlebten die Radikalsozialisten mit den Sozialisten in der sogenannten „Belle époque“ von 1901 bis vor allem 1906, und in schwächerer Form kam es immer wieder noch zur Zusammenarbeit zwischen Radikalsozialisten und Sozialisten bis zum Ausbruch des Ersten Weltkriegs; vgl. M. Rebérioux, La République radicale?, S. 42116; J.-P. Azéma/M. Winock, La IIIe République, S. 125-200; A. Bergounioux, Socialisme et République avant 1914, in: S. Berstein/O. Rudelle (Hg.), Le modèle républicain, S. 117-128. Zum Sozialismus und Radikalismus siehe A. Thibaudet, Les idées politiques de la France, Paris 1932, S. 182-199.

20 A. Siegfried, Tableau des partis en France, S. 89.

21 Ebenda, S. 103.

$22 \mathrm{Zu}$ den verschiedenen Ausdrucksformen der republikanischen Kultur ab den 1880er Jahren der Dritten Republik in Form von Festen und Feiertagen: R. Sanson, Les 14 juillet, fête et conscience nationale 1789-1975, Paris 1976; J.-P. Bois, Histoire des 14 juillet: 1789-1914, Nantes 1991; C. Amalvi, Le 14 juillet. Du dies irae à Jour de fête, in: P. Nora (Hg.), Les lieux de mémoire. Bd. 1: La République, Paris 1984, S. 421-472; J. El Gammal, Recherches sur les poids du passé dans la vie politique française de 1885 à 1900, Paris 1990, S. 89 ff.; M. Ozouf, Le premier 14 juillet, in: L'Histoire 25 (1980), S. 11-19; D. Mollenhauer, Auf der Suche nach der „wahren“ Republik, S. 186-214. Weitere Ausdrucksformen der republikanischen Kultur stellten auch Staatsbegräbnisse der Dritten Republik dar; vgl. A. Ben-Amos, Les funérailles de gauche sous la IIIe République: deuil et contestation, in: A. Corbin/N. Gérome/D. Tartakowsky (Hg.), Les usages politiques des fêtes aux XIXe - XXe siècles, Paris 1994, S. 199-210; O. Ihl, La fête républicaine, Paris 1996.

${ }_{23}$ S. Hoffmann, Paradoxes of the French Political Community, in: Derselbe u. a. (Hg.), In Search of France, S. 1-117.

${ }_{24}$ Vgl. dazu ebenda, S. 26-34. Zu den Versuchen, in den dreißiger Jahren eine Änderung herbeizuführen, siehe N. Roussellier, La contestation du modèle républicain dans les années 30: la réforme de l'Etat, in: S. Berstein/O. Rudelle (Hg.), Le modèle républicain, S. 319-336. 


\section{Das Hoffmannsche Modell der „republikanischen Synthese“}

Stanley Hoffmann faßte in seinem Modell der „republikanischen Synthese“ die wichtigsten Faktoren des politischen Grundkonsenses der französischen Gesellschaft zusammen, der lange Zeit das Funktionieren des politischen Systems in Frankreich gewährleistete, allerdings dessen Reformfähigkeit auch stark einschränkte. Im Zentrum des Hoffmannschen Modells ${ }^{25}$ stand das Faktum der „blockierten Gesellschaft“. Unter diesem Begriff faßte Hoffmann Struktur und Werte der französischen Gesellschaft, die das gesamte 19. Jahrhundert bis zur Weltwirtschaftskrise andauerten, zusammen. Hoffmann konstatierte, daß sich die französische Gesellschaft in ökonomischer Hinsicht nur teilweise und auch nur sehr langsam modernisierte; aufgrund dieser Entwicklung konnten traditionelle Bestände bewahrt bleiben, die sich ihrerseits wiederum bremsend auf die industrielle Entwicklung auswirkten. Als Folge vertrat das sozial führende Bürgertum Werte, die auch von den ländlichen und traditionell kleinbürgerlichen Schichten mitgetragen wurden. So entstand ein politisch-sozialer Konsens, der stark von den seit der Französischen Revolution herausgebildeten liberal-republikanischen Grundwerten geprägt war und zunächst das Industriepoletariat weitgehend unberücksichtigt ließ. Diesen Konsens faßte Hoffmann unter dem Begriff „republikanische Synthese" zusammen. Weitere Spezifika, die Hoffmann neben der Kombination aus traditionellen und modernen Strukturen wie auch Werten als prägend für Frankreich feststellte, war ein gewisser Hang der französischen Gesellschaft zum autoritären Modus der Konfliktlösung ${ }^{26}$, der allerdings einherging mit der Ablehnung eines starken Staates und weitreichender Eingriffe in die sozialen Grundlagen ${ }^{27}$. Trotz der inneren Fragmentierung des Bürgertums stimmte die Gesellschaft unter der dominanten Führung des Bürgertums in einem negativen Konsens gegen einen autoritären Staat überein. Der ebenfalls wichtige und prägende Faktor des Individualismus erschwerte erheblich die Institutionalisierung von intermediären Organisationen wie den Parteien und trug dazu bei, daß der Typus des Honoratiorenpolitikers dem des Parteipolitikers vorgezogen wurde.

In einem zweiten Schritt versuchte Hoffmann anhand dieser Merkmale der französischen Gesellschaft die Besonderheiten des politischen Systems zu erklären. Allerdings konstatierte er, daß vor der Gründung der Dritten Republik dem sozialen Konsens kein politischer Konsens entsprach, da sich - geprägt durch den wechselhaften Verlauf der Geschichte Frankreichs seit 1789 - verschiedene politische Denkschulen herauskristallisiert hatten (Konterrevolutionäre, Konservative, Demokraten, Sozialisten ${ }^{28}$ ), die die Frage nach der autoritären Macht der Zentralgewalt in das Zentrum stellten. Nach Hoffmann hatte die Dritte Republik einen

25 Im folgenden nehme ich immer wieder Bezug auf die Studie Hoffmanns, Paradoxes of the French Political Community, in: Derselbe u. a. (Hg.), In Search of France, S. 1-117.

${ }^{26}$ Hoffmann sah in diesem Zug das Erbe der feudal-aristokratischen Gesellschaft; vgl. derselbe, Paradoxes of the French Political Community, S. 10.

27 Dieses Verhalten wiederum führte Hoffmann auf die bürgerliche Furcht sowohl vor einer feudalen wie auch vor einer proletarischen Herrschaft zurück; ebenda, S. 10.

$28 \mathrm{Zu}$ den verschiedenen Entwicklungssträngen und Ausprägungen der politischen Denkschulen, die sich im 19. Jahrhundert in Frankreich nacheinander ablösten, siehe R. von Albertini, Freiheit und Demokratie in Frankreich. Die Diskussion von der Restauration bis zur Résistance, Freiburg 1957. 
entscheidenden Vorteil im Vergleich zu den vorangegangenen politischen Systemen: „The genius of the Third Republic was the devising of an institutional set-up more effectively adapted to French society “29. Hoffmann verstand darunter, daß das politische System weder eine starke Exekutive noch die Entwicklung von konkurrierenden sozialen und politischen Entwürfen sowie die Durchsetzung von bürokratischen Parteiapparaten zuließ und damit die konservativen, aber stabilen Strukturen der Gesellschaft weiter stärkte. Die Stabilität der Dritten Republik resultierte demnach aus der Übereinstimmung der politischen mit den sozialen Mechanismen der Konfliktregelung. Gleichzeitig bedeutete dies aber auch, daß die Regierung in ihrer Handlungsfähigkeit eingeschränkt war. Das war zum einen durch eine relativ starke Bürokratie, die mit den tagespolitischen Geschäften kaum in Berührung kam, bedingt, hing zum anderen auch damit zusammen, daß die größtenteils nur aus der Mitte gebildeten Parlamentsmehrheiten nicht die erwarteten konkreten politischen Ergebnisse hervorbrachten. Letztlich bedeutete dies, daß das System der Dritten Republik zwar politische Krisen (wie z.B. die Dreyfus-Affäre) durch die Zentripetalkräfte ihrer politischen Institutionen überwinden konnte, aber bei großen wirtschaftlichen Problemen unter Druck geriet. Dieses Gefüge aus sozialen Strukturen und politischen Institutionen, das sich in der Dritten Republik formiert hatte, verband sich mit einem spezifischen Selbstbild, das sich vom europäischen Umfeld abhob. So wurde z. B. die Universalität der eigenen Werte betont, und in Verbindung mit einem klassischen Großmachtprestige war die Dritte Republik mit der Devise der "mission civilisatrice“ angetreten, ein Kolonialreich aufzubauen, ohne es wirtschaftlich „auszubeuten“. Obwohl bereits erste Zeichen der Krise vor dem Ersten Weltkrieg deutlich waren, die sich nach dem Ersten Weltkrieg verschärften, führten exogene und endogene Faktoren der dreißiger Jahre ${ }^{30}$ zur Unterminierung der sozialen Grundlagen der auf der „republikanischen Synthese“ beruhenden gesellschaftlichen Ordnung.

Die im Zuge der Weltwirtschaftskrise getroffenen Maßnahmen ${ }^{31}$ dienten eigentlich dem Ziel, die „blockierte Gesellschaft“ zu stützen, aber sie erhöhten nur die ihr inhärenten Spannungen. Es zeigte sich schließlich spätestens ab der Legislaturperiode 1932, daß das politische System der Dritten Republik nicht imstande war, diese neuen Probleme zu bewältigen, am deutlichsten wurde dies sichtbar an der Krise des Parti radical in der Legislaturperiode von 1932 bis $1936^{32}$. Erstaunlicherweise gelang es den Parteien des Linksblocks zwar noch immer, in Wahlkämpfen den republikanischen Mythos zu beschwören, aber das politische System der Dritten Republik ließ nur die Wahrung des Status quo zu, es vermochte nicht, durch eine kohärente Politik geeignete Kompromisse zur Lösung der Weltwirtschaftskrise zu schließen. Hoffmann sah in dieser Zeit deutlich die zuneh-

29 Ebenda, S. 14

30 Hoffmann führt hier vor allem die außenpolitischen und wirtschafts- und finanzpolitischen Faktoren an; derselbe, Paradoxes of the French Political Community, S. 22-26.

31 Beliebte Finanz- und Wirtschaftsmaßnahmen der diversen Regierungen in den dreißiger Jahren waren eine Deflationspolitik und die Wiederherstellung eines stabilen Staatshaushaltes. Detailliert zur Wirtschafts- und Finanzpolitik der dreißiger Jahre in Frankreich A. Sauvy, L'Histoire économique de la France entre les deux guerres. Bd. 2 (1931-1939), Paris 1967.

32 Vgl. dazu die Ausführungen in Prozeßbeispiel II, Kapitel 7. 
mende Aufweichung der „republikanischen Synthese“, die letztlich zum Regime von Vichy überleitete ${ }^{33}$.

\section{Die Wahlkämpfe der Linksbündnisse in der Zwischenkriegszeit}

\section{Der Wablkampf von 1924}

Wenden wir uns zunächst dem Wahlkampf von 1924 und der anschließenden Regierung Herriot zu, der mit sozialistischer Unterstützung von Juni 1924 bis April 1925 regierte. Nach dem Ausscheiden des Parti radical aus dem Regierungsbündnis des Bloc national im Frühjahr 1924 gingen die Radikalsozialisten auf die Sozialisten zu, weil sie für die Wahlen 1924 einen Bündnispartner brauchten. Das aus Parti radical und SFIO entstandene Linksbündnis ideologisierte im Wahlkampf 1924 die politischen Gegensätze als Auseinandersetzung zwischen zwei seit 1789 mehr oder minder konstanten Großlagern, die alternative gesellschaftliche und politische Grundwerte verkörperten. Angesichts der vorhandenen Heterogenität des eigenen Lagers galt es freilich, Kompromisse zu finden. Im Cartel des gauches einigte man sich auf einen Minimalkonsens ${ }^{34}$, der aus fünf Punkten bestand, jedoch bestritten sowohl Parti radical als auch die SFIO den Wahlkampf mit ihrem jeweils eigenen Programm ${ }^{35}$. Anhand der Professions de foi, den Wahlaussagen, mit denen die einzelnen Kandidaten zur Wahl antraten, wird deutlich, daß divergierende Fragen weitgehend eliminiert wurden, dafür der Schwerpunkt auf konsensfähige, teilweise künstlich hochstilisierte Themen verlagert wurde. Verwiesen sei hier z. B. auf Themen der Kulturpolitik, die zwischen Parti radical und SFIO einen Konsens herstellen konnten, wie das Festhalten am Laizismus, die Ablehnung der Wiedereröffnung der französischen Botschaft beim Vatikan, die Ablehnung der Wiedereinführung von Kongregationen und das Festhalten an der Einheitsschule. Das Cartel des gauches versuchte mit diesem Themenblock eine künstliche Wiederbelebung des Gegensatzes Laizismus - Klerikalismus herzustellen. Damit hoffte es zum einen, an seine erfolgreiche Zeit der republikanischen Politik $^{36}$ vor dem Ersten Weltkrieg anzuknüpfen, zum anderen diente ihm dieses

33 Nach Hoffmann wirkte die Volksfrontregierung für die noch immer dominante Mittelklasse der französischen Gesellschaft wie ein Katalysator für deren Antiparlamentarismus, der das intellektuelle Klima von Vichy vorwegnahm. Die Mittelklasse kritisierte zunehmend den Parlamentarismus als zuwenig entscheidungsfreudig und optierte für eine stärkere personalistische Führung in der Politik, d.h. sie setzte auf eine starke Führungspersönlichkeit. So trat deutliche Kritik von rechts verstärkt auf den Plan, die zunehmend zur Unterstützung des Vichy-Regimes führte. Jedoch kam auch auf der anderen Seite, der durchaus demokratischen Seite, Kritik am politischen System der Dritten Republik auf, so z.B. durch die Christdemokraten oder die "Planistes", die mit ihrer Kritik bereits die Nachkriegsplanungen und die Diskussionen um die Vierte Republik vorwegnahmen; vgl. S. Hoffmann, Paradoxes of the French Political Community, S. 24-34.

34 Zum Minimalkonsens zwischen den beiden Wahlpartnern vgl. Prozeßbeispiel I, Kapitel 3.

35 Zum Programm des Parti radical und der SFIO vgl. Prozeßbeispiel I, Kapitel 4.

36 Gemeint war, an die Zeit der "Belle époque“, in der der Parti radical mit sozialistischer Unterstützung eine für die Republik sehr erfolgreiche Politik gestalten konnte, anzuknüpfen. Auf diese Phase der „Belle époque“ berief sich der Parti radical und vor allem Herriot sehr oft. Zur Politik 
Vorgehen dazu, von den Differenzen innerhalb des Cartel des gauches hinsichtlich der dringenden zentralen Probleme wie Währungskrise und Inflationspolitik abzulenken. Ein weiteres Politikfeld, in dem es partiell zu Divergenzen zwischen den beiden Bündnispartnern gekommen war, stellte die Außenpolitik dar. So erfuhren Themen wie z.B. die Anerkennung Sowjetrußlands und die Ruhrbesetzung, die der Parti radical in seinem Programm eher vernachlässigend behandelte, während sie bei der SFIO einen primären Rang einnahmen, eine zurückhaltende Behandlung im Wahlkampf. Themen aus den Problemfeldern Finanz- und Sozialpolitik, die Dissens hervorriefen, wurde nur eine nachrangige Bedeutung beigemessen. Aber gerade diese Themenblöcke drängten während der Regierungsphase des Cartel des gauches zu politischen Lösungen.

Diese im Wahlkampf von 1924 praktizierte Taktik der Ideologisierung bestimmter Themen und die gleichzeitige Reduzierung der Dissensthemen kann in allen weiteren Wahlkämpfen der Zwischenkriegszeit, in denen zwischen dem $P$ arti radical und der SFIO eine Art Bündnispolitik betrieben wurde, konstatiert werden.

Der Wahlkampf von 1924 verlief summa summarum in einer Konfrontation von zwei Wahlblöcken, auf der einen Seite stand der Block der Linkskräfte und auf der anderen Seite das Lager der Rechtskräfte ${ }^{37}$. Der rechte Block wiederum führte einen Wahlkampf, der sich ebenfalls auf republikanische Werte zu stützen versuchte, aber dabei andere Elemente betonte. Bevor hier näher auf die essentiellen Komponenten des rechten Wahlblocks, des Bloc national, einzugehen ist, muß betont werden, daß diese beiden Wahlblöcke nicht als zwei monolithische Blöcke gesehen werden dürfen, sondern sich vielmehr durch ihre starke Heterogenität auszeichneten. So wurde auch innerhalb des linken Lagers keineswegs in allen Departements das Wahlbündnis eingehalten; es lassen sich durchaus in einigen Departements Abweichungen vom offiziellen Wahlbündnis des Cartel des gauches ausmachen, und zwar in den Fällen, in denen die Radikalsozialisten zusammen mit Kandidaten des Bloc national auf einer Liste zur Wahl antraten ${ }^{38}$. Auch auf sozialistischer Seite konnten einige Abweichungen von der offiziellen Wahllinie festgestellt werden ${ }^{39}$. Hinzu kam bei den Sozialisten, daß sie 1924 einen Zweifrontenwahlkampf zu bestreiten hatten ${ }^{40}$, da die kommunistische Partei ihre Angriffe im Wahlkampf nicht nur gegen die rechten politischen Kräfte richtete, sondern auch gegen die Sozialisten, die durch ihre Nichtakzeptanz der vom 2. Kongreß der Kommunistischen Internationale in Moskau 1920 beschlossenen 21 Bedingungen die Durchsetzungsfähigkeit und Schlagkraft für die Arbeiterinteressen in den Augen der Kommunisten empfindlich geschwächt hatten ${ }^{41}$.

des Parti radical vor dem Ersten Weltkrieg siehe S. Berstein, Histoire du Parti radical, Bd. 1: La recherche de l'age d'ôr 1919-1926, Paris 1980, S. 23-86.

37 Im Bloc national schlossen sich die Alliance républicaine démocratique, die Fédération républicaine und das Comité républicaine du commerce, de l'industrie et de l'agriculture zusammen; vgl. G. Bourgin/J. Carrère (Hg.), Manuel des partis politiques en France, S. 53-57.

38 So traten 18 radikalsozialistische Kandidaten auf einer Liste des Bloc national gegen eine Liste des Cartel des gauches an; vgl. dazu ausführlicher das Prozeßbeispiel I, Kapitel 4 dieser Studie.

39 Vgl. dazu die Listenverbindungen der SFIO bei den Wahlen von 1924, in: Le Temps vom 13. 5. 1924, S. 1-5.

40 Vgl. hierzu genauer Prozeßbeispiel I, Kapitel 4 dieser Arbeit.

4) Seitdem die Sozialisten das Angebot der Kommunisten für einen Bloc ouvrier, der allerdings von 
Ebenso zeichnete sich der rechte Wahlblock durch eine innere Zerklüftung aus; so präsentierte sein äußerster rechter Flügel eigene Listen, die mit den Listen des Bloc national konkurrierten. Der Bloc national, der vor allem aus den größeren politischen Gruppierungen der Alliance républicaine démocratique und der Fédération républicaine bestand, bestritt seinen Wahlkampf unter der Leitung Poincarés mit der Devise, dem Cartel des gauches eine „Union républicaine et concorde nationale" entgegenzusetzen. Auch der Bloc national versuchte, auf dem Fundament der republikanischen Kultur seinen Wahlkampf zu führen und konzentrierte sich in diesem republikanischen Rahmen auf folgende Schlagworte: „Réforme des méthodes parlementaires, respect des lois scolaires, paix réligieuse, réformes sociales". Außenpolitisch hatte sich das Bündnis des Bloc national auf die strikte Einhaltung und Durchführung des Versailler Friedensvertrags und der deutschen Reparationszahlungen verständigt, während innenpolitisch das besondere Interesse den in seinen Augen notwendigen Reformen zur Verbesserung der parlamentarischen Arbeit galt ${ }^{42}$.

Im Vergleich zu den Wahlen vom November 1919, die André Siegfried als "élections d'apaisement" bezeichnet hatte, können die Wahlen von 1924 als „élections de lutte "43 charakterisiert werden. Dafür spricht zum einen, daß der Wahlkampf relativ hart und zum großen Teil polemisch geführt wurde, außerdem zielte er auf die Wählermobilisierung, die mit einer Wahlbeteiligung von über 84 Prozent auch erreicht worden ist und nach 1871 die stärkste Wahlbeteiligung darstellte. Der Bloc national erhielt zwar mehr Stimmen ${ }^{44}$ als das Linksbündnis; gleichwohl konnte das Cartel des gauches die Wahl für sich entscheiden, da es mehr Mandate 45 als der Bloc national bekam. So gelang es dem Cartel des gauches, in 28 Wahlkreisen die absolute Mehrheit zu erreichen, während die rechten politischen Kräfte, die einen weniger bündnisintensiven Wahlkampf geführt hatten, nur in 18 Wahlkreisen die absolute Mehrheit holen konnten ${ }^{46} .1924$ zeigte sich, daß das Linksbündnis wieder als Alternative ernst zu nehmen war.

Im Juli 1926 übernahm Poincaré die Regierung und bildete ein Kabinett der Union nationale, dem auch vier Minister des Parti radical angehörten, an erster Stelle Edouard Herriot. Poincaré regierte mit seinem Kabinett der Union nationale bis zum Ende der Legislaturperiode und konnte sich mit seiner erfolgreichen Wirtschafts- und Finanzpolitik eine gute Ausgangsposition für den Wahlkampf von 1928 verschaffen. Der Wahlkampf von 1928 nahm jedoch eine Sonderstellung ein, denn kurz vor den Wahlen im Frühjahr wurde auf Anregung Poincarés und mit Hilfe der Radikalsozialisten, denen sich nach einigem Zögern auch die Sozia-

Moskau gelenkt worden wäre, abgelehnt hatten, führten die Kommunisten gegen die Sozialisten einen polemischen Wahlkampf. Zum Angebot der Kommunisten und ihrem Wahlkampf von 1924 siehe G. Bourgin/J. Carrère (Hg.), Manuel des partis politiques en France, S. 187 f.

42 Vgl. hierzu ausführlicher Prozeßbeispiel I, Kapitel 4.

43 Vgl. dazu R. Rémond, Frankreich im 20. Jahrhundert. 1. Teil: 1918-1958, Stuttgart 1994, S. 100.

44 Insgesamt gesehen konnten die Regierungskräfte des Bloc national 4,5 Millionen Stimmen auf sich vereinen, während die Linkskräfte nur 4,2 Millionen der Wählerstimmen erhielten. Zum Wahlergebnis von 1924 siehe G. Lachapelle, Élections législatives du 11 mai. Résultats officiels, Paris 1924.

45 Jedoch konnten die Linkskräfte mit 286 Mandaten mehr Sitze im Parlament erobern als der bisher regierende Bloc national, der nur auf 233 Mandate kam; siehe ebenda.

46 Ebenda. 
listen angeschlossen hatten, eine Änderung des Wahlmodus ${ }^{47}$ eingeführt. Aber abgesehen von dem veränderten Wahlverfahren nahm der Wahlkampf von 1928 auch unter dem Aspekt der Wahlbündnispolitik eine Sonderstellung ein, denn im Lager der Linkskräfte war es nicht zu einem erneuten Bündnis gekommen; im Gegenteil, die Sozialisten verzichteten 1928 auf ein Bündnis und traten allein an, mußten sich aber einer verstärkten Gegnerschaft der Kommunisten erwehren, die nicht einmal mehr die Einhaltung des "désistement républicaine“ im zweiten Wahlgang zugunsten der Sozialisten praktizieren wollten. Obwohl es zu keinem Bündnis zwischen Sozialisten und Radikalsozialisten gekommen war, konnten viele Radikalsozialisten im zweiten Wahlgang vom „désistement“ der Sozialisten profitieren, aber noch viel mehr vom nicht praktizierten „désistement" der Kommunisten, das vor allem die Sozialisten einige Mandate kostete ${ }^{48}$.

Nachdem die Radikalen bei den Wahlen von 1928 einen Mandatsverlust hinnehmen mußten, wobei sie vor allem ihre Mandate im zweiten Wahlgang nur mit Hilfe des "désistement" und nicht bereits im ersten Wahlgang aus eigener Kraft erringen konnten, setzte allmählich bei den Radikalsozialisten ein Umdenkungsprozeß ein und sie näherten sich allmählich wieder den Linkskräften an ${ }^{49}$.

\section{Der Wablkampf von 1932}

$1932^{50}$ begegneten sich erneut zwei größere Wahlblöcke, wobei die Radikalsozialisten und die Sozialisten bei dieser Wahl kein offizielles Bündnis eingingen, sondern dieses allein auf den zweiten Wahlgang beschränkten. Innerhalb des sogenannten Linksblocks herrschte vor allem ein starkes Konkurrenzverhalten zwischen Radikalsozialisten und Sozialisten um die Wählergunst. Das rechte Wahllager versuchte, diese Konkurrenzsituation zwischen den beiden wichtigsten Mitgliedern des linken Wahllagers für sich zu nutzen. So führte der rechte Wahlblock unter der Leitung Tardieus einen massiven Wahlkampf gegen die Sozialisten und hoffte inständig, die Radikalsozialisten für den rechten Wahlblock gewinnen zu können. Tardieu forderte die Radikalsozialisten auf, sich dem antisozialistischen Block anzuschließen. Er verfolgte damit das Ziel, nach der Wahl mit Hilfe der Radikalsozialisten eine Regierung der Concentration bilden zu können. Nachdem Tardieu nach dem ersten Wahlgang einsehen musste, daß die Radikalsozialisten im zweiten Wahlgang zur Einhaltung der „discipline républicaine“ zusammen mit den Sozialisten bereit waren, verhärteten sich in diesem Wahlkampf die Fronten. Der Wahlkampf des rechten Blocks reduzierte sich zunehmend auf die Kritik an der politischen Bilanz, die die Cartelregierung zu verantworten hatte, und die

47 Das 1919 eingeführte gemischte Verhältniswahlrecht wurde durch ein scrutin d'arrondissement mit zwei Wahlgängen, wie es bereits vor 1914 existiert hatte, abgelöst; vgl. dazu E. Bonnefous, L'Histoire de la Troisième République, vol. 4, S. 226; A. Soulier, L'instabilité ministérielle, S. 503-506.

48 Zum Wahlergebnis von $1928 \mathrm{vgl}$. G. Lachapelle, Elections législatives 22-29 avril 1928. Résultats officiels, Paris 1928.

49 Siehe in dicsem Kontext auch den Parteitag von 1928, der zum Austritt der radikalsozialistischen Minister aus dem Kabinett Poincaré geführt hatte. Zum Parteitag des Parti radical vom 3. 11.5. 11. 1928: $25^{\mathrm{e}}$ Congrès du Parti républicain radical et radical-socialiste du 3.11-5.11.1928 à Angers, Paris 1928.

5o Vgl. ausführlich zum Wahlkampf der Linksparteien 1932 Prozeßbeispicl II, Kapitel 2. 
Warnung vor einer Neuauflage. Der sogenannte Linksblock setzte der AntiCartel-Wahlparole die Devise "battre la réaction“ entgegen. Generell ist festzuhalten, daß der linke Wahlblock trotz der Annäherung zwischen Sozialisten und Radikalsozialisten sich zunächst weniger geschlossen nach außen präsentierte; im Gegenteil, beide größeren Linksparteien wiesen ausdrücklich auf ihre Unabhängigkeit hin, während der rechte Block sich 1932 relativ geschlossen zeigte. Die Radikalsozialisten setzten auch in diesem Wahlkampf, aus dem sie immerhin als stärkste Fraktion hervorgehen konnten, auf die klassischen Elemente der linksrepublikanischen politischen Kultur der Dritten Republik: Verteidigung des Laizismus und Festhalten an der Einheitsschule.

Auch bei der Wahl von 1932 bot das sogenannte rechte Wahllager, das mindestens bis zu Beginn der dreißiger Jahre als systemkonform ${ }^{51} \mathrm{zu}$ bezeichnen ist, innerhalb des republikanischen Rahmens einen alternativen Wertekonsens an. Deutliche Trennlinien zwischen dem rechts- und linksrepublikanischen Lager zogen z.B. Themen wie die Trennung von Kirche und Staat, die mit der Durchsetzung des Laizismus einherging, die Herausbildung eines starken machtpolitischen Nationalismus, der sich vom 1789 entstandenen jakobinischen stark ideellen $\mathrm{Na}$ tionalbewußtsein abhob, und die politisch-soziale Herausforderung des Bürgertums durch die internationale bzw. französische Arbeiterbewegung. Die Politik der Rechten ruhte auf den folgenden Säulen: Klerikalismus, Nationalismus und Antisozialismus bzw. Antimarxismus. So zog die republikanische Rechte, wie besonders im Wahlkampf 1932 unter Tardieu spürbar wurde, eine starke Abgrenzung zur sozialistischen Linken, deren Internationalismus sie einen konservativen Nationalismus und deren sozialistischen Kollektivismus sie einen im 19. Jahrhundert entstandenen liberalen Individualismus entgegensetzte. Außerdem lehnte die politische Rechte in Frankreich52 die mit fortschreitender Industrialisierung zunehmenden Forderungen der Arbeiter nach weiterer sozialer und politischer Mitbestimmung ab. Die politische Rechte unterschied sich von der Linken auch in der konservativen Besetzung einiger Schlüsselbegriffe des staatlichen und sozialen Systems. So spiegelte sich nach Auffassung der politischen Rechten die Nation in einem starken Machtstaat wider, dessen gesellschaftliche Grundlage eine autoritär und hierarchisch strukturierte Familie bilden sollte. Darüber hinaus setzten die rechten Kräfte zur Verteidigung Frankreichs auf einen starken Militärapparat, in

51 Die im Parlament vertretenen rechten politischen Kräfte können für die Zeit des „ralliement“ nach der Dreyfus-Affäre bis zum Beginn der Weltwirtschaftskrise in Frankreich Anfang der dreißiger Jahre als systemkonform bezeichnet werden, da sie ebenfalls die republikanische Staatsform sowie den entstandenen gesellschaftlichen Herrschaftskonsens akzeptierten. Ein erneutes Erstarken der antirepublikanischen Kräfte, wie z.B. der Jeunesses Patriotes, dem Faisceau, dem Croix de Feu, setzte erst wieder mit Beginn der Weltwirtschaftskrise und der damit verbundenen politischen, sozialen und ökonomischen Krise in Frankreich ein und führte außerdem wieder zu engeren Beziehungen der rechten parlamentarischen Kräften mit der außerparlamentarischen rechten Opposition; vgl. R. Rémond, Les Droites en France, Paris ${ }^{4} 1982$; S. Berstein, Le 6 février 1934, Paris 1975; J. Philippet, Les Jeunesses patriotes et Pierre Taittinger (1924-1940), Paris 1967; J.-Ch. Petitfils, L'extrême droite en France, Paris 1983.

52 Zur politischen Rechten in der Zwischenkriegszeit mit besonderem Focus auf die Jahre der sich verschärfenden wirtschaftlichen, sozialen und politischen Krise in Frankreich (1928-1934): H. Weinreis, Liberale oder autoritäre Republik. Regimekritik und Regimekonsens der französischen Rechten zur Zeit des nationalsozialistischen Aufstiegs in Deutschland (1928-1934), Göttingen/ Zürich 1986. 
dem sie einen Garanten für die Verteidigung des Versailler Systems erblickten. In diesem Punkt kam es zu starken Abweichungen von der politischen Linken, die auf das kollektive Sicherheitssystem des Völkerbundes baute. Außerdem war die politische Rechte erklärte Anhängerin und Verfechterin des Eigentums und betonte ebenso vehement den Respekt vor Autoritäten.

Die Radikalsozialisten konnten die Wahl von 1932 für sich entscheiden, die Sozialisten wurden immerhin zweitstärkste Kraft. Die Probleme dieser Legislaturperiode begannen aber bereits bei der Regierungsbildung Herriots im Juni 1932, der zwar die Wahlen in loser Zusammenarbeit mit den Sozialisten bestritten hatte, aber mit einer Mehrheit der Concentration regieren wollte ${ }^{53}$. Dieses Wahlergebnis hatte gezeigt, daß der republikanische Mythos trotz wirtschaftlicher und politischer Krise noch immer politische Zugkraft hatte. Jedoch bevorzugten die Radikalsozialisten unter Herriot nach den Cartelerfahrungen eine Regierung der Mitte, da sie zur Bewältigung der vorhandenen Finanz- und Wirtschaftsprobleme hier mehr Konsensfähigkeit zu finden hofften.

\section{Der Wablkampf von 1936}

Setzt man den Wahlkampf von 1936 mit allen anderen Wahlkämpfen der Zwischenkriegszeit und insbesondere mit denen der Jahre 1924 und 1932 in Vergleich, fallen sofort zwei Unterschiede auf. Zum einen traten die beiden Wahlblöcke 1936 nach außen am geschlossensten auf, wodurch es zu einer starken Polarisierung des Wahlkampfes kam, und zum anderen, bestand der Linksblock dieses Mal aus drei größeren Parteien. Am auffallendsten war aber, daß zum ersten Mal nach der Spaltung der SFIO von 1920 eine Zusammenarbeit zwischen Sozialisten und Kommunisten in einem Wahlkampf möglich wurde. Die Wahlen von 1936 fanden in einer besonderen Situation statt, denn die veränderte außenpolitische Lage führte dazu, daß die Stimmung sehr aufgeladen war und der linke Wahlblock den Wahlkampf ganz auf die Verteidigung der Republik gegen die faschistische Gefahr konzentrierte. Obwohl eine große Geschlossenheit nach außen demonstriert wurde, zeigte sich auch bei diesen Wahlen, daß zwar in einigen Punkten Konsens herrschte, ansonsten doch erhebliche Divergenzen zwischen den Wahlpartnern besonders in wirtschafts-, finanz- und sozialpolitischer Hinsicht bestanden. Deshalb einigten sich die Wahlpartner des Front populaire darauf, mit ihren eigenen Programmen anzutreten ${ }^{54}$, jedoch verständigten sie sich auf eine gemeinsame Wahlplattform, die sich auf verschiedene Elemente der linksrepublikanischen Kultur stützte. So führte der Front populaire einen sehr propagandistischen Wahlkampf, den er im besonderen auf die griffige Formel „Verteidigung der Republik und des parlamentarischen Systems " zuspitzte. Darüber hinaus konzentrierte sich die Wahlplattform des Front populaire auf folgende Aussagen: 1) Auflösung aller faschistischen Ligen und Organisationen; 2) Verteidigung und Sicherung der de-

53 Ausführlich zu den Verhandlungen über die Regierungsbildung Herriots im Juni 1932 vgl. Prozeßbeispiel II, Kapitel 3.

54 Vgl. zu den einzelnen Wahlprogrammen der drei großen Parteien des Front populaire Fallbeispiel III, Kapitel 2 dieser Arbeit und G. Dupeux, Le Front populaire et les élections de 1936, Paris 1959, S. 101-111. 
mokratischen Freiheiten; 3) Verteidigung des Laizismus; 4) Verbesserung des Erziehungs- und Bildungssystems; 5) Einrichtung von Untersuchungskommissionen über die Vorgänge in den Kolonien ${ }^{55}$. Neben diesen sicheren und bewährten Komponenten der linksrepublikanischen Kultur wurden konsensfähige Themen aus dem außenpolitischen Politikfeld in der gemeinsamen Wahlplattform angeführt: 1) Aufrechterhaltung und Sicherung des Friedens im Rahmen von Abrüstung und kollektiver Sicherheit; 2) Die Stärkung des Völkerbundes; 3) Die Ablehnung der Geheimdiplomatie und die Ausdehnung des französisch-sowjetischen Beistandspaktes auf alle Staaten Mittel- und Osteuropas ${ }^{56}$. Bei den ökonomischen Themen beschränkte man sich auf einige wenige unumstrittene Forderungen wie die Errichtung einer nationalen Getreidebehörde oder die Reform der Bank von Frankreich.

Obwohl der Linksblock sich nach außen hermetisch geschlossen zeigte, gestaltete sich das Innenleben dieses Wahlbündnisses dann doch sehr viel differenzierter, als dies auf den ersten Blick zu vermuten gewesen wäre. Die drei großen Parteien traten jeweils mit ihrem eigenen, teilweise sehr detaillierten Programm an, wie sich mit einem Blick auf die Professions de foi ${ }^{37}$ der einzelnen Kandidaten feststellen läßt. So gesehen, handelte auch bei diesen Wahlen nicht ein monolithischer Linksblock, sondern im Detail ein relativ heterogenes Gebilde.

Dem Lager der Volksfront stand der konkurrierende Block der nationalen Front ${ }^{58}$ der rechten politischen Kräfte gegenüber, die nur in einer sehr losen Form ein Wahlbündnis eingegangen waren. Das Lager der nationalen Front konnte nur einen sehr defensiven Wahlkampf führen, da es den wirkungsvollen Schlagworten „Brot, Frieden und Freiheit" der Volksfrontanhänger keine entsprechend schlagkräftige Parole entgegenzusetzen vermochte und die unpopuläre Deflationspolitik der Regierung Laval sich nicht gerade als eine günstige Ausgangsposition des rechten Wahlblockes erwies. Außerdem kam hinzu, daß die politischen Kräfte der nationalen Front noch in der Regierungsverantwortung standen und keine Erfolge vorweisen konnten, sich aber sehr vehement für die Reformierung des Staates wie der parlamentarischen Arbeit einsetzten: „Nous ne sorterons pas de la crise, et de graves dangers nous menacent, pourquoi? Parce que le régime parlementaire, tel que nous pratiquons, est incapable d'assurer un gouvernement stable et fort, agissant avec fermeté et en toute liberté, (...) aussi première des réformes est celle de l'Etat lui-même (... ") 59 . So konzentrierte sich der Wahlkampf des rechten Blocks auf die abschreckenden Visionen einer künftigen Volksfrontregierung, der vor allem wegen der kommunistischen Beteiligung eine verhängnisvolle Entwicklung vorhergesagt wurde. Die rechten politischen Kräfte präsentierten sich als Alternative, die sich durch eine „majorité de gouvernement homogène et dura-

55 Vgl. das Programm des Front populaire in Le Populaire vom 11. 1. 1936, S. 1/2, hier besonders S. 2.

56 Ebenda.

57 Barodet, Professions de foi , Paris 1936.

s8 Die drei großen Parteien, die überwiegend den Front national bildeten, waren die Alliance démocratique, die Fédération républicaine, der Parti démocrate populaire. Zum Wahlkampf des Front national vgl. G. Dupeux, Elections de 1936, S. 112-122.

59 Dieses Zitat stammt aus den Professions de foi eines Kandidaten der Républicains nationales indépendants, der im ersten Wahlkreis von Besançon, dem Departement Doubs, antrat, vgl. dazu G. Dupcux, Elections de 1936, S. 115. 
ble" ausgezeichnet habe ${ }^{60}$. Auch die rechten Kräfte leisteten durch ihren Wahlkampf der Polarisierung Vorschub, da sie in einer Broschüre des Centre de propagande des républicains nationaux in einer vier Punkte umfassenden Wahlplattform ganz dezidiert vor dem Front populaire warnten: „La constitution du Front populaire divise la France en deux clans, irréductiblement opposés: celui de l'ordre et celui de l'anarchie; celui de la République et celui de la dictature du prolétariat. Entre les deux, il faut prendre parti. Il faut choisir. Toute position intermédiaire, toute équivoque est condamnée" 61 . Die Wahlen von 1936 entschied der Front populaire für sich, jedoch war der Verlust auf seiten des rechten Wahllagers, des Front national, nicht so gravierend wie im Vorfeld vermutet worden war; die Stimmenmehrheit, die der Front populaire erhielt, kam durch die im Vergleich zu 1932 größere Wahlbeteiligung zustande ${ }^{62}$. Die Sozialisten gingen zum ersten Mal in der Zwischenkriegszeit als stärkste Fraktion aus den Wahlen hervor, während die Radikalsozialisten auf Platz zwei zurückfielen.

Wie aus der kurzen Darstellung der Wahlkämpfe im Frankreich der Zwischenkriegszeit deutlich zutage tritt, verfügte das politische System Frankreichs über eine politische Kultur, die auf einem parteiübergreifenden Grundwertekonsens fußte. $\mathrm{Zu}$ allen Wahlen der Zwischenkriegszeit gelang es mehr oder weniger, daß sich zwei Wahllager mit unterschiedlichem Schwerpunkt im Rahmen dieses Grundwertekonsenses der republikanischen politischen Kultur gegenüberstanden und um die Wählergunst konkurrierten. Es kam bei den Wahlen fast zu einem regelmäßigen Pendelausschlag zwischen den systemkonformen politischen Kräften und damit wurde eine gewisse Stabilität des politischen Systems gewährleistet, die nicht systemkonformen Kräften im Parlament keine Chance ließ. Obwohl ab den dreißiger Jahren die Krisenanfälligkeit des politischen Systems, - die Regierungen wechselten sich in immer kürzerer Zeit ab -, zunahm, gelang es sogar 1936, trotz der stark veränderten außenpolitischen Situation und dem vermehrten Auftreten von exogenen Krisenfaktoren, wie z.B. der Weltwirtschaftskrise, ein Parlament zu wählen, das sich aus systemkonformen Kräften zusammensetzte; wobei erneut das linksrepublikanische Lager durch seine Wahlkampfthemen einen siegreichen Wahlausgang für sich erringen konnte.

60 Vgl. dazu dic Radioansprache von Flandin, dem Parteivorsitzenden der Alliance démocratique, die dieser am 14. 4. 1936 hielt und welche auch in Le Temps vom 16. 4. 1936 abgedruckt wurde.

61 G. Dupeux, Elections de 1936, S. 119.

62 Ebenda, S. 125-140. 


\section{Die Organisationsstrukturen von Parti radical und SFIO und ihr Einfluß auf die Bündnisfähigkeit}

\section{Der Parti radical et radical-socialiste}

Da die Bündnisfähigkeit zwischen dem Parti radical und der sozialistischen Partei Frankreichs, der SFIO, für die Linksbündnisse in der Dritten französischen Republik während der Z wischenkriegszeit eine wichtige Rolle spielte, ist für uns die Frage nach den Faktoren, die die Möglichkeiten und Grenzen dieser Linksbündnisse bestimmt haben, sehr entscheidend. Die Frage der Bündnisfähigkeit zwischen SFIO und Parti radical lenkt unweigerlich den Blick auf die unterschiedlichen Parteistrukturen, das Parteiverständnis sowie die Mechanismen bzw. das Verhältnis zwischen Partei, Parteiführung und parlamentarischer Gruppe dieser beiden Parteien. Das Spannungsdreieck Parteiführung - Fraktion - Parteitag dient als Analyseinstrumentarium für die Frage, inwieweit die parteiinterne Willensbildung und das koalitionspolitische Verhalten der hier zu betrachtenden Parteien durch ihre Organisationsstruktur determiniert worden sind.

Als fruchtbar für die Untersuchung der Bündnisfähigkeit von Parteien erweist sich die Orientierung an der zeitgenössischen Parteientypologie Sigmund Neumanns ${ }^{1}$. Dieser hob eine enge Korrelation zwischen der Typologie einer Partei und der Koalitionsfähigkeit hervor, letztere schien ihm nachgerade eine „Scheidelinie für die Parteitypisierung " 2 zu bilden. Nach der Typologie Neumanns war der Parti radical am ehesten dem Typus der liberalen Repräsentationspartei ${ }^{3}$ zuzurechnen, wenngleich er auch teilweise Züge einer demokratischen Integrationspartei ausprägte, während die SFIO am ehesten dem Neumannschen Idealtypus der demokratischen Integrationspartei ${ }^{4}$ entsprach.

1 S. Neumann, Die Parteien der Weimarer Republik. Mit einer Einführung von K.-D. Bracher, Stuttgart 51986 . Die Erstauflage dieses Werkes erschien bereits 1932.

2 Ebenda, S. 108.

3 Zur Definition einer liberalen Repräsentationspartei nach Neumann siehe ebenda, S. 105. Neumann entwickelte diesen Typus vor allem für die DDP und dic DVP. Charakteristika dieses Typus sind „freie Werbung“ und "freie" Repräsentation“. Für ihre Parteianhänger gilt nach Neumann, daß sie fast ausschließlich bei den Parlamentswahlen in Erscheinung treten, d.h. die Partei konzentriert sich größtenteils nur auf die Wahlphasen, in denen sie um Wählerstimmen wirbt. Die Abgeordneten dieses Parteityps sind "dann nur ihrem Gewissen unterworfen und nicht an Aufträge gebunden“. Genau dieses Element ist zentraler Bestandteil der radikalsozialistischen Doktrin. Vgl. dazu Alain, Élements d'une doctrine radicale, Paris 1925, S. 179/180.

+ Typische Charakteristika einer demokratischen Integrationspartei sind nach Neumann „eine intensive Bindung und relative Beständigkeit ihrer Anhängerschaft, straffe Organisation, hohes $\mathrm{Ma} ß$ an innerparteilicher Demokratie und Selbstbestimmung “; vgl. S. Neumann, Die Parteien, S. $106 \mathrm{f}$. 
Im Mittelpunkt dieses Kapitels stehen die unterschiedlichen Organisationsstrukturen des Parti radical und der SFIO sowie die Machtverteilung der einzelnen Gremien innerhalb dieser Parteien, wobei ein besonderes Augenmerk auf das Verhältnis zwischen Partei und Fraktion zu legen sein wird. Parti radical und SFIO wiesen in ihrem Erscheinungsbild, in ihrer Organisations- und in ihrer Führungsstruktur erhebliche Unterschiede auf. Um diese Unterschiede deutlich herauszuarbeiten, empfiehlt es sich, neben dem Blick auf das Verhältnis Partei und Fraktion auch auf die Stellung des Abgeordneten näher einzugehen'.

Der $1901^{6}$ gegründete Parti radical verkörperte die Parteiorganisation des Radikalismus und trat mit großen Zielen vor allem für die Wahlen im Jahre $1902^{7}$ an: „(..) en vue de rassembler les forces démocratiques pour la campagne électorale de 1902, et qu'il devait écarter tout ce qui aurait pu diviser les Républicains et ne point connaître d'ennemies à gauche "8. Diese Partei setzte sich maßgebend für das repräsentative Modell der parlamentarischen Demokratie ein und hielt daran unerschütterlich fest ${ }^{9}$. Diese Idee wurde geradezu zum Kern der radikalsozialistischen Doktrin ${ }^{10}$, die noch einige andere konstitutive Elemente aufwies. Zu diesen gehörte zum einen die Pflege der Werte der Französischen Revolution, so z.B. die Verteidigung individueller Freiheitsrechte gegenüber staatlichen, militärischen oder kirchlichen Interventionen. Das Bekenntnis des Parti radical zur parlamentarischen Demokratie und zur republikanischen Staatsform stand im Zentrum seiner politischen Grundsätze. Die Elemente der radikalsozialistischen Doktrin fanden im Grundsatzprogramm von Nancy ${ }^{11} 1907$ ihren Niederschlag. Zu ihnen gehörte außerdem als unverzichtbarer Bestandteil des Programms der Einsatz für den Laizismus, d. h. die Forderung nach der Trennung von Kirche und Staat ${ }^{12}$. Auf dem Gebiet der Wirtschafts- und Sozialpolitik konzentrierten sich die Radikalsozialisten auf die Erhaltung des Privateigentums für das mittlere und das Kleinbürgertum. Außerdem setzten sie sich auch für die progressive Einkommenssteuer und Altersrente sowie für die Verstaatlichung von Betrieben mit Monopolstellung ein, womit sie sich von der Großindustrie abgrenzten. Außenpolitisch befürwor-

5 Vgl. dazu Teil A, Kapitel IV dieser Studie.

6 Zum Gründungsakt siehe den Bericht des ersten Parteitages, der vom 21.6.-23. 6. $1901 \mathrm{stattfand}$ und als konstituierende Sitzung des Parti radical bezeichnet werden kann. Als Gründungsziel der Partei wurde die Stärkung der politischen Kraft für die Wahlen von 1902 angegeben. Außerdem zum Gründungsakt P. Andréani, La formation du parti radical-socialiste, in: Revue politique et parlementaire 1952/1, S. 33-56; D. Bardonnet, Évolution de la structure du Parti radical, Paris 1960, S. 13-17.

7 Der erste Wahlgang fand am 27.4. 1902 statt und der zweite folgte am 11.5. 1902.

8 Zur Zirkularnote des Organisationskomitees des ersten Parteitages des Parti radical, dem Comité d'action pour les réformes républicaines: F. Buisson, La Politique radicale, Paris 1908, S. $283 \mathrm{f}$.

9 Vgl. zur Frühphase der Dritten Republik ausführlich D. Mollenhauer, Auf der Suche nach der "wahren Republik“; J.-M. Mayeur, Les débuts de la IIIe République 1871-1898, Paris 1973.

10 Alain, Élements d'une doctrine radicale, S. 137-311; F. Buisson, La politique radicale, S. 129-266; L.-E. Jacques, Les partis politiques sous la Troisième République, S. 223-264.

11 Zum Text des Programmes von Nancy (1907) siehe F. Buisson, La politique radicale, S. 338-342 und grundsätzlich zum Programm des Parti radical J. Carrère/G. Bourgin, Manuel des partis politiques en France, S. 122-129 sowie Anmerkung 10.

121905 wurde die Trennung von Kirche und Staat unter dem radikalsozialistischen Ministerpräsidenten Combes gesetzlich festgelegt; vgl. dazu M. Ozouf, L'École, l'église et la République, 18711914, Paris 1963; aus verfassungsrechtlicher Sicht J.-J. Chevalier, u. a., Histoire des institutions et des régimes politiques de la France de 1789 à nos jours, S. 437-441. 
teten sie den Völkerbund als eine Art Schlichtungsstelle bei internationalen Konflikten und machten sich für Rüstungsbeschränkungen stark, ohne dabei die nationale Sicherheit zu vernachlässigen ${ }^{13}$.

Der nachhaltige und unermüdliche Einsatz für das repräsentative Modell der parlamentarischen Demokratie schlug sich auch im Aufbau der Parteiorganisation nieder ${ }^{14}$. Der Parti radical et radical-socialiste ging aus einer nationalen Wahlorganisation hervor, aus der sich später Komitees bildeten ${ }^{15}$, die sich auf Departementsebene in Föderationen zusammenschlossen. Diese Komitees blieben auch in der Zwischenkriegszeit die Keimzelle der Parteibasis'6. Sie bildeten im Gesamtaufbau des Parti radical die Grundstruktur auf lokaler Ebene. Das organisatorische Kernstück des Parti radical, das Parteizentrum, stellte sich folgendermaßen dar:

Nach den Parteistatuten ${ }^{17}$ war die höchste Instanz in der Partei der jährliche Parteitag18. Dort wurden die Berichte der verschiedenen Parteigremien vorgelegt, zur Diskussion gestellt und darüber abgestimmt. Außerdem erfolgte auf dem Parteitag die Bestellung der verschiedenen Parteigremien mittels Wahlen, sowie die Festlegung des Parteiprogramms und der Parteitaktik. Darüber hinaus wurde dort auch das Comité exécutif ${ }^{19}$ gewählt, das während des Jahres, also bis zum nächsten Parteitag, als höchste Parteiinstanz fungierte, allerdings praktisch fast keine Möglichkeiten besaß, Verstöße gegen Parteitagsbeschlüsse zu ahnden. Denn im Unterschied zum höchsten Parteigremium der SFIO, dem CAP, verfügte das Comité exécutif über keine Sanktionsmöglichkeiten. Neben der Besetzung des Comité exécutif fand auf dem Parteitag auch die Wahl des Parteivorsitzenden ${ }^{20}$ statt. Der Einfluß des Parteivorsitzenden war je nach Persönlichkeit sehr unterschiedlich. In der Zwischenkriegszeit fand eine starke Prägung durch die beiden dominanten Parteivorsitzenden Edouard Herriot ${ }^{21}$ und Edouard Daladier statt, die kraft ihres

13 Ausführlich zum Programm des Parti radical für die Zwischenkriegszeit auch J. Carrère/G. Bourgin, Manuel des partis politiques en France, S. 122-129; F. Corcos, Catéchisme des partis politiques. Paris 1927, S. 73-98.

$14 \mathrm{Zu}$ den verschiedenen Strukturen der Parteiorganisation gibt am eindruckvollsten eine Graphik in der Untersuchung von S. Berstein, Parti radical, vol. 1, S. 178/179 Auskunft.

15 Eine ausführliche Studie zum Organisationsaufbau des Parti radical liefert D. Bardonnet, Évolution de la structure du parti radical. Zum Komitee- und Föderationssystem des Parti radical siehe insbesondere Ebenda, S. 31-70.

16 Besonders in den 1926 und 1935 erneuerten Parteitstatuten wurde diese Keimzelle der Basis nochmals genau definiert. Drei Faktoren galten als konstitutive Elemente der Komitees: „(...) les membres de droit, les journaux, à condition qu'ils soient présentés par la fédération départementale, et les groupements dont le comité constitue le type“; vgl. S. Berstein, Parti radical, vol. 1, S. 180.

17 Zu den Parteistatuten des Parti radical vgl. L.-E. Jacques, Les partis politiques sous la Troisième République, S. 516-528.

18 Zur Funktion und Bedeutung des Parteikongresses und seiner Zusammensetzung im Detail siehe D. Bardonnet, Évolution, S. 71-86; S. Berstein, L'Histoire du Parti radical, vol. 1, S. 198-204; J.-Th. Nordmann, Histoire des Radicaux 1820-1973, S. 305-307.

19 Zum Aufgabenbereich des Comité exécutif und seiner Zusammensetzung siehe D. Bardonnet, Évolution, S. 92-109; S. Berstein, Parti radical, vol. 1, S. 205-225; J.-Th. Nordmann, Histoire des Radicaux, S. 307/308.

20 Zur Funktion des Parteivorsitzenden im Parti radical siehe D. Bardonnet, Évolution, S. 120-124; S. Berstein, Parti radical, vol. 1, S. 232/233; J.-Th. Nordmann, Histoire des Radicaux, S. 309/310.

21 Zur Bedeutung Herriots als Parteivorsitzenden bzw. als personifiziertes Symbol der Dritten Republik besonders in der Zwischenkriegszeit siehe S. Jessner, Edouard Herriot. Patriarch of the Republic, New York 1974, besonders S. 143-154. 
Amtes den Parti radical in politischen Entscheidungen zu beeinflussen und zu führen verstanden ${ }^{22}$. Wesentlich geringfügigere Einflußmöglichkeiten standen ihnen zur Verfügung, wenn es sich um organisatorische Maßnahmen und Fragen der Disziplin handelte, da die Fraktion bei den Radikalsozialisten stets sehr stark war und sich ihre Unabhängigkeit zu bewahren wußte ${ }^{23}$.

Das Comité exécutif tagte einmal im Monat; aus seinen Reihen wurde ein Bur$e a u^{24}$ bestellt, das sich um die laufenden Geschäfte kümmerte. Da die Mitglieder des Comité exécutif aus verschiedenen Föderationen kamen, führte dies dazu, daß an den monatlichen Sitzungen immer nur ein Teil seiner Mitglieder teilnahm. Dennoch konnten die einzelnen Föderationen ihren Einfluß gegenüber der obersten Parteiinstanz erhalten. Wiederholte Versuche, eine straffere Parteiorganisation zu etablieren, blieben erfolglos, da die Komitees und Föderationen sich gegen einen Eingriff zentraler Parteistellen stets hartnäckig wehrten. Als z.B. das Comité exécutif 1910 den Versuch unternahm, bezahlte Parteifunktionäre für Propagandazwecke einzustellen, protestierten die Komitees und Föderationen in den Departements vehement mit der Begründung, daß die eingesetzten Funktionäre nicht mit den Besonderheiten der einzelnen Departements vertraut seien und damit ihre Aufgabe nicht erfolgreich erfüllen könnten ${ }^{25}$.

In dieser knappen Skizze des Parteiaufbaus des Parti radical zeigt sich deutlich, $\mathrm{da} ß$ die hierarchischen Strukturen in dieser Partei nicht sehr ausgeprägt waren und somit die Komitees und die Honoratioren eine signifikante Rolle spielten. Darin unterscheidet sie sich grundsätzlich von der SFIO, deren Organisationsstruktur pyramidenförmig verlief.

Das Verhältnis zwischen Partei und Parlament läßt sich am besten anhand der Beziehung zwischen Parteigremien und Fraktion ("Groupe“) beurteilen.

Um dieses Verhältnis beurteilen zu können, ist es notwendig, sich kurz die organisatorischen Anfänge des Parti radical et radical-socialiste zu vergegenwärtigen. Die Ursprünge dieser Partei gehen auf eine nationale Wahlorganisation zurück. Vor den Wahlen schlossen sich die Parlamentarier des Parti radical et radical-socialiste zur Verbesserung ihrer Wahlchancen zusammen. Für die Wiederwahl eines Abgeordneten spielte die Unterstützung seines Wahlkomitees eine entscheidende Rolle. Dies führte dazu, daß die Beziehung zwischen Parlamentarier und seinem Komitees bedeutend enger und ausgeprägter war als zu seiner Partei.

Einen weiteren wesentlichen Faktor stellte auch die Frage der Wahlbündnisse dar, d.h. mit welchen anderen politischen Kräften vor Ort auf einer Liste kandidiert werden sollte. Obwohl die Frage des Wahlbündnisses auf dem Parteitag entschieden wurde und die Föderationen dem Comité exécutif jedes Wahlbündnis zur Genehmigung vorlegen mußten, kam es immer wieder zu Abweichungen. So

22 Erinnert sei hier an den Koalitionswechsel unter Herriot ab 1923, der den Parti radical unter seinem Vorsitz aus dem Bündnis des Bloc national herausführte und zur Bündnispolitik mit der $S F I O$ in den Jahren 1924 bis 1926 überleitete; vgl. Prozeßbeispiel I, Kapitel 2-7 dieser Studie.

23 Als Daladier ab 1927 versucht hatte, die Partei straffer zu organisieren und vor allem auch die radikalsozialistische Fraktion zu disziplinieren, verlor er letztlich die Auseinandersetzung mit der Fraktion; vgl. Prozeßbeispiel II, Kapitel 1.

${ }_{24}$ Zur Zuständigkeit und Tätigkeit des Parteibüros vgl. D. Bardonnet, Évolution, S. 110-119; S. Berstein, Parti radical, vol. 1, S. 227-232; J.-Th. Nordmann, Histoire des Radicaux, S. 308/309.

25 Vgl. hierzu R. von Albertini, Parteiorganisation und -begriff, S. $576 \mathrm{f}$ 
koalierten z.B. einige Kandidaten mit rechten Kräften, obwohl auf nationaler Ebene ein Bündnis mit den linken Kräften vereinbart worden war. Erstaunlicherweise hat der Parti radical versucht, die Kandidatenaufstellung zentralistisch zu organisieren, was in starkem Widerspruch zur sonstigen föderalen Ausformung der Gesamtorganisationsstruktur der Partei stand und folglich auch zu Konflikten zwischen den Föderationen und der Parteispitze führte.

Hinzu kam außerdem, daß mangels einer dichten Organisationsstruktur auch der Wahlkampf ohne Hilfe der Partei bestritten werden mußte. In der Zeit von 1901 bis 1914 war es gängige Praxis, daß Parlamentarier innerhalb der Partei eine besondere Stellung einnahmen, d.h. sie waren Parteimitglied kraft ihres Mandates im Parlament und nicht aufgrund ihrer eingeschriebenen Mitgliedschaft in der Partei. Es kam sogar des öfteren vor, daß einige Parlamentarier noch nicht einmal eingeschriebene Parteimitglieder waren, was allerdings nach 1913 unterbunden wurde ${ }^{26}$.

Ein charakteristisches Merkmal des französischen Parteiensystems stellte zweifelsohne die gängige parlamentarische Praxis dar, daß die Parteien nicht immer mit den Fraktionen identisch waren, d.h., daß Parlamentarier einer Partei sich nicht zu einer Fraktion oder Gruppe im Parlament zusammenschlossen, sondern sich auf mehrere Gruppen verteilten. Die Bildung einer kohärenten Fraktion im Parlament hätte durch eine straffe Organisation gefördert werden können. Aber trotz einiger Versuche in der Zwischenkriegszeit, die Parlamentsgruppen zu reformieren, blieb es bei der parlamentarischen Vielfalt einzelner Parteien.

Bis 1913 war es auch im Parti radical et radical-socialiste üblich, daß sich die radikalsozialistischen Parlamentarier auf zwei oder auch drei Gruppen verteilten ${ }^{27}$. Es gab also keine einheitliche Gruppe, die die Partei im Parlament repräsentierte. Dieses Manko gab immer wieder Anlaß zu Diskussionen und zu verschiedenen Disziplinierungsmaßnahmen, um ein einheitliches Votum und eine Abstimmungsdisziplin zu erzwingen. Die Abgeordneten wehrten sich jedoch jedes Mal mit größter Vehemenz gegen diese Disziplinierungsbestrebungen der Parteizentrale. Da aber die „militants“ in den Föderationen auf Departementsebene immer wieder auf den Zusammenschluß der Abgeordneten des Parti radical et radicalsocialiste in einer Gruppe drängten, weil sie sich durch ein geschlossenes Auftreten eine bessere Durchsetzung ihrer Interessen erhofften und außerdem gegen Rechtsabweichler die Parteidoktrin besser gewahrt sehen wollten, wurde schließlich 1913 die Praxis der Abgeordneten, sich einer Fraktion ihrer Wahl anzuschließen, unterbunden ${ }^{28}$. Die Ernennung eines Generalsekretärs für die „Groupe“ des Parti radical im Parlament erfolgte erst 192929.

26 Seit der Gründung von 1901 wurde diese Problematik im Parti radical diskutiert, vor allem auf dem Parteitag von 1907 stellte dieses Thema eine zentrale Frage dar, aber erst 1913 konnte ein endgültiger Beschluß gefaßt werden. Vgl. dazu die Parteitage des Parti radical von 1907 und 1913, sowie R. von Albertini, Parteiorganisation und -begriff, S. 578/579.

27. So waren vor 1913 Abgeordnete des Parti radical in den beiden Gruppen Parti radical und Parti radical-socialiste, aber auch in einer Gruppe der Alliance démocratique zu finden; vgl. ebenda.

28 Vgl. dazu die Parteitage des Parti radical vom 6. 10.-9. 10. 1910 in Rouen und vom 16. 10.-19. 10. 1913 in Pau, aber auch D. Bardonnet, Évolution, S. 140-147.

29 Vgl. den Parteitag des Parti radical vom 24. 10.-27. 10. 1929 in Reims: 26e Congrès du Parti républicain radical et radical-socialiste à Reims 1929, S. 285, aber auch R. von Albertini, Parteiorganisation und -begriff, S. 579. 
In engem Zusammenhang mit der Formierung einer einheitlichen Fraktion im Parlament steht auch das Bestreben, die Fraktionsdisziplin zu stärken. Während der gesamten Zwischenkriegszeit blieb die Forderung nach einer Fraktionsdisziplin aufrechterhalten, jedoch gelang es nicht, diese auch tatsächlich durchzusetzen. Die oberste Parteiinstanz, das Comité exécutif, das die Einführung einer Fraktionsdisziplin hätte beschließen können, wurde weitgehend von den Parlamentariern beeinflußt. Obwohl im Comité exécutif mehr Nicht-Parlamentarier vertreten waren, setzten sich die Abgeordnetenmitglieder durch, da sie im Gegensatz zu den Nicht-Parlamentariern in Paris vor Ort häufiger an den Sitzungen des Comité exécutif teilnehmen konnten. Durch den Vorteil des höheren Anwesenheitsgrades gelang es ihnen, ihren Einfluß geltend zu machen und dieses Gremium in ihrem Sinne zu dominieren. Hinzu kam außerdem noch, daß der Fraktionsvorsitzende meist auch der Präsident des Comité exécutif war. Das Comité exécutif konnte zwar das Befolgen seiner Beschlüsse verlangen, verfügte aber nicht über Instrumente, um diese durchzusetzen, sondern war größtenteils auf das Einverständnis der Abgeordneten angewiesen.

Beispiele aus den Jahren 192330, $1927^{31}$ und $1936^{32}$ veranschaulichen die mehrmaligen Versuche des Parti radical, die Organisation zu stärken und die Durchsetzung einer Fraktionsdisziplin zu erreichen. 1923 versuchte das Comité exécutif, bei der Frage der Ruhrbesetzung eine Stimmenthaltung der radikalsozialistischen Fraktion zu erreichen, doch hielten sich von 85 Deputierten nur 35 an diesen Beschluß. Im Senat war die Lage noch diffuser, da sich dort die Mitglieder des Parti radical auf mehrere Gruppen ${ }^{33}$ verteilten. In der Ruhrfrage stimmten sie sogar gegen die Vorgabe des Comité exécutif und votierten für die Ruhrbesetzung ${ }^{34}$.

Auch bei Vertrauensfragen und Regierungsbestätigungen gelang es nur teilweise, eine einheitliche Abstimmung der Fraktion und eine Übereinstimmung mit den Parteigremien durchzusetzen. Eine große Bedeutung kam auch immer wieder einzelnen Führungspersönlichkeiten des Parti radical zu. So z. B. im Juli 1926, als Herriot ohne Rücksprache mit dem oberstem Parteigremium in das Kabinett der Union nationale unter Poincaré eintrat ${ }^{35}$ und somit den Parti radical aus dem Bündnis des Cartel des gauches herauslöste. Ebenso muß hier das eigenmächtige Handeln einer kleinen Gruppe unter der Führung Caillaux' auf dem Parteitag von 1928 genannt werden, die kurz vor Ende des Parteitages, als bereits der Großteil der Delegierten abgereist war, in einer spontan einberufenen Sitzung einen Zusatz zum Parteitagsbeschluß verabschiedete, der letztlich zum Rücktritt der radikalsozialistischen Minister aus der Regierung Poincaré führte. ${ }^{36}$

30 Vgl. Prozeßbeispiel I, Kapitel 2 und 3.

31 Daladier drohte auf dem Parteitag vom 27. 10.-30. 10. 1927 in Paris bei Verstoß gegen die Disziplin mit Ausschluß aus der Partei.

32 Das Comité exécutif des Parti radical konnte in einer Sitzung vom 18. 1. 1936 den Übergang zur Regierung Laval erzwingen; vgl. L’Oeuvre vom 19.1. 1936, S. 1/2; D. Bardonnet, Évolution, S. 108.

33 Die radikalsozialistischen Abgeordneten verteilten sich im Senat z.B. auf folgende Gruppen: Groupe de l'Union républicaine, Groupe de la Gauche démocratique radicale et radicale-socialiste.

34 Vgl. dazu Prozeßbeispiel I, Kapitel 2 dieser Studie.

35 Hierzu ausführlicher in Prozeßbeispiel I, Kapitel 7.

36 Siehe Prozeßbeispiel II, Kapitel 1. Sehr ausführlich sind die gedruckten Parteitagsprotokolle des 
Resümierend läßt sich für den Parti radical festhalten: Kernpunkt seines Parteibegriffes stellt das Verhältnis zwischen Wähler und Gewähltem dar, das Alain in seinem einschlägigen Werk "Éléments d'une doctrine radicale" folgendermaßen umschrieb: „Ce que j'appelle liberté, c'est la dépendance étroite de l'élu par rap-

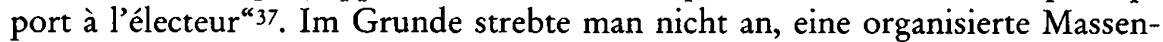
partei zu sein, denn dies hätte das Fundament der radikalsozialistischen Doktrin zerstört. D.h. der Abgeordnete hätte sich dann in den Dienst der Parteigremien stellen müssen, und der Wähler wäre seines Kontaktes und seiner Kontrolle zum Gewählten beraubt gewesen. Damit wäre eine Realität geschaffen worden, die mit der radikalsozialistischen Doktrin unvereinbar gewesen wäre, denn der Parti radical lehnte die Partei als Zwischeninstanz zwischen Wähler und Gewähltem entschieden ab. In engem Zusammenhang damit wird auch das Mißtrauen der Radikalsozialisten gegenüber der Staatsgewalt verständlich, denn mit der Ablehnung straff organisierter Parteien verband sich der Verzicht auf die Stärkung des parlamentarischen Systems, die für die Stabilität, Autorität und Kontinuität der Exekutive von Bedeutung gewesen wäre.

Die Mehrheit der Parteimitglieder des Parti radical et radical-socialiste strebte jedoch weiterhin nach der Aufrechterhaltung der Unabhängigkeit des Abgeordneten, deshalb hielt man bewußt den Einfluß des Comité exécutif möglichst gering und vermied es, ihm Sanktionsmittel gegen einzelne Parlamentarier an die Hand zu geben.

\section{Charakteristika des Parti radical und ibr Einfluß auf den innerparteilichen Entscheidungsproze $\beta$}

Neben der erwähnten Einflußnahme einzelner Führungspersönlichkeiten gab es noch drei weitere Faktoren, die auf die Geschicke des Parti radical einwirkten und die Geschichte dieser Partei in der Dritten Republik entscheidend geprägt haben. 1) Der Gegensatz zwischen der Parteibasis und den Parlamentariern; 2) Der Antagonismus zwischen den Radikalen auf nationaler und denen auf regionaler Ebene; 3) Die vage Formulierung der Statuten ${ }^{38}$.

1) Es kam zwischen den Abgeordneten und der Parteibasis immer wieder zu Konflikten, da sich letztere nicht gebührend mit ihren spezifischen Interessen berücksichtigt sah und den direkten Kontakt der Abgeordneten mit ihrem Wahlkreis reklamierte, wie dies z.B. ein Mitglied der Parteibasis auf dem Parteitag von 1935 in aller Deutlichkeit eingefordert hatte: „Je m'étais figuré que les parlementaires, si heureux de se dire militants du Parti, une semaine avant les élections législatives, et pendant celles-ci, étaient nos mandataires et, comme tels, devaient se faire un devoir strict d'assister à nos Congrès, d'être assidus à nos séances, pour suivre nos discussions et s'efforcer ensuite de faire aboutir nos conclusions (...).“39

Parti radical: $25^{\mathrm{c}}$ Congrès du Parti républicain radical et radical-socialiste à Angers du 3-5 novembre 1928, S. 362-365, hier vor allem S. 365.

37 Alain, Éléments d'une doctrine radicale, S. 198.

38 Vgl. dazu auch D. Bardonnet, Évolution, S. 23-29.

$3932^{\mathrm{e}}$ Congrès du Parti républicain radical et radical-socialiste à Paris du 24-27 octobre 1935, S. $333 \mathrm{f}$. 
2) Der Gegensatz zwischen Provinz und Paris trat meistens in der Diskussion über die prozentuale Besetzung der Parteigremien wie des Comité exécutif hervor, wobei man hoffte, durch eine prozentual höhere Besetzung dieser Parteigremien mit Delegierten aus der Provinz ein Gegengewicht zur Zentrale in Paris gefunden zu haben. Obwohl prozentual die Delegierten aus der Provinz in diesen Parteigremien in der Mehrheit waren, überwog dennoch das Gewicht der Pariser, da sie an Sitzungen des Comité exécutif häufiger teilnahmen als auswärtige Mitglieder aus der Provinz. Das war vor allem auch durch die Faktoren Zeit und finanzielle Ressourcen bedingt ${ }^{40}$.

3) Die Statuten des Parti radical, die 1902 zum ersten Mal in vier Artikeln schriftlich fixiert worden sind, waren sehr ungenau. Sie bestimmten die Zusammensetzung der Partei, den Sitz der Partei, die jährliche Einberufung eines Parteitages, der das Comité exécutif wählen sollte, und die Verbindlichkeit des Parteiprogramms für jedes Parteimitglied ${ }^{41}$. Diese Parteistatuten erfuhren im Laufe der Jahre zahlreiche Zusätze und Änderungen ${ }^{42}$, wobei es auch zur Aufnahme widersprüchlicher Festlegungen kommen konnte. Außerdem wurden diese Statuten nur selten in letzter Konsequenz angewandt ${ }^{43}$ und blieben meist sehr unübersichtlich bzw. waren teilweise nicht in allen Parteigremien bekannt, wie z.B. der Berichterstatter einer Kommission zur Reform der Statuten auf dem Parteitag von 1936 ausführte: „Le manque de cohésion entre nos divers organismes directeurs (...) provenait moins d'une insuffisance ou d'une absence de règles que de la méconnaissance et de la non-observation des règles en vigueur." ${ }^{44}$

Schließlich nahmen verschiedene Politiker des Parti radical mit eigenen Presseorganen Einfluß auf die Partei. So unterhielten z.B. Caillaux mit L'Oeuvre oder aber die Brüder Albert und Maurice Sarraut mit La Dépêche de Toulouse wichtige Zeitungen, die eine Einflußnahme auf die verschiedenen Parteiströmungen des Parti radical erlaubten. Außerdem gelang es ihnen, in der Öffentlichkeit Zustimmung für ihre Parteitendenz zu finden. Ein sehr anschauliches Beispiel stellt der Radikalsozialist Emile Roche dar, der mit seiner Zeitung La République ${ }^{45}$ gegen die Einbindung der Radikalsozialisten in die Volksfront Stimmung machte und

40 Vgl. dazu auch D. Bardonnet, Évolution, S. 26/27.

41 Vgl. dazu Le Rappel vom 21.6. 1901, S. 2.

42 Auf dem Parteitag von 1931 wurden nochmals Änderungen und Zusätze beschlossen, vgl. dazu $28 \mathrm{c}$ Congrès du Parti républicain radical et radical-socialiste à Paris du 5-8 novembre 1931 .

43 Laut Statuten hätte z. B. der Parteivorsitzende nur für ein Jahr gewählt werden dürfen und war eigentlich nicht wiederwählbar. Jedoch hielt man sich nicht daran. Vor allem in der Zwischenkriegszeit war der Parteivorsitz fest in den Händen von Herriot und Daladier, die sich in der Führung der Partei abwechselten. So bemerkte ein Mitglied auf der Konferenz der Vorsitzenden und Generalsekretäre auf dem Parteitag von 1929: „On prend des décisions réglementaires, dont il faut reconnaître qu'en principe elles doivent être appliquées, mais nous sommes un parti de transformation, et il faut bien admettre que parfois un règlement institué dans l'intérêt général du Parti peut avoir besoin d'être interprété."; $26^{e}$ Congrès du Parti républicain radical et radical-socialiste à Reims du 24-27 octobre 1929, S. 425.

44 33e Congrès du Parti républicain radical et radical-socialiste à Biarritz du 22-25 octobre 1936, S. 425. Zur Thematik siehe auch M. Duverger, Les partis politiques, S. XI. Duverger erklärt dieses Verhalten damit, daß Statuten gegen den Individualismus der Radikalsozialisten verstoßen hätten.

45 Emile Roche, der ein Anhänger Caillaux' und seiner Kabinettspolitik war, gründete La République am 10. 6. 1929. Zur Einordnung in die Presselandschaft der Radikalsozialisten siehe C. Bellanger u. a. (Hg.), Histoire générale de la presse française, vol. 3: De 1871 à 1940, Paris 1972, S. 563 f. 
damit letztlich auch dazu beigetragen hatte, daß innerhalb des Parti radical im Laufe der Jahre 1937/38 ein Umschwung stattfand ${ }^{46}$.

Führt man alle Charakteristika des Parti radical zusammen, ergibt sich ein Gesamttableau mit drei Schwerpunkten, denen zufolge der Parti radical in der von Neumann entwickelten Parteitypologie, dem Typus der liberalen Repräsentationspartei zugeordnet werden kann. Denn erstens sind die Mitglieder der Parteibasis im Parteiverband nur lose engagiert, d.h. nicht der ganze Mensch wird umfassend und ständig in der Partei gefordert, wie dies bei Parteien mit totalitärem Anspruch, wie z. B. den Kommunisten, der Fall ist. So definiert Maurice Duverger in seinem Buch über die politischen Parteien das einfache Parteimitglied des Parti radical folgendermaßen: "Le parti tient une place très faible dans la vie du premier: Il assiste de temps en temps aux réunions de son comité; il tache quelquefois d'obtenir des faveurs par l'intermédiare de son député; il suit les combinaisons politiques nationales et surtout locales; il envisage les candidatures et les alliances relatives aux futures élections. Il lit un journal radical, s'il en existe; il est quelquefois inscrit à la Ligue des Droits de l'Homme, dont l'activité n'est pas très grande, ou à une loge maconnique, ou à quelque autre groupement similaire (...). La participation conserve un caractère purement politique, sans déborder ce domaine très limité: le Parti radical est un parti spécialisé." 47

Zweitens ist der Parti radical zum einen eine Honoratiorenpartei und zum anderen eine Weltanschauungspartei. Denn ein ursprünglicher Wesenszug des Parti radical war, daß sich zu Wahlzeiten Honoratioren in Komitees zusammenfanden, um sich um die Wahlgeschäfte zu kümmern. Der Parti radical verkörperte eine Partei, die als Prototyp der abstrakten Parteien ${ }^{48}$ bezeichnet werden kann, weil sie sich weder primär als Vertreter einer sozialen Schicht noch einer bestimmten wirtschaftlichen Kategorie verstand. Verschiedene Versuche, den Parti radical zu einer Massenpartei zu transformieren, sind stets gescheitert.

Drittens weist der Parti radical an seiner Spitze eindeutig Machtformen einer Oligarchie auf. Seine Organisationsstrukturen begünstigten die Herausbildung von Klans bzw. Interessensgruppierungen, denn die Führungspersönlichkeiten kümmerten sich vorzugsweise um die Wahlen und konnten damit ihren Einfluß geltend machen. Außerdem hatten sie sich kraft der Statuten und in der Praxis wesentlich mehr Einfluß einräumen können als die Vertreter der Parteibasis. Dies führte dazu, daß es zu ständigen Rivalitätskämpfen zwischen den Fraktionen und Tendenzen in der Partei gekommen ist ${ }^{49}$.

Die überwiegend bürgerlich ausgerichteten politischen Kräfte bevorzugten das repräsentative Modell der parlamentarischen Demokratie, das eine straffe Organisationsstruktur nicht nur entbehrlich machte, sondern sogar eher ablehnte. Im Gegensatz dazu stand entschieden die sozialistische Partei, die damit in der französischen Parteienlandschaft eine gewisse Sonderstellung einnahm.

46 Ausführlich dazu ist Prozeßbeispiel III, Kapitel 5 und 6.

${ }_{47}$ M. Duverger, Les parties politiques, S. 141.

48 Die Terminologie stammt von G. Burdeau, Traité de Science politique, vol. 5, Paris 21970, S. 157/ 158.

$49 \mathrm{Vgl}$. dazu auch M. Duverger, Les partis politiques, S. 179; D. Bardonnet, Évolution, S. 273. 


\section{Die $S F I O$}

Nach der Parteitypologie Neumanns nimmt die SFIO eine Zwitterstellung zwischen dem alten Typ der liberalen Repräsentationspartei und dem neuen Typ der absolutistischen Integrationspartei ${ }^{50}$ wie sie die kommunistische ${ }^{51}$ und die nationalsozialistische Partei ${ }^{52}$ darstellten, ein, d.h. sie repräsentierte ein Übergangsmodell zwischen diesen beiden Parteitypen und gehörte somit dem Typus einer demokratischen Integrationspartei an.

Mit dem föderativen Element wollte die SFIO dem Autonomiestreben der regionalen und lokalen Organisationen Rechnung tragen, während das zentralistische Element eine effiziente und starke Führung ermöglichen sollte, um die Einhaltung und Umsetzung der Parteitagsbeschlüsse auch durchsetzen zu können.

Die sozialistische Partei ist $1905^{53}$ unter dem Druck der Internationale ${ }^{54}$ gegründet worden und setzte sich aus verschiedenen historisch gewachsenen Strömungen des Sozialismus ${ }^{55}$ zusammen. Die geeinigte sozialistische Partei Frankreichs trat mit dem Anspruch an, eine organisierte Klassenpartei zu werden, und orientierte sich dabei stark am Vorbild der deutschen sozialdemokratischen Partei. Die SFIO stellte in gewisser Weise ein eigenartiges Konstrukt dar, denn unter organisatorischem Gesichtspunkt strebte sie danach, eine moderne Massenpartei mit ausgeprägtem Parteiapparat zu sein, jedoch war sie unter dem Aspekt der Mitgliederstärke weit davon entfernt ${ }^{56}$. Diese Diskrepanz zwischen Organisationsgrad und Mitgliederstärke ist auf mehrere Gründe zurückzuführen. Hier spielt einerseits auch eine gewisse Abneigung, sich in Großorganisationen zusammen-

50 S. Neumann, Die Parteien, S. 107/108.

51 Allgemein zur Typologie der kommunistischen Partei siehe S. Neumann, Die Parteien, S. 87-95.

52 S. Neumann, Die Parteien, S. 73-86.

53 Vgl. zum Gründungsmoment T. Judt, La reconstruction du Parti socialiste 1921-1926, Paris 1976; L.-E. Jacques, Les partis politiques sous la Troisième République, S. 266-315. Die SFIO entstand aus dem Zusammenschluß der beiden rivalisierenden Vereinigungen PSF (Französische sozialistische Partei) und der PSDF (Sozialistische Partei Frankreichs) am 23. 4. 1905, die wiederum in verschiedene sozialistische Strömungen unterteilt waren.

54 Im August 1904 auf dem Kongreß der Internationale in Amsterdam wurden nach heftigen Rededuellen von Jaurès, Guesde und Bebel die französischen Sozialisten zum Zusammenschluß in einer Partei aufgefordert. Entzündet hatte sich der Streit u.a daran, daß der Parti socialiste français unter Jaurès weiter an einer Zusammenarbeit mit dem Parti radical festhalten wollte. Es wurde deshalb bezweifelt, ob Jaurès noch ein Sozialist war. Dennoch fand man eine Verständigung. Ausführlich dazu J. Braunthal, Geschichte der Internationale, Bd. 1, Braunschweig 1961, S. 284-290; M. Rebérioux, Die sozialistischen Parteien Europas: Frankreich, Frankfurt a. Main 1975, S. 100-103.

55 Zur Genese der geeinten sozialistischen Partei Frankreichs und den unterschiedlichen sozialistischen Strömungen vor 1905 vgl. L.-E. Jacques, Les partis politiques sous la Troisième République, S. 266-271; G. Lefranc, Geschichte des französischen Sozialismus, S. 96-109; A. Noland, The Founding of the French Socialist Party 1893-1905, Cambridge 1956, vor allem S. 1-33; C. Willard, Geschichte der französischen Arbeiterbewegung. Frankfurt am Main 1981, S. 14-137; G. Ziebura, Léon Blum, S. 56-78. Nach der Vereinigung der sozialistischen Partei Frankreichs 1905 unterschied man vor allem zwei Stränge in der Partei. Zum einen die marxistisch geprägte Richtung, die von Jules Guesde angeführt wurde, und zum anderen die reformistische Tendenz, an deren Spitze Jean Jaurès stand. Diese beiden Grundtendenzen waren mit verschiedenen Untertendenzen über die gesamte Dritte Republik bestimmend. Vgl. dazu auch T. Judt, La reconstruction, S. 12.

56 Vgl. hier folgende Zahlenbeispiele: 1905: 40000; 1912: 63700; 1914: 90725. Nach der Spaltung von 1921: 39000 und 1932: 137000 Mitlgieder, dazu im Vergleich die SPD, die bereits 1914 über eine Million Mitglieder verfügte. Vgl. hierzu R. von Albertini, Parteiorganisation und -begriff, S. 586. 
zuschließen, eine Rolle, was ein Spezifikum Frankreichs darstellte; andererseits hing das auch damit zusammen, daß sich die soziale Struktur der Mitglieder der SFIO von der der SPD unterschied. In Frankreich rekrutierten sich die Mitglieder der sozialistischen Partei meist mehr aus landwirtschaftlichen Kreisen mit kleinen und mittleren Betrieben als aus reinen Industriekreisen. Dies hing damit zusammen, daß die industrielle Entwicklung in Frankreich zu diesem Zeitpunkt im Vergleich zu Deutschland noch rückständig war ${ }^{57}$. Nicht nur der parteipolitische Organisationsgrad der Arbeiterschaft in Frankreich war gering, auch die Gewerkschaften klagten über den Mangel an Mitgliedern. Im Vergleich zu Deutschland zeigt sich deutlich, daß die französische Arbeiterschaft weniger stark gewerkschaftlich organisiert war ${ }^{58}$.

Der Versuch der SFIO, innerhalb ihrer Organisationsstruktur auch dem Prinzip der innerparteilichen Demokratie Rechnung zu tragen, fand seinen deutlichen Ausdruck in der Aufbaustruktur der Partei. Die unterste Organisationsebene bildete die „Section“. Ihre Aufgabe war es, Mitglieder zu werben und auch zwischen den Wahlkämpfen Veranstaltungen für die Parteibasis anzubieten. Sie verfügte über einen kleinen Apparat, um ihrer Aufgabe vor Ort gerecht werden zu können, die in der ganzjährigen Betreuung ihrer Parteimitglieder, d.h. der politisch-ideologischen Bildung, lag. Die Section bildete die kleinste geschlossene Einheit innerhalb der Parteistruktur und nicht eine autonome Vereinigung von einigen Honoratioren vor Ort, die nur zu Wahlzeiten in Aktion traten, wie die Komitees beim Parti radical.

Die Sections schlossen sich auf Departementsebene in Föderationen zusammen. Diese Föderationen zeigten ein starkes Streben nach Autonomie und besaßen auch politischen Einfluß und Bedeutung. Ihre Bedeutung resultierte daraus, daß die Sections zwar die Kandidatenaufstellung durchführten, jedoch mußten ihre Entscheidungen von den Föderationen bestätigt werden. An der Spitze dieser Föderationen stand ein eigenes Führungsorgan, das Komitee, das von den kleinen Parteitagen der jeweiligen Föderation gewählt wurde. Hinzu kam, daß wichtige Parteiführer an der Spitze der Föderationen standen, die dementsprechend bei Diskussionen und Konflikten Einfluß auf die politische Haltung der Gesamtpartei nehmen konnten. Dadurch, daß sich in den verschiedenen Regionen die Sozialstruktur der Parteimitglieder sehr unterschiedlich gestaltete ${ }^{59}$, formierte sich nur

57 H. Kaelble, Nachbarn am Rhein. Entfremdung und Annäherung der französischen und deutschen Gesellschaft seit 1880, München 1991, S. 87-101; H.-G. Haupt, Frankreich. Langsame Industrialisierung und republikanische Tradition, in: Derselbe ( $\mathrm{Hg}$.), Europäische Arbeiterbewegungen im Vergleich, Göttingen 1983, S. 39-76; S. Jauch/R. Morell/U. Schickler, Gewerkschaftsbewegung in Frankreich und Deutschland. Ein kontrastierender Vergleich ihrer zentralen Merkmale bis zum Ersten Weltkrieg, Frankfurt a. M. 1984.

58 Die SFIO hatte 1932138000 Mitglieder, während die SPD 19301040000 Mitglieder aufweisen konnte. Ebenso gab es einen großen Unterschied zwischen SFIO und SPD bezüglich Ihres Verhältnisses zu den Gewerkschaften: Für die $S F I O$ galt, daß sie nur lose Verbindungen zu Gewerkschaften pflegte, eine autonome Politik gegenüber organisierten Interessen betrieb. Bei der SPD bestand allgemeinhin eine enge Verbindung zu Gewerkschaften, vgl. dazu: H. A. Winkler, Klassenkampf versus Koalition. Die französischen Sozialisten und die Politik der SPD 1928-1933, in: Geschichte und Gesellschaft 17 (1991), S. 182-219, hier besonders S. 186/187, und zum unterschiedlichen Organisationsgrad der Gewerkschaften H. Kaelble, Auf dem Weg zu einer europäischen Gesellschaft. Eine Sozialgeschichte Westeuropas 1880-1980, München 1987, S. 84.

59 Vgl. R. von Albertini, Parteiorganisation und -begriff, S. 586-588. Im Norden z. B. überwiegen die 
schwer eine homogene Interessensmeinung, vielmehr waren sehr stark heterogene Vorstellungen in der Partei vertreten, die sich durch die unterschiedliche Klientel bedingten.

Dem jährlichen Parteikongreß kam in der SFIO eine zentrale Bedeutung zu. An ihm nahmen Delegierte der Föderationen teil, die ihn als politische Plattform nutzten, um in ausführlichen Diskussionen die Richtung und die Leitlinien der Parteipolitik zu bestimmen. Die Themen und Diskussionspunkte des Parteikongresses wurden sowohl von den Sections und Föderationen im Vorfeld als auch von der Parteispitze vorbereitet, die in Form von Zirkularschreiben und der Versendung von Propagandamaterial auf den Ablauf des Parteikongresses Einfluß zu nehmen versuchte. Die Sekretäre der Föderationen übernahmen kraft ihres Amtes und im Interesse ihrer Föderation eine zusätzlich gestaltende Rolle. Das föderative Prinzip wirkte sich im Hinblick auf eine einheitliche Beschlußfassung und die Gewinnung eines homogenen Parteiwillens als tendenziell nachteilig aus. Es wurde bereits auf den kleinen Parteitagen der einzelnen Föderationen über zu verabschiedende Resolutionsanträge abgestimmt ${ }^{60}$, danach galt es auf dem großen nationalen Parteitag einen gemeinsamen Nenner zu finden.

Das Spannungsverhältnis zwischen dezentralistisch-demokratischen und zentralistischen Elementen der Partei schlägt sich in dem eben erwähnten Beispiel anschaulich nieder und spiegelt gleichzeitig das. Dilemma der SFIO wider. Ein dezentralistisch-demokratisches Element enthielt z.B. das Parteistatut ${ }^{61}$, das der innerparteilichen Minderheit zubilligte, proportional in den Parteigremien vertreten zu sein. Es wurde also Wert darauf gelegt, daß eine Minderheit nicht einfach überstimmt werden konnte, sondern auch in den Parteigremien Berücksichtigung fand. Die unterschiedlichen Meinungen innerhalb der Partei führten zur Bildung von zwei Parteiflügeln, die sich besonders während der Zwischenkriegszeit herausgebildet haben und ihre Verankerung in den Regionen besaßen, aber auch über eigene Presseorgane ${ }^{62}$ verfügten. Die Entwicklung eines starken rechten und eines starken linken Flügels innerhalb der SFIO förderte die Rolle eines starken Partei-

Industriearbeiter, in anderen Regionen mehr kleinbürgerlicher und bäucrlicher Anhang. Siehe dazu auch F. Goguel, Géographie des elections françaises de 1870-1951, Paris 1951, S. 82; dieser bezieht sich allerdings mehr auf die Wähler und nicht auf die Mitglieder.

60 So wurde z. B. über die zentrale Frage der Regierungsbeteiligung nach dem Wahlerfolg des Cartel des gauches im Mai 1924 bereits im Vorfeld des großen nationalen Sonderparteitages vom 1.6.2.6. 1924 auf den kleinen Parteitagen der einzelnen Föderationen abgestimmt. Vgl. dazu in Le Populaire die Abstimmungen auf den kleinen Parteitagen der einzelnen Föderationen; Le Populaire vom 25. 5.-31. 5. 1924, jeweils S. $1,3$.

61 In Artikel 19 der Parteistatuten wurde der Minderheit eine proportionale Besetzung in allen wichtigen Parteigremien zugesichert: „Chaque fois que l'entente n'aura pu se réaliser, la minorité aura droit à tous les degrés de l'organisation du Parti: Section, Fédération, C.A.P. et pour toutes les Commissions ou délégations de ces divers organismes, à une représentation proportionnelle. La même mesure sera appliquée à la nomination des délégations collectives dans les oeuvres auxquelles il participe“; L.-E. Jacques, Les partis politiques sous la Troisième République, S. 527.

62 Die große Parteizeitung nach der Spaltung von 1920 in Tours für die SFIO war Le Populaire. Jedoch hatten auch die verschiedenen Strömungen in der SFIO ihre eigenen Pressorgane, wie z. B. La Vie socialiste, das Presseorgan des reformistischen rechten Flügels um Varenne, Auriol und Paul-Boncour, der für eine Regierungsbeteiligung der SFIO war. La Bataille hingegen repräsentierte den linken Flügel um Bracke und Zyromski. Und schließlich stand L'Etincelle, das zwischen 1924 und 1929 erschien, für den extrem linken Flügel in der SFIO. Zur Presse in Frankreich in der Dritten Republik allgemein vgl. C. Bellanger u.a. (Hg.), Histoire générale de la presse française, vol. 3, hier besonders S. 574-577. 
führers, die Léon Blum einnahm, um immer wieder zwischen den beiden Flügeln vermittelnd zu wirken und einen gemeinsamen ausgleichenden Nenner zu finden. Trotz aller Vorkehrungen, um das demokratische Element in der SFIO gebührend zu berücksichtigen, entstanden auch hier Teiloligarchien, die die Macht in ihren Händen hielten.

Zu den zentralistischen Elementen der SFIO gehörte einerseits der Anspruch, daß die Parteibeschlüsse von den verschiedenen Ebenen der Partei als verbindlich zu akzeptieren waren, andererseits die Bestimmung, daß die Mitgliedschaft nicht auf lokaler Ebene erworben werden konnte, sondern nur über die Zentrale der Partei, an die auch die Mitgliedsbeiträge zu entrichten waren und die diese wiederum an die lokalen Ebenen verteilte. Diese Regelung kann nur vor dem Hintergrund des Parteicharakters der SFIO richtig verstanden werden, der sich grundlegend von dem des Parti radical unterschied, denn in der SFIO war den Mitgliedern bewußt, daß die Partei nicht nur Wahlzwecken diente, um möglichst viele Mandate zu erwerben, sondern sie sah sich als Kampf- und Klassenpartei, deren Aufgabe die Veränderung der Gesellschaft war. Die SFIO strebte langfristig durch die Vergesellschaftung der Produktionsmittel eine Transformation der kapitalistischen Gesellschaft in eine kollektivistische an. Nach dem Ersten Weltkrieg fand eine Überarbeitung der Parteidoktrin ${ }^{63}$ statt, die von reformistischen Zügen geprägt war. Der Kern der sozialistischen Doktrin blieb jedoch unverändert: Durchsetzung des Gleichheitsprinzips, der Einsatz für das Kollektiveigentum, Internationalismus und Klassenkampf, Laizismus, soziale Revolution und Antimilitarismus ${ }^{64}$.

Kehren wir zur Organisationsstruktur zurück. Der Parteikongreß hatte außerdem auch die Aufgabe, einen Conseil national zu wählen, der sich wiederum aus Mitgliedern folgender Gremien zusammensetzte: Er umfaßte Delegierte der Föderationen, Mitglieder der Commission administrative permanente (CAP) und Mitglieder einer Delegation der Fraktion ${ }^{65}$. Der Conseil national vertrat den Parteikongreß während des Jahres, die CAP trat mehr als exekutives Organ in Erscheinung. Die SFIO verfügte über einen Parteiverwaltungsapparat und damit über ständige Parteifunktionäre, die sich um die Organisation und die Propaganda kümmerten. Es läßt sich weniger ein Spannungsverhältnis zwischen Parteifunktionären und Abgeordneten feststellen als vielmehr zwischen den "militants" und den Abgeordneten. Um ein demokratisches Verhältnis zwischen der Partei und der Parlamentsfraktion herzustellen, fand eine strenge Reglementierung hinsichtlich des Gewichts der Parlamentarier innerhalb der Parteigremien statt. Es wurde darauf geachtet, daß die "militants" zahlenmäßig gegenüber den Parlamentariern

63 Programme d'action du Parti socialiste, Paris 1919.

64 Ausführlich zur Parteidoktrin und -programm der SFIO vor und nach 1919 G. Bourgin/J. Carrère (Hg.), Manuel des partis politiques en France, S. 159-165.

65 Die Fraktion war anfänglich nur sehr schwach im obersten Parteigremium vertreten, denn zunächst sollten sie darin gar nicht präsent sein, wie Artikel 28 des Parteistatuts vorsah. Grund dafür war die Furcht, daß eine zu starke Einflußnahme der Parlamentarier in der Partei, die teilweise sehr starke reformistische Vorstellungen vertraten, erfolgen könnte. In den Augen der Parteibasis unterlagen die Parlamentarier durch ihre tagespolitische Arbeit einer starken Tendenz zur Verbürgerlichung; siehe dazu G. Ziebura, Blum, S. 220. 
in den Parteigremien überrepräsentiert waren ${ }^{66}$. Hintergrund dieser Forderung bildete das Streben der Partei nach einer engen Bindung und Kontrolle der Parlamentsfraktion, die die Parteiführung sich unterordnen wollte.

Auch in der Frage der Parteidisziplin unterschied sich die SFIO von den anderen Parteien grundlegend, was vor allem stark mit ihrem differierenden Parteibegriff zusammenhing, denn die SFIO verlangte von ihren Parlamentariern strikte Fraktionsdisziplin. Sie sah den Abgeordneten als einen Delegierten der Partei im Parlament und in der Regierung, während die anderen Parteien ihre Abgeordneten nur ihrem Gewissen verpflichtet hielten und sich auf das nicht-imperative Mandat beriefen. Dies ging bei der SFIO sogar so weit, daß Léon Blum sich 1936 die Übernahme der Regierungsverantwortung von der $C A P$ und dem Parteikongreß bestätigen ließ67. Dieses Beispiel charakterisiert das Kernprinzip der SFIO in der Zwischenkriegszeit, sie stellte die Partei als die absolute Instanz über den Abgeordneten und unterstrich damit nicht nur die Abhängigkeit des Abgeordneten von der Partei, sondern bestimmte ihn zum Mandatar der Partei. Das Beispiel Blums von 1936 führt deutlich die Problematik der SFIO in der Zwischenkriegszeit vor Augen, denn selbst wenn ein sozialistisches Kabinett die Regierungsverantwortung übernahm, galt der Grundsatz, daß die Regierungsmannschaft nur Repräsentant der Partei war und weiterhin der Kontrolle der Partei unterlag. Diesem theoretischen Standpunkt der SFIO lag die Furcht zugrunde, daß sich ein sozialistisches Kabinett durch die Übernahme der Regierungsverantwortung doktrinär wie taktisch von den Grundprinzipien der Partei entfernen könnte. Diese Grundproblematik Partei - Fraktion stellte ein Kernproblem einer modernen Massenpartei, wie sie die SFIO war - dar.

In diesem Punkt zeigte sich das eigentliche Dilemma der SFIO, das Spannungsverhältnis zwischen Theorie und Praxis, Ideologie und politischer Realität ganz deutlich. Die "militants" verfolgten stets mit größtem Mißtrauen das politische Handeln der sozialistischen Abgeordneten. Es kam auch wiederholt zu Konflikten zwischen den "militants" und den Abgeordneten, insbesondere in der Frage der Regierungsbeteiligung. Die „militants“ fürchteten, daß die Parlamentarier im politischen Alltag allzu leicht die theoretisch geforderte Reinhaltung der Parteidoktrin opfern könnten.

Die Parlamentsfraktion ist mehrmals von den obersten Parteigremien in ihren Entscheidungen korrigiert und zur Umsetzung dieser Korrekturen verpflichtet worden ${ }^{68}$. Dieses konfliktbeladene Verhältnis zwischen Partei und Parlamentsfraktion entzündete sich immer wieder an der Frage der Regierungsbeteiligung und führte letztlich 1933 zur Abspaltung der "Neosozialisten“. Wie sich in den Fallbeispielen des Hauptteils zeigen wird, entwickelte sich die Frage der Tolerie-

66 Im Conseil national durften die Parlamentarier nicht als Einzelmitglieder, sondern nur als Gruppe vertreten sein und nicht mehr als ein Zehntel des Gremiums ausmachen. Zur CAP hatten die Abgeordneten erst ab 1913 Zutritt, durften aber nur ein Drittel der Mitgliederzahl stellen; vgl. R. von Albertini, Parteiorganisation und -begriff, S. 589.

67 Vgl. dazu Fallbeispiel III, Kapitel 4.

68 So z. B. nahm die Mehrheit der sozialistischen Fraktion das Angebot Daladiers einer Regierungsbeteiligung im Oktober 1929 an, was zur Folge hatte, daß die CAP einen Tadelantrag forderte und die sozialistische Fraktion letztlich ihre Zusage zurückziehen mußte; vgl. dazu auch Prozeßbeispiel II, Kapitel 1. 
rung und später die der Regierungsbeteiligung (der „participation“) zur zentralen Thematik in der SFIO. Die Geschichte der SFIO in der Zwischenkriegszeit wurde von dieser Auseinandersetzung dominiert, die zu einem ständigen spannungsgeladenen Konflikt zwischen den beiden Flügeln der Partei führte. So sprach sich der rechten Flügel, der stärker im Parlament vertreten war, für die Regierungsbeteiligung aus, während der linke Flügel, der die Parteigremien beherrschte, sich gegen die Beteiligung an bürgerlichen Kabinetten wandte. Diese Konstellation führte zu einer zusätzlichen Belastung des ohnehin vorhandenen Gegensatzes zwischen der Partei und der Fraktion.

\section{Prägende Faktoren der SFIO und ibr Einfluß auf die Bündnisfäbigkeit}

Die Bündnisfähigkeit der SFIO wurde durch folgende Faktoren beeinflußt: Erstens vom Gegensatz zwischen Partei und Fraktion; zweitens vom Grundverständnis der Partei im Hinblick auf den Parteienbegriff; drittens vom Gegensatz zwischen Doktrin und Praxis, der sich vor allem immer wieder an der Frage Regierungsbeteiligung oder Oppositionsrolle entzündete. Da diese drei Punkte alle sehr eng miteinander verzahnt sind, können sie komprimiert erläutert werden.

Obwohl sich die SFIO im nationalen Parteiensystem Frankreichs von den anderen Parteien durch ihren Anspruch, Klassenpartei zu sein, abhob und sich dies auch in ihrer Organisationsstruktur widerspiegelte, stellte sie unter dem Aspekt der Parteitypologie eine Übergangsform dar, denn sie ist nach ihren Charakteristika dem Typus der demokratischen Integrationspartei zuzuordnen. So wies die SFIO entsprechend einer demokratischen Integrationspartei folgende Merkmale auf: 1) Sie verfügte über eine ,intensive Bindung und relative Beständigkeit ihrer Anhängerschaft und eine straffe Organisation" ${ }^{69}$, was sich z.B. darin bestätigte, daß der Parteibasis ein ziemlich großes Gewicht durch die Bedeutung der Sections und Föderationen eingeräumt wurde. Die Sections hielten ganzjährig Veranstaltungen $\mathrm{ab}$ und stellten auf der Ebene der Parteibasis ebenso ein Forum dar wie der kleine Parteitag der Föderationen. So konnte eine enge Bindung der Mitglieder an die Partei aufgebaut und die Mitarbeit in den Parteigremien aktiviert werden. Um der Parteibasis einen entsprechenden Einfluß zu sichern, wurde ihr auch in den Führungsgremien proportional eine stärkere Vertretung zugesprochen. 2) Außerdem zeichnete sich die SFIO entsprechend dem Typus einer demokratischen Integrationspartei durch ein "hohes Maß an innerparteilicher Demokratie und Selbstbestimmung "70 aus. Gerade durch diesen Anspruch der innerparteilichen Demokratie ergab sich jedoch der Dualismus in der SFIO zwischen Partei und Fraktion, denn die Fraktion ist in den Führungsgremien der Partei erst nach und nach in der Zwischenkriegszeit fest verankert worden. Vorher verfügte sie über mehr Handlungsspielraum, da sie sich zeitweilig der Kontrolle der Partei entziehen konnte.

69 Vgl. die Kriterien der demokratischen Integrationspartei, die S. Neumann, Die Parteien, S. $106 \mathrm{f}$ anhand des deutschen Parteiensystems in der Weimarer Republik analysiert hat. Die Organisation der SFIO ist im Vergleich mit den Parteien, die rechts von der SFIO standen, als straff zu bezeichnen. Im Vergleich mit der SPD relativiert sich diese Straffheit.

70 Zur Begriffsbestimmung der demokratischen Integrationspartei siehe S. Neumann, Die Parteien, S. $106 f$. 
Die Einschränkung der politischen Handlungsfreiheit ging - wie schon ausgeführt - auf das extreme Mißtrauen der "militants“ gegenüber den Parlamentariern zurück, die stets eifersüchtig auf die Reinhaltung oder Priorität der Doktrin gegenüber der parlamentarischen Praxis achteten. So herrschte trotz der Organisationsstruktur, der das Prinzip der innerparteilichen Demokratie zugrunde gelegt worden war, eine Dominanz der kleinen Gruppe der "militants“, die die Politik der Partei mit restriktivem doktrinären Kurs bestimmte. Obwohl die Beseitigung des Dualismus zwischen Partei und Fraktion durch die Schaffung eines starken Führungsorganes während der gesamten Zwischenkriegszeit immer wieder in Angriff genommen wurde ${ }^{71}$, konnte dieses Problem letztlich nicht befriedigend gelöst werden.

Vergleicht man abschließend den Parti radical und die SFIO, treten die wesentlichen Unterschiede deutlich hervor. Besonders sichtbar werden sie im unterschiedlichen Verständnis des Parteibegriffs des Parti radical und der SFIO. Während im Parti radical die Freiheit des Abgeordneten ein zentrales Element darstellte - auch wenn man versuchte, diese zu beschränken -, herrschte in der SFIO die Devise, daß der sozialistische Abgeordnete streng der Partei unterstand. Dem Parti radical ermöglichte die Freiheit des Abgeordneten eine parlamentarische Flexibilität, die mit dem Selbstverständnis der Partei, eine Regierungspartei zu sein, kongenial harmonierte, während die SFIO mit einem ausgeprägten Kontrollapparat über den Abgeordneten die Priorität der Doktrin vor parlamentarischen Kompromißlösungen über weite Strecken aufrecht erhalten konnte und sich in erster Linie als Oppositionspartei verstand ${ }^{72}$.

71 Ausführlich zur Schaffung eines starken Führungsorgans in der SFIO: G. Ziebura, Blum, S. 228237.

72 So konnte die strikte Auffassung der Doktrin, die die SFIO oft hinderte, eine Regierungspartei zu sein, mit den beiden abstrakten Formeln "conquête du pouvoir" und "exercice du pouvoir" etwas differenziert werden, wobei der Fraktion dadurch ein gewisser Handlungsspielraum im Parlament eingeräumt werden konnte. 


\section{Die Stellung des Abgeordneten innerhalb der Parteien}

In den vorangegangenen Kapiteln, besonders in Kapitel eins und drei dieses Teils, ist deutlich geworden, daß sich die fünf Parteien in Frankreich vor allem in zwei Punkten unterscheiden. Zum einen besteht ein erheblicher Unterschied im Grad der Zentralisation der Parteiorganisation. Hier läßt sich eine deutliche Trennlinie zwischen den Parteien rechts vom Parti radical und links vom Parti radical ziehen. Zum anderen treten deutliche Unterschiede zwischen den Parteien auf, was die Stellung des Abgeordneten und sein Verhältnis zur Parteispitze betrifft. Auch hier bildet der Parti radical die Nahtstelle.

\section{Der Abgeordnete im Parti radical}

Ähnlich wie Sigmund Neumann hat der französische Politologe Maurice Duverger unter Berücksichtigung der Parteien der Dritten Republik Frankreichs eine Parteientypologie ${ }^{1}$ entwickelt. Er teilte die Parteien in folgende drei Kategorien ein: 1) die Partei, die von Parlamentariern eindeutig dominiert wird; 2) der Parteitypus, der ein relativ stabiles Gleichgewicht zwischen den Parlamentariern und den Parteiführern aufweist; 3) schließlich die Partei, die die Parlamentarier beherrscht. Duverger ordnete den Parti radical eindeutig der ersten Kategorie zu; während er die SFIO und die Démocrates chrétiens der zweiten Kategorie zuteilte und schließlich die kommunistische Partei bzw. die faschistischen Parteien der dritten Kategorie zuwies.

Folgt man also der Typologie Duvergers, ist der Parti radical geradezu ein $\mathrm{Pa}$ radebeispiel für den Parteitypus, der von den Parlamentariern dominiert wird. Dies hängt zum einen sehr eng mit der radikalsozialistischen Doktrin zusammen und zum anderen mit der dezentralistischen Organisationsstruktur des Parti radical. So wurde in den Gründungsstatuten von 1901 im Artikel 1 folgendes festgelegt: „Il est formé entre les membres des groupements, les élus et les journaux adhérents aux présents statuts, une association dénommée „Parti républicain radical et radical-socialiste" 2 . In diesem Statut ist der Parlamentarier noch nicht besonders hervorgehoben, jedoch stellt Fournier richtig fest, „c'est donc leur qualité

1 M. Duverger, Les partis politiques, S. 211-232.

2 Le Rappel vom 24. 6. 1901, S. 2; Le Radical vom 24. 6. 1901, S. 2. Auf dem Gründungsparteitag von 1901 wurden provisorische Artikel von I-VI festgelegt und auf dem Parteitag vom 9.-12. 10. 1902 in Lyon sind die endgültigen Parteistatuten verhandelt worden; vgl. Le Rappel vom 13.10. 1902, S. 2, sowie L.-E. Jacques, Les partis politiques sous la Troisième République, S. 510 und D. Bardonnet, L'Evolution, S. 137. 
même d'élus qui fait des parlementaires des membres du Parti radical, et non l'inverse" 3 . In diesem Punkt tritt bereits ein ganz entscheidender Unterschied im Vergleich zur SFIO hervor, denn die Position des radikalsozialistischen Abgeordneten hob sich durch das Vertrauen, das ihm durch den Wahlakt entgegengebracht wurde, vom normalen Parteimitglied ab, das nur durch ein Komitee der Parteibasis mit der Partei verbunden war. Durch das Prinzip des repräsentativen Modells, das zu den zentralen Elementen der radikalsozialistischen Doktrin gehörte, wurde die Herausgehobenheit der radikalsozialistischen Abgeordneten zusätzlich unterstrichen. Das Verhältnis zwischen Wähler und Gewähltem sollte nicht durch eine Zwischeninstanz in Form einer Partei beeinträchtigt werden, denn damit wäre der Abgeordnete vom Wähler getrennt und in den Dienst der Parteigremien gestellt worden. Mit dieser Konstellation hätte sich ein eklatanter Widerspruch zum repräsentativen Modell der parlamentarischen Demokratie ${ }^{4}$, das der Parti radical als Idealform betrachtete, ergeben.

Ein weiterer Faktor, der den Vorrang der Parlamentarier im Parti radical festigte und unterstrich, war ihr Gewicht in den zentralen Gremien der Partei, wie z. B. im Comité exécutif, wo sie nicht nur durch ihr Prestige als Abgeordnete einflußreich waren, sondern auch quantitativ durch die Festlegung der Quotierung der Abgeordneten im Verhältnis zu den anderen Mitgliedern dieses Gremiums ${ }^{5}$. Dieses Übergewicht der Abgeordneten galt auch für das zentrale Parteibüro, jedoch nicht für die Conférence des Présidents et Secrétaires généraux, wo sie quantitativ in der Minderheit waren.

Diese Vorrangstellung der Abgeordneten wurde im gewissen Sinne durch die dezentrale Organisationsstruktur noch verstärkt, da der Abgeordnete in seinen Komitees vor Ort relativ frei war. Diese Freiheit hing damit zusammen, daß es keine straff organisierte Binnenstruktur im Kern des Parti radical gab. Zwar hatte das Comité exécutif mehrmals besonders in Zeiten der Wahlkampfperioden ${ }^{6}$ durch die Bestimmung der Kandidatenbestätigung versucht, ein zentralistisches Element in die Organisationsstruktur des Parti radical einzubringen. Aber der Einfluß des Comité exécutif griff nicht im gewünschten Maße. Duverger verglich die Konstellation Comité exécutif und Abgeordnete folgendermaßen: „La direction centrale ressemble un peu à un roi féodal sans pouvoir ni prestige à l'égard des grand vassaux "7. Immerhin wurde in der Zwischenkriegszeit vom Comité exécutif bei permanenten Verstößen gegen die Abstimmungsdisziplin durch die Androhung eines Ausschlußverfahrens versucht, eine gewisse Homogenität bei den Abstimmungen zu erreichen. Doch das Ausschlußverfahren, das das Comité exécutif gegen Abgeordnete des rechten Flügels am 5. März 1924 geführt hat, stellt eher eine Ausnahme dar. Der Grund für das Ausschlußverfahren: Die radikalsozialistischen Parlamentarier hatten trotz vorausgehender Aufforderung des Parteivorsit-

3 M. Fournier, Le Parti radical de 1906 à 1914, Paris 1949.

$4 \mathrm{Vgl}$. Teil A dieser Studie, Kapitel I und III.

5 M. Duverger, Les partis politiques, S. 212/213.

6 Erstaunlicherweise galt im Parti radical das Reglement, daß die Aufstellung der Kandidaten in jeder Circonscription vom Comité exécutif zu genehmigen war. De facto war es jedoch möglich, daß auch einzelne Kandidaten unter Umgehung des vorgegebenen Wahlbündnisses mit anderen politischen Kräften auf einer Liste kandidierten; vgl. hier z. B. Prozeßbeispiel I, Kapitel 4.

7 M. Duverger, Les partis politiques, S. 213. 
zenden Herriot, gegen die Finanzvollmachten für Poincaré zu stimmen, und trotz Androhung disziplinarrechtlicher Konsequenzen bei Nichteinhaltung dafür votiert $^{8}$. Obwohl die Parteispitze versucht hatte, mit Hilfe eines konstruierten Formfehlers das Ausschlußverfahren doch noch umgehen zu können, mußten Herriot und die führenden Parteimitglieder dem Protest der Parteibasis, die mit zweihundert Vertretern anwesend war, nachgeben. Aus taktischen Gründen war Herriot zu diesem Opfer bereit, um wenigstens die beiden prominenten Minister Albert Sarraut und Paul Lafont, die ebenfalls dafür gestimmt hatten, zu schützen. Aber trotz aller Bemühungen mußten auch sie sich dem Ausschlußbeschluß, der mit 135 zu 59 Stimmen verabschiedet worden war, beugen'. Dieser Vorfall ist insofern bemerkenswert, da es ansonsten im Parti radical fast unmöglich war, gegen Abweichler mit Sanktionen vorzugehen.

Vielmehr spalteten sich einzelne Abgeordnete oder kleinere Gruppen wegen notorischer Abstimmungsabweichungen von der radikalsozialistischen Fraktion ab. Diese Abspaltungstendenzen traten sowohl auf dem rechten wie auch auf dem linken Flügel auf. Stellvertretend sei hier nur auf eine kleine Gruppe unter Franklin-Bouillon auf dem rechten Flügel hingewiesen, die sich im November 1927 separierte. Diese Gruppe entschied sich zur Abspaltung, weil sie für die Wahlen von 1928 auf ein Bündnis mit den gemäßigten Kräften der politischen Rechten setzte, dabei aber der Mehrheit der Partei unterlag, die sich für ein Bündnis mit den Linkskräften im zweiten Durchgang ausgesprochen hatte ${ }^{10}$. Da Franklin-Bouillon im Vorfeld des Parteitages von 1927 diese Entscheidung zur Gretchenfrage erhoben und gleichzeitig mit der Abspaltung seiner Gruppe gedroht hatte, erfolgte nach der Niederlage auf dem radikalsozialistischen Parteitag im Oktober der Rückzug seiner Gruppe aus dem Parti radical11.

Ein weiteres Beispiel für eine Abspaltung aus einer inneroppositionellen $\mathrm{Hal}$ tung heraus stellt das Ausscheiden einer Gruppe um Gabriel Cudenet vom linken Flügel im Rahmen eines außerordentlichen Parteitages in Clérmond-Ferrand im Mai 1934 dar. Als sich bei der Abstimmung über den weiteren Verbleib des Parti radical im Kabinett Doumergue die Mehrheit der Partei hinter Herriot, der selbst ein Ministeramt in dieser Regierung übernommen hatte, stellte, spaltete sich am 14. Mai 1934 die Gruppe um Cudenet $\mathbf{a b}^{12}$.

Die Freiheit des Abgeordneten gegenüber der Partei konnte immer wieder Auswirkungen auf die Gesamtpartei haben, deshalb wurde mehrmals im Parti radical versucht, die Abgeordneten zu disziplinieren, jedoch scheiterten - bis auf die erwähnte Ausnahme - alle Versuche in dieser Richtung.

8 Vgl. dazu Prozeßbeispiel I, Kapitel 2.

9 Zum Ausschlußverfahren siehe Le Temps vom 7. 3. 1924, S. 1.

10 Vgl. dazu: Le 24e Congrès du Parti républicain radical et radical-socialiste à Paris du 27-30 octobre 1927, S. 179 f.; L'Oeuvre vom 28. 10. 1927, S. 1.

11 Vgl. dazu auch Prozeßbeispiel II, Kapitel 1 dieser Studie. Außerdem auch D. Bardonnet, Évolution, S. 147/148; S. Berstein, Parti radical, vol. 2, S. 42-50, sowie Le 24e Congrès du Parti républicain radical et radical-socialiste à Paris du 27-30 octobre 1927; L'Oeuvre vom 28.-31. 10. 1927. Zum Rücktrittsschreiben Franklin-Bouillons an Cazal vom 2. 11. 1927 siehe L'Oeuvre vom 3.11. 1927, S. 2.

12 Ausführlicher dazu D. Bardonnet, Évolution, S. 148/149; J. Goguel, La politique des partis, S. 493; Le Temps vom 6. 5. 1934, 8. 5. 1934, 11. 5. 1934, jeweils S. 1, 3; und vor allem zum Austritt selbst Le Temps vom 15. 5. 1934, S. 8. 
Das signifikanteste Beispiel stellt sicherlich der Versuch Daladiers dar, die Abstimmungsdisziplin auf sehr rigorose Art und Weise im Parti radical einzuführen. Als Daladier auf dem Parteitag von 1927 zum Parteivorsitzenden gewählt worden war, wollte er nach dem Debakel der Cartelerfahrung und dem anschließenden Eintritt Herriots in das Kabinett Poincaré einen grundlegenden Neuanfang für den Parti radical organisieren. Daladier hoffte, mit Unterstützung der Parteibasis ein Gegengewicht zu den Abgeordneten schaffen zu können, indem er ihnen ein straffes Regelwerk an Disziplinierungsmaßnahmen vorlegte. Daladier kündigte sein Vorgehen folgendermaßen an: „Le Parti s'est uni sur un programme et sur une tactique, et une méthode (...) quiconque contesterait désormais l'un ou l'autre serait hors du Parti. "13 Um seine Entschlossenheit in dieser Organisationsreform zu unterstreichen, ließ Daladier durch den Parteitag von 1927 ein "Comité de vigilance et d'arbitrage" einrichten, das zum einen die Aufgabe hatte, dafür zu sorgen, daß die Abgeordneten auf Parteilinie blieben, und das zum anderen als ein Schiedsgericht bei der Kandidatenaufstellung der einzelnen Wahlkreise für den Fall fungieren sollte, daß es bei der Kandidatenfrage zwischen dem Comité exécutif und dem einzelnen Wahlkreis zu Differenzen käme. Falls Verstöße gegen die von der Partei festgelegte Wahltaktik oder Programmatik auftreten sollten, mußten diese von dem eingesetzten Komitee sofort öffentlich bekannt gemacht werden. Der Parteivorsitzende sollte an der Spitze dieses Komitee stehen ${ }^{14}$. Außerdem untermauerte Daladier diesen Restrukturierungsversuch des Parti radical kurz nach dem Parteitag von 1927 mit dem Hinweis, daß er sich als „le Président qui réaliserait l'unité du groupe parlementaire et l'unification du Parti tout entier" 15 verstehe. Jedoch lösten diese Absichten Daladiers heftige Proteste aus, und vor allem Nogaro verteidigte an exponierter Stelle die Freiheit der radikalsozialistischen Abgeordneten ${ }^{16}$. In der Abstimmung über den Staatshaushalt für 1928 wurde deutlich, daß sich die radikalsozialistischen Abgeordneten auf keinen Fall in ein Disziplinierungskorsett zwängen lassen wollten. Die Fraktion zerfiel in drei Gruppen: Es stimmen 64 Abgeordnete des Parti radical dafür, 54 dagegen und sieben enthielten sich. Nicht einmal die drei führenden Radikalsozialisten waren sich einig. Der Parteivorsitzende Daladier stimmte gegen den Haushalt, der Vorsitzende der parlamentarischen Gruppe des Parti radical, Cazal, stimmte dafür und Malvy, der Vorsitzende der Finanzkommission, enthielt sich ${ }^{17}$.

Weitere Beispiele, die als Verstoß gegen einen Parteitagsbeschluß angeführt werden können, sind zum einen der Eintritt von sechs Radikalsozialisten in das Kabinett Laval im Juni $1935^{18}$ und zum anderen das Votum für die Finanzvoll-

13 J. Kayser, Le Parti radical et le Rassemblement populaire (1935-1938), in: Société d'Histoire de la IIle République 14 (1955), S. 72. Vgl. dazu auch Le $24^{\mathrm{e}}$ Congrès du Parti républicain radical et radical-socialiste à Paris du 27-30 octobre 1927.

14 Ausführlich zur Konzeption dieses Gremiums auf dem Parteitag des Parti radical von 1927 in: L'Oeuvre vom 27. 10.-31. 10. 1927, jeweils, S. 1, 3, hier speziell vom 29. 10. 1927, S. 3.

15 D. Bardonnet, Évolution, S. 166.

16 Vgl. dazu Prozeßbeispiel II, Kapitel 1.

17 Vgl. dazu Le Temps vom 20.11. 1927, S. 3 sowie Le Temps vom 14. 1. 1928, S. 3 und auch D. Bardonnet, Évolution, S. 166.

18 Dem vierten Kabinett Laval traten die Radikalsozialisten Edouard Herriot, Georges Bonnet, Joseph Paganon und Philipp Marcombes bei; vgl. dazu Le Temps vom 8. 6. 1925, S. 1/2, S. 8. 
machten vom Oktober $1935^{19}$. Obwohl beide Maßnahmen gegen die Parteitagsbeschlüsse von 1935 verstießen, blieben sie ohne Konsequenzen für die radikalsozialistischen Abgeordneten ${ }^{20}$.

Es war also selbst dem Parteivorsitzenden, der in der Zwischenkriegszeit über eine gewisse Autorität kraft seiner Persönlichkeit verfügte, nicht möglich, den Parlamentariern Abstimmungsdisziplin abzuverlangen. Obwohl eine Abstimmungsdisziplin mehr als wünschenswert gewesen wäre, da die parlamentarische Gruppe des Parti radical größtenteils so heterogen war, daß sie bei wichtigen Abstimmungen in drei Teile zerfiel, d.h. einige stimmten dafür, andere dagegen und einige enthielten sich, wodurch sich ihre politische Schlagkraft stark verminderte, pochten die Abgeordneten auf ihre Freiheit.

Andererseits jedoch ermöglichte dieser Mangel an Fraktionsdisziplin dem Parti radical, äußerst wendig und flexibel zu sein und damit gleichzeitig seine Funktion als Scharnier für Regierungen der linken oder rechten Mitte im Parlament wahrzunehmen. Das Festhalten der radikalsozialistischen Abgeordneten am freien Mandat sicherte somit dem Parti radical eine parlamentarische Flexibilität und hielt damit seine Fähigkeit zum Kompromiß aufrecht, was sich besonders in den verschiedenen Koalitionsmöglichkeiten des Parti radical widerspiegelte. In diesem Zusammenhang muß auch kurz der Blick auf die radikalsozialistischen Senatoren gelenkt werden, die in der zweiten Kammer des französischen Parlaments, dem Senat, oft für Irritationen, wenn nicht sogar für Regierungsstürze verantwortlich waren ${ }^{21}$. Die radikalsozialistischen Senatoren waren über mehrere Gruppen verteilt ${ }^{22}$ und können im Vergleich zu den radikalsozialistischen Abgeordneten der Deputiertenkammer als konservativer eingestuft werden. Gerade durch die Kombination der Faktoren mangelnde Disziplin und Verteilung auf mehrere Senatsgruppen konnte das Abweichen von der politischen Linie nur bei den radikalsozialistischen Abgeordneten in der Deputiertenkammer nachgezeichnet werden $^{23}$. Insgesamt gesehen trat diese Heterogenität im Abstimmungsverhalten bei folgenden Gelegenheiten auf: 1) bei Regierungsbestätigungen, d.h. wenn ein Kabinett sich bei Regierungsantritt der Vertrauensfrage stellte24; 2) bei ministeriellen Krisen bzw. bei Regierungsstürzen; 3) bei wichtigen Abstimmungen, wie z.B. bei der Gewährung von Vollmachten.

Ein weiterer wichtiger Aspekt, der diesen strukturellen Aufbau des Parti radical und damit den Primat des Abgeordneten verständlich macht, ist das Selbstver-

19 Die radikalsozialistische Fraktion zeigte bei dieser Abstimmung wieder ihre starke Heterogenität im Abstimmungsverhalten: 74 Abgeordnete stimmten dafür, 56 dagegen, 19 enthielten sich und sechs waren abwesend; vgl. Le Temps vom 30.11.1935, S. 3.

20 D. Bardonnet, Evolution, S. 166; Vgl. auch die Parteitagsbeschlüsse des außerordentlichen Parteitages vom 28. 3.-31. 3. 1935 in: L'Oeuvre vom 1. 4. 1935, S. 1, 4.

21 Vom Senat wurden z. B. folgende Regierungen im Frankreich der Zwischenkriegszeit gestürzt: Die erste Regierung Herriot am 12. 4. 1925; 3. Regierung Laval am 16. 2. 1932; 2. Regierung Blum am 8. April 1937.

22 Die radikalsozialistischen Senatoren verteilten sich auf folgende Gruppen: Groupe de l'Union républicaine, Groupe de la Gauche démocratique radicale et radicale-socialiste.

23 Z. B. spielten die radikalsozialistischen Senatoren in den Entscheidungen um die Finanzvollmachten der beiden Regierungen Blum in der Volksfrontzeit eine ausschlaggebende Rolle. Vgl. dazu ausführlich Prozeßbeispiel III, Kapitel 5 und 6.

24 Vgl. dafür D. Bardonnet, Évolution, S. 160-163. 
ständnis des Parti radical. Der Parti radical sah sich stets als eine Regierungspartei, was sich darin niederschlug, daß er fast an allen Regierungen der Zwischenkriegszeit ${ }^{25}$ beteiligt war. Regierungsbeteiligung und Wählergunst standen in einem engen Verhältnis. Als Maxime galt: „Le Parti radical est un syndicat d'intérets électoraux qui bénéficie du prestige des hommes d'Etat qui en font partie." ${ }^{26}$

\section{Der Abgeordnete in der SFIO}

Nach der Parteienkategorisierung Duvergers gehörte die SFIO dem Parteientyp an, den ein relatives Gleichgewicht zwischen den Parlamentariern und den Parteiführern kennzeichnet. Auf den ersten Blick mag dies etwas erstaunen, denn eigentlich war die Organisationsstruktur der SFIO so angelegt, daß der Abgeordnete der Parteiführung unterstand. Aber de facto war durch diese vorgegebene Hierarchie stets eine gewisse Spannung zwischen der Fraktion/dem Abgeordneten und der Parteispitze gegeben, die zu einer Art Gleichgewicht zwischen den Abgeordneten und den Parteiführern führte. Es kam so weder zu einer reinen Dominanz der Parteiführer noch der Abgeordneten. Es handelte sich in der SFIO vielmehr um eine Trennung der Macht, die zwischen der Zentrale der Partei und den Parlamentariern aufgeteilt worden war, was zu einer ständigen Rivalität zwischen beiden Einheiten führte27. Damit ist, wie oben bereits angedeutet, der grundlegende Unterschied zwischen dem Parti radical und der SFIO angesprochen. Denn der Abgeordnete der SFIO war im Unterschied zum radikalsozialistischen Abgeordneten nicht frei, sondern er war ein Mandatar der sozialistischen Partei. In Artikel 17 der Parteistatuten der SFIO von 1911 war das Verhältnis zwischen dem Abgeordneten und der Partei eindeutig festgelegt worden: „L'élu qui, pour une cause quelconque, quitte le Parti doit tenir son mandat à la disposition de l'organisation qui l'a fait élire et qui seul a le droit de décider s'il le conservera ou donnera sa démission. En cas d'exclusion du Parti, la remise du mandat est obligatoire." 28

Das Mandat, das der Gewählte bei den Wahlen erhielt, gehörte also der Partei, und nach seinem Ausscheiden mußte er dieses wieder an die Partei zurückgeben. Das Mißtrauen der Partei war gegenüber dem Abgeordneten teilweise so stark, daß Parlamentarier zunächst nicht im obersten Parteiorgan CAP vertreten sein durften: „Les élus au Parlement ne peuvent être individuellement délégués au Conseil national. Ils y sont représentés par une délégation collective conformément aux articles 30 et 32 . Ils ne peuvent pas faire partie de la CAP." 29 Jedoch erfuhr diese Regelung noch vor dem Ersten Weltkrieg auf der Tagung des Conseil National vom 13. Juli $1913^{30}$ eine, wenn auch nur sehr bescheidene Änderung,

25 Zeitweilig befand sich der Parti radical in der Oppositionsrolle, so z. B. von April bis Juni 1924 oder nach seinem Ausscheiden aus der Regierung Poincaré im November 1928 bis Herbst 1929. Vgl. E. Bonnefous, Histoire politique de la Troisième République, vol. 4, S. 291-339.

26 D. Bardonnet, Évolution, S. 140, Anm. 18.

27 M. Duverger, Les partis politiques, S. 219.

${ }^{28}$ L.-E. Jacques, Les partis politiques sous la Troisième République, S. 527.

29 Ebenda, S. 529.

30 Auf dem Conseil national vom 13.7. 1913 wurde das Statut dahingehend geändert, daß die Mit- 
denn ohne Einbindung des Abgeordneten in die Parteigremien verringerten sich die Möglichkeiten, ihn zu kontrollieren. Auch nach der Spaltung von Tours 1920 blieb der Dualismus zwischen Fraktion und der Parteispitze CAP weiterhin ein Problem, das Blum während der Zwischenkriegszeit immer wieder zu lösen versuchte. Das ursprüngliche Mißtrauen gegenüber dem Abgeordneten rührte vor allem auch daher, daß die aktive Parteibasis, der „militant“, befürchtete, daß die sozialistischen Parlamentarier in der Tagespolitik zu viele Kompromisse mit den bürgerlichen Parteien eingehen würden und dadurch die Reinhaltung der Doktrin nicht aufrechterhalten werden könne. Um aber die Abgeordneten unter Kontrolle zu halten, blieben unter den oben genannten Umständen - der beinahen Ausgliederung der Abgeordneten aus den Parteigremien - nur zwei Möglichkeiten: 1) Für den Fall, daß die Abgeordneten gegen bindende Parteitagsbeschlüsse verstießen, konnten sie a posteriori mit Hilfe eines Antrags der CAP getadelt werden ${ }^{31}$, was aber zusätzlich das Verhältnis zwischen den Abgeordneten und der Parteispitze belasten mußte. 2) Die Parlamentarier wurden angehalten, politische Entscheidungen zu vertagen, um die Meinung des Conseil National einzuholen ${ }^{32}$.

Obwohl diese Regelung grosso modo von der Fraktion akzeptiert worden ist, führte die Frage der Regierungsbeteiligung während der gesamten Zwischenkriegszeit immer wieder zu Spannungen zwischen den Abgeordneten und der Parteispitze. Immerhin hatte die SFIO auch Möglichkeiten, bei Verstößen gegen Parteitagsbeschlüsse und gegen die Doktrin oder Taktik, wie z. B. bei permanenter Mißachtung der Abstimmungsdisziplin durch die Fraktion, mit Sanktionen einzugreifen, um dagegen vorzugehen. Durch diese Sanktionsmöglichkeiten und die eindeutig festgelegten Regeln zur Abstimmungsdisziplin konnte es auch immer wieder zum Ausschluß von Abgeordneten, die ständig dagegen verstießen, kommen. So z.B. 1933 als der Ausschluß bzw. die Abspaltung der „Neosozialisten“ erfolgte ${ }^{33}$.

Bereits nach der Spaltung von 1920 hatte Blum versucht, das Mißtrauen gegen die Abgeordneten auf dem Parteitag von 1921 auszuräumen und das Verhältnis zwischen Parteispitze und Fraktion zu verbessern ${ }^{34}$. Unmittelbar nach dem Ersten Weltkrieg funktionierten die Beziehungen zwischen den beiden Gremien

gliederzahl für die CAP erhöht wurde und auch Abgeordnete in dieses Gremium gewählt werden konnten, jedoch mit der Einschränkung, daß sie nicht mehr als ein Drittel der Mitglieder dieses Gremiums stellen durften; vgl. L'Humanité vom 14. 7. 1913, S. 1.

31 So z. B. geschehen, als im Oktober 1929 die parlamentarische Gruppe der SFIO das Angebot einer Regierungsbeteiligung angenommen hatte. Vgl. dazu Prozeßbeispiel II, Kapitel 1, aber auch G. Ziebura, Blum, S. 399-404; L'OURS (Hrsg.), Histoire du Parti socialiste, SFIO, Teil 7: des années 1929 à 1931, Cahiers et Revue 48 (1974); Le Populaire vom 29.10. 1929-2.11.1929, jeweils S. 1.

32 Als das Cartel des gauches 1924 die Wahlen gewonnen hatte, bot Herriot den Sozialisten die Regierungsbeteiligung an. Die Sozialisten beriefen zur Klärung dieser Frage einen außerordentlichen Parteitag für den 1./2.6.1924 ein, wobei sich die Mehrheit eindeutig gegen eine Beteiligung an der Regierung Herriot aussprach; vgl. Le Populaire vom 2.6. 1924 und vom 3.6. 1924, jeweils S. 1.

33 Zum Verfahren vgl. den Parteitag der SFIO vom 14.-17. 7. 1933; außerdem Prozeßbeispiel II, Kapitel 6 sowie Le Populaire vom 15.-18.6. 1933, jeweils S. 1, 3. Im Oktober 1933 schieden die "Neosozialisten" endgültig aus der SFIO aus.

${ }^{34}$ Vgl. dazu Le Populaire vom 31. 10. 1921, S. 1/2, hier besonders S. 1: "Ce que j'affirme, c'est que, depuis le début de la législature, dans l'ancienne CAP avec Frossard, aujourd'hui avec Paul Faure, jamais il n'y a eu divergence entre eux et le secrétaire du groupe parlementaire que je suis. Le groupe a toujours eu le souci, pour toutes ses initiatives, de se mettre, d'abord avec les organismes centraux du Parti.“ 
mehr oder weniger reibungslos, da in der Oppositionsrolle eine Einheit der sozialistischen Fraktion gewährleistet war. Nach dem Wahlerfolg von 1924 brachen jedoch erneut Probleme zwischen Fraktion und Partei auf, da die SFIO die Regierung Herriot unterstützte und es während der Phase des Cartel des gauches zu Differenzen zwischen Partei und Fraktion und auch zu Streitigkeiten innerhalb der Fraktion in der Frage gekommen war, wie weit die Sozialisten die Entscheidungen der Regierung Herriot mittragen konnten. Erschwerend kam hinzu, daß die Fraktion nach ihrem Beschluß, die Regierung Herriot zu unterstützen, ein zusätzliches Organ, eine Fraktionskommission ${ }^{35}$, eingerichtet hatte. Diese Fraktionskommission diente als eine Art Exekutivorgan, das die Aufgabe wahrnahm, mit der Regierung zu verhandeln, die Beschlüsse der Fraktion umzusetzen und bei Abstimmungen die Fraktion auf eine Linie zu bringen. In diesem Gremium, das zwar streng nach bestimmten Proportionen besetzt wurde, konnte sich eine Mehrheit des rechten Flügels etablieren. Dies führte nicht nur zum Dualismus zwischen Fraktion und CAP, sondern auch inhaltlich hatten sich zwei Schwerpunkte herauskristallisiert: die Fraktionskommission vertrat mehr die Linie des rechten Flügels und die CAP stärker die Richtung des linken Parteiflügels. Es hatte sich im doppelten Sinne ein Konfliktpotential aufgebaut ${ }^{36}$. Durch diese Entwicklung wurde es dringlicher denn je, eine Lösung des Führungsproblems in der SFIO zu finden; dennoch konnte trotz verschiedener Anläufe kein wirklich befriedigendes Ergebnis erreicht werden. Vor allem Léon Blum hatte immer wieder in seiner Funktion als Parteichef und Fraktionssekretär, der bei entstandenen Konflikten zwischen CAP und Fraktion den Mittler bildete, versucht, eine Lösung voranzutreiben. So z. B. auf dem Conseil National am 1./2. November 1925, als die Dringlichkeit dieses Themas immerhin dazu führte, daß zwei Anträge zur Abstimmung gebracht wurden. Einer der beiden Anträge war von Blum und Renaudel eingereicht worden; er beinhaltete eine wirkliche Neustrukturierung des Conseil National, der zukünftig die Befugnis erhalten sollte, die Aufgaben und die Autorität der $C A P$ zu übernehmen.

Der andere Antrag stammte von Compère-Morel, Lebas und Paul Faure und zeichnete sich durch wesentlich behutsamere Vorschläge aus. Die CAP sollte ihre bisherige Funktion beibehalten, jedoch sollte sie eine Mitgliedererweiterung erfahren. Der letztgenannte Antrag konnte sich mit 1579 zu 1117 Stimmen behaupten ${ }^{37}$. Aber trotz dieser Erneuerung konnte keine entscheidende Verbesserung

35 In der Fraktionssitzung am 3.6. 1924 wurde der Beschluß gefaßt, eine Fraktionskommission einzurichten. In einer späteren Fraktionssitzung am 18.11. 1926 wurde eine Geschäftsordnung beschlossen, die die Struktur dieses Organs festlegte. Es sollte zu Beginn jeder Legislaturperiode ein Sekretär, ein stellvertretender Sekretär und ein Schatzmeister von der Fraktion gewählt werden, außerdem wurden 18 Mitglieder jährlich zu Jahresbeginn als Exekutivdelegation ernannt. Vgl. dazu: Le Populaire vom 14. 6. 1924, S. 1/2. Ausführlich zur Errichtung dieses Gremiums bei G. Ziebura, Blum, S. 231, und S. 231, Anm. 45. Zur Festlegung vom 18.11.1926 vgl. die Parteitagsprotokolle der SFIO von 1927, S. 74-77, sowie Le Populaire vom 19.11. 1926, S. 3.

$36 \mathrm{Vgl.} \mathrm{G}$. Ziebura, Blum, S. 231, Anm. 45. Der Beschluß zur Einrichtung einer Fraktionskommission erfolgte in einer Fraktionssitzung am 3.6. 1924. Am 18. 11. 1926 verabschiedete die Fraktion einstimmig eine Geschäftsordnung für die Fraktionskommission, die später in eine Exekutivdelegation überging. Zum Text der Geschäftsordnung siehe die Rapports du $24^{e}$ Congrès National à Lyon du 17-20 April 1927, Paris 1927, S. 74-77 sowie Le Populaire vom 19. 11. 1926, S. 1.

37 Vgl. ausführlich zu dieser Diskussion auf dem Conseil National die Rapports du 23e Congrès 
und erst recht keine definitive Lösung geschaffen werden, denn das Grunddilemma in der Organisationsstruktur blieb erhalten, und so kam es immer wieder zu Konflikten zwischen der CAP und den anderen Organen der sozialistischen Partei ${ }^{38}$. Auch ein weiterer Versuch Blums auf dem Parteitag von 1928, dieses Problem zu lösen, war nur vorübergehend erfolgreich, denn die Delegierten auf dem Parteitag von 1928 stimmten zwar zu, daß die CAP am 1 . November 1928 eine Sitzung des Conseil National einberufen solle, um ernsthaft ein neues Statut zur Lösung des Führungsproblems in der SFIO auszuarbeiten. Aber die von dem Parteitag ausgehende erneute Schubkraft zu einer endgültigen Lösung des Problems reichte nicht aus. Erst Anfang 1929 konnte ein Entwurf für das neue Statut vorgelegt werden ${ }^{39}$. Dieser war aber letztlich so umstritten, daß weder auf der Tagung des Nationalrats am 2./3. Februar 1929 noch auf dem Parteitag vom 9. bis 12. Juni 1929 eine Einigung zustande kam, so daß der stellvertretende Generalsekretär Séverac empfahl, den Entwurf ad acta zu legen ${ }^{40}$. Immerhin konnten sich die Delegierten auf dem Parteitag von 1929 darauf verständigen, die Mitgliederzahl des Conseil National zu verringern, um ihm eine größere Beweglichkeit zu verleihen. Die Mitglieder des Conseil National sollten sich aus den Föderationen, aus den Vertretern der CAP und der Exekutivdelegation der Fraktion rekrutieren ${ }^{41}$. Obwohl angesichts der zunehmenden Bedeutung der SFIO im Parlamentsleben in der Zwischenkriegszeit ein klar definiertes Führungsorgan wünschenswert gewesen wäre, wurden Blums Vorstöße in diese Richtung mit Vorwürfen quittiert. Man hielt ihm vor, eine stark zentralistische Organisationsform nach dem Vorbild der SPD in die Statuten der SFIO einführen zu wollen. Der Grund für die mehrheitlich starke Gegnerschaft in der SFIO gegen eine eindeutig zentralistische Führungsstruktur lag wohl darin, wie der Publikation des stellvertretenden Generalsekretärs Séverac zu entnehmen war ${ }^{42}$, daß vor allem die Parteibasis auf eine demokratische Struktur der SFIO Wert legte, während die Führung der SFIO darauf

National à Clermond-Ferrand du 23 - 26 mai 1926, Paris 1926, S. 26/27 und vor allem G. Ziebura, Blum, S. 232/233.

38 So kam es bei den Wahlen 1928 zwischen der CAP und einzelnen Föderationen zu Konflikten in der Frage des désistement. Vgl. dazu auch G. Ziebura, Blum, S. 233/234.

39 Als Vorlage dieses erneuten Entwurfs diente der Antrag Blums aus dem Jahre 1925. Da dieser neue Entwurf entscheidende Korrekturen im Vergleich zu dem von 1925 enthielt, war klar, daß das eigentliche Problem nur in abgeschwächter Form gelöst werden würde. Der Entwurf von 1929 sah folgende Lösung vor: Anstelle des Nationalrats war ein Zentralrat geplant, der aus 60 Mitgliedern bestehen sollte, die wiederum vom Parteitag aufgrund einer von den Föderationen aufgestellten Liste zu wählen waren. Der Zentralrat sollte aus den Reihen seiner Mitglieder einen Exekutivausschuß von 15 Mitgliedern ernennen, die vom Parteitag bestätigt werden mußten. Anstelle der CAP wollte man den Exekutivausschuß setzen. Aber auf dem Parteitag von 1929 stimmten 2030 dagegen, 817 dafür, daß die aktuellen Statuten beibehalten werden, wobei die Zahl der Vertreter der Föderationen im Conseil national reduziert werden sollte. Vgl. dazu die Rapports du 26e Congrès National à Nancy du 9-12 juin 1929, Paris 1929, sowie Le Populaire 13. 6. 1929, S. 1, 5.

40 Ausführlich zu den einzelnen Etappen hinsichtlich der Änderung des Zentralorgans der SFIO bei G. Ziebura, Blum, S. 228-237, und ebenso die verschiedenen Parteitagsprotokolle der sozialistischen Parteitage von 1925-1929.

4) Dieser Beschluß wurde auf dem Parteitag der SFIO von 1929 verabschiedet. Eine Minderheit hatte sich für die große Reform der Errichtung eines Zentralrates ausgesprochen, die Mehrheit hingegen stimmte für die Beibehaltung der aktuellen Statuten, aber die Zahl der Vertreter der Föderationen im Conseil national sollte reduziert werden. Vgl. dazu die Rapports du $26^{\mathrm{e}}$ Congrès National à Nancy du 9-12 juin 1929, Paris 1929, sowie Le Populaire vom 13.6. 1929, S. 1, 5.

42 J.-B. Séverac, Le Parti socialiste, ses principes et ses tâches. Lettres à Brigitte, Paris 1933, S. 32/33. 
achtete, daß der Abgeordnete den Primat der Reinhaltung der Doktrin gegenüber der Tagespolitik einhielt. Damit wurde der unterschiedliche Parteienbegriff der SFIO erneut hervorgehoben und seine immense Tragfähigkeit unterstrichen.

Die rigide Einhaltung der Fraktions- und Abstimmungsdisziplin in der SFIO, die notfalls auch mit Sanktionen durch das oberste Parteigremium CAP erzwungen werden konnte, trug dazu bei, daß die Koalitionsbereitschaft der SFIO vom einzelnen Abgeordneten nicht beeinflußt werden konnte und insgesamt gesehen eher eingeschränkt war. 